\title{
A review on plasma-catalytic methanation of carbon dioxide - looking for an efficient catalyst
}

\author{
Radosław Dębek ${ }^{a, b, *}$, Federico Azzolina-Jury ${ }^{a}$, Arnaud Travert ${ }^{a}$, Françoise Maugéa
}

${ }^{a}$ Normandie Univ, ENSICAEN, UNICAEN, CNRS, Laboratoire Catalyse et Spectrochimie, 14000 Caen, France

${ }^{b}$ AGH University of Science and Technology, Faculty of Energy and Fuels, Department of Fuels Technology, 30 A. Mickiewicza Avenue, 30-059, Kraków, Poland

*corresponding author: debek@ensicaen.fr, debek@agh.edu.pl

\begin{abstract}
The review focuses on presenting recent findings on $\mathrm{CO}_{2}$ methanation plasma-catalytic process. In order to understand the background of the research, firstly a summary of thermal catalytic $\mathrm{CO}_{2}$ methanation is presented. Secondly, discussion on plasma $\mathrm{CO}_{2}$ hydrogenation including various plasma types and process parameters is addressed. Catalytic $\mathrm{CO}_{2}$ methanation is already an industrial process achieving high conversions of $\mathrm{CO}_{2}$ and $\mathrm{CH}_{4}$ yield. However, the need to optimize this process (decrease reaction temperature, increase catalyst activity, selectivity and stability) resulted in the development of plasma technology. It was proven that plasma can actively convert $\mathrm{CO}_{2}$. The main product of plasma $\mathrm{CO}_{2}$ hydrogenation is, however, carbon monoxide. Therefore, a plasma process is not selective for $\mathrm{CH}_{4}$ production and the presence of a catalyst is necessary to effectively convert $\mathrm{CO}_{2}$ to $\mathrm{CH}_{4}$ under plasma conditions. The study of plasma-catalytic $\mathrm{CO}_{2}$ methanation is quite a new topic focused mainly on the application of dielectric barrier discharge plasma and Ni-based catalyst. This review summarizes recent advantages of the plasma catalytic process and discusses possible directions of catalyst development.
\end{abstract}

Keywords: catalyst, plasma, non-thermal plasma, $\mathrm{CO}_{2}$ hydrogenation, $\mathrm{CO}_{2}$ methanation, $\mathrm{CO}_{2}$ valorization, $\mathrm{H}_{2}$ storage, 
List of abbreviations:

AC - Activated Carbon

DBD - Dielectric Barrier Discharge

DME - Dimethyl ether

DRM - Dry Reforming of Methane

EC - Energy Cost

EU - European Union

GA - Gliding Arc

GD - Glow Discharge

$\mathrm{HC}-$ Hydrocarbons

HERFD - XANES - High Energy Resolution Fluorescence Detected X-ray Absorption Near Edge Structure

MW - Microwave

OES - Optical Emission Spectrosocpy

$\mathrm{RF}$ - Radio frequency

RWGS - Reverse Water Gas Shift

SEI - Specific Energy Input

TOF - Turnover frequency

VOC - Volatile Organic Compounds 


\section{Introduction}

In the last decade, the $\mathrm{CO}_{2}$ methanation reaction (eq. 1.1), also known as Sabatier reaction, has gained much attention due to the possibility of storing in a chemical form, the energy excess from renewables energies [1,2]. The reaction produces methane which may be stored or transported using existing infrastructure. At the same time, the reaction contributes to the chemical valorization of carbon dioxide. Among such processes as hydrogenation of $\mathrm{CO}_{2}$ to methanol [3] or dimethyl ether (DME) [4], reverse water gas shift reaction [5], dry reforming of methane [6,7], oxidative dehydrogenation of hydrocarbons $(\mathrm{ODH})$ with $\mathrm{CO}_{2}[8]$, or production of synthetic fuels via FischerTropsch synthesis from $\mathrm{CO}_{2} / \mathrm{H}_{2}$ mixtures [9], $\mathrm{CO}_{2}$ methanation is an important process contributing to creating new carbon dioxide based economy $[10,11]$. Therefore, the process is extensively studied and developed which has already resulted in the launch of first pilot plants, located especially in Germany $[1,2]$. $\mathrm{CO} 2$ methanation is an exothermic reaction, performed at $300-400^{\circ} \mathrm{C}$ using a nickelbased catalyst. Nickel was the first choice as an active material for that reaction due to its lower price and abundant availability with respect to noble metals. For more information concerning operation of $\mathrm{CO}_{2}$ methanation plants interested readers are referred to recent literature $[1,2,12-14]$.

$$
\begin{array}{ll}
\mathrm{CO}_{2}+4 \mathrm{H}_{2} \leftrightharpoons \mathrm{CH}_{4}+2 \mathrm{H}_{2} \mathrm{O} & \Delta \mathrm{H}^{0}=-164 \mathrm{~kJ} \cdot \mathrm{mol}^{-1} \\
\mathrm{CO}_{2}+\mathrm{H}_{2} \leftrightharpoons \mathrm{CO}+\mathrm{H}_{2} \mathrm{O} & \Delta \mathrm{H}^{0}=-42 \mathrm{~kJ} \cdot \mathrm{mol}^{-1}
\end{array}
$$

Taking into account thermodynamic considerations (Fig.1), it is still possible to improve catalyst performance via shifting operation temperatures to lower values, increasing at the same time $\mathrm{CH}_{4}$ yield and selectivity via decreasing influence of side reactions e.g. reverse water gas shift (RWGS, eq. 1.2). For these reasons the issue of finding and selecting an efficient $\mathrm{CO}_{2}$ methanation catalyst is still an open question. 
Fig. 1 Equilibrium $\mathrm{CO}_{2}$ conversion, $\mathrm{CH}_{4}$ and $\mathrm{CO}$ selectivity as a function of temperature at various pressures. Temperature range $25-600^{\circ} \mathrm{C} ; \mathrm{CO}_{2} / \mathrm{H}_{2}=1 / 4$. Thermodynamic calculations were performed using Gibbs free energy minimization method and HSC Chemistry Software.

Another approach to improving the overall efficiency of the $\mathrm{CO}_{2}$ methantion (decreasing reaction temperature while increasing $\mathrm{CO}_{2}$ conversion and $\mathrm{CH}_{4}$ yield) is to use non-equilibrium plasma instead of an external thermal energy source.

Plasma is an ionized gas consisting of various activated species i.e. ions, electrons, radicals or excited molecules. Non-thermal plasma (often referred to as non-equilibrium plasma or low-temperature plasma) is created through the application of electric power to gas. If the applied voltage is high enough, so-called breakdown voltage, it breaks down gas to positive ions, electrons and other species. As electrons are much lighter than other plasma components, they gain much of their energy from the electric field, thus they are characterized by very high energy and temperature (1-10 $\mathrm{eV},<\mathrm{ca} .11000-110000^{\circ} \mathrm{C}>$ ). At the same time, the temperature of much heavier species in the plasma is close to gas temperature $\left(25-700^{\circ} \mathrm{C}\right)$ [15]. Electrons accelerated in the electric field towards positive electrode interact and collide with other plasma species and gas molecules. Cations, on the other hand, are accelerated towards negative electrode, where they cause secondary electron emission, which may further interact with plasma species. These processes make plasma selfsustaining [16]. Collisions of electrons with other molecules may result in ionization, excitation or dissociation producing an abundance of highly active species which may interact with each other creating in this way new compounds. Thus, gas does not need to be heated and may remain close to room temperature. It has been proven that plasma is able to activate even strongly endothermic reactions i.e. $\mathrm{CO}_{2}$ splitting, $\mathrm{H}_{2} \mathrm{O}$ splitting or dry reforming of methane [16-21]. 
Table 1 Characteristics of low and high temperature plasma. Adapted from: [22,23]

\begin{tabular}{|l|c|c|}
\hline & Low temperature plasma & High temperature plasma \\
\hline Temperature & $\begin{array}{r}\text { Low gas temperature } \\
\text { (up to ca. } 1000^{\circ} \mathrm{C} \text { ) } \\
\text { High electron temperature }\end{array}$ & $\begin{array}{c}\text { High gas and high electron } \\
\text { temperature }\end{array}$ \\
\hline Pressure & $10^{-6}-1$ bar & $\geq 1$ bar \\
\hline Degree of ionization & $10^{-8}-0.8$ & Filamentary \\
\hline Appearance current & Homogenous & $10-10^{5}$ \\
\hline $\begin{array}{l}\text { Discharge } \\
\text { density }\left(\mathrm{A} / \mathrm{cm}^{2}\right)\end{array}$ & $0.001-1$ & \\
\hline
\end{tabular}

Depending on several factors such as supply of power to create plasma, configuration of electrodes or dielectric material, various plasmas can be obtained including: direct current and alternative current glow discharges (GD), radio frequency discharges (RF), microwave discharges (MW), dielectric barrier discharges (DBD), gliding arcs (GA), plasma jets and plasma torches [24]. These various types of plasma are characterized by different characteristics and therefore they find various applications [25-28], some of their characteristics (vis a vis characteristics of thermal plasma) are shown in Table 1 and Fig. 2. For conversion of $\mathrm{CO}_{2}$, the most commonly plasma used are DBD, $\mathrm{MW}$ and GA [16]. The plasma types used for plasma-catalytic $\mathrm{CO}_{2}$ methanation will be characterized in more details in section 3 .

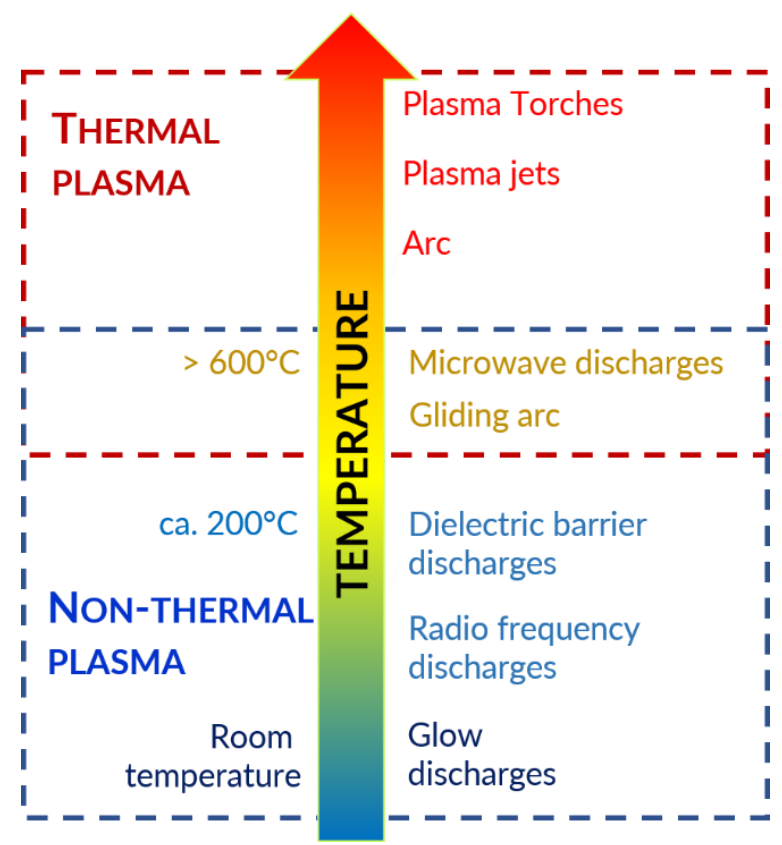

Fig. 2 Temperature characteristics of several types of plasma applied in $\mathrm{CO}_{2}$ technologies. Adapted from: [24]

The application of plasma to catalytic process can have strong advantages as it activates gaseous reactants and may modify catalyst surface as well, creating in this way new active sites. The plasma 
may interact with catalyst surface through etching and sputtering, heating, charging, deposition or photon irradiation. The origin of these processes comes from the interaction of highly energetic plasma species with catalyst surface and may result in creation of surface vacancies, defects, doping roughed surface, increase in the active sites and modification of surface functional groups. Such surface modifications affect surface adsorption properties and thus may open new reaction pathways. At the same time, the catalyst may interact with the plasma properties. Presence of the solid between the electrodes may enhance the electric field intensity as well as create microdischarges in the pores of the catalyst resulting in the change of species generated in plasma and discharge type. Thus, presence of the catalyst may affect the reactions occurring in the plasma. This clearly points out codependency between plasma and catalyst as well as the complexity of their interactions. For more information concerning plasma-catalyst interactions, the reader is referred to $[15-17,24,29]$. Therefore, the main goal of combining plasma and catalysis is to get the synergetic effect between both which creates new reaction pathways and changes in this way activation energy and therefore increases the efficiency of the reaction. The synergetic effect and co-interactions of plasma and catalysis are schematically presented in Fig. $3[15,16]$. It is important to underline that the negative effects of plasma application, such as formation of hot spots, may be also observed.

The concept of combining plasma and catalyst is considered quite new. The research in this area has already shown promising and interesting results, especially when it comes to the combustion of VOC or dry reforming of methane $[25,26,30-33]$. However, understanding of the true reaction mechanisms and codependence of both plasma and catalyst still requires much attention, as well as research and development of new techniques and approaches.

\section{Enhancement of electric field}

2. Micro-discharges in pores of catalyst

3. Change in discharge type

4. Change of concentration of plasma species

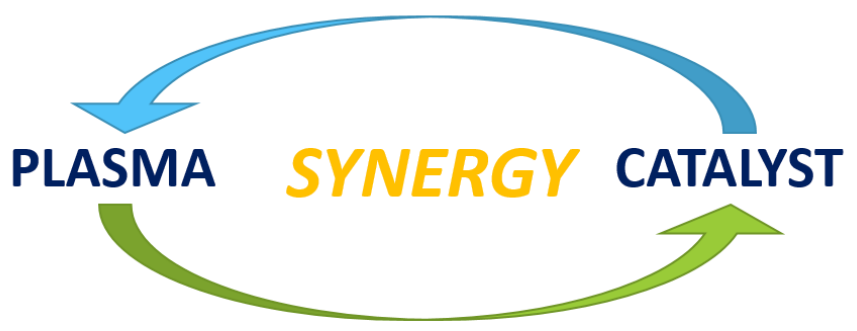

1. Change of physicochemical properties

2. Hot spot formation

3. Activation via photon radiation

4. Lowering activation barrier

5. Changing surface reaction pathways

Fig. 3 Plasma-Catalysts interactions resulting in a synergetic effect. Adapted from [15,16] 
It is important to correctly select and understand the reference of each system. For the plasmacatalytic process, a natural baseline is either to study gas discharges without the presence of a catalyst or catalytic process without plasma discharges. Therefore, in this review, both concepts will be firstly discussed, and finally, a review of recent studies concerning plasma-catalytic $\mathrm{CO}_{2}$ methanation will be presented. It is obvious that without a catalyst, plasma alone is not able to produce $\mathrm{CH}_{4}$ in the considerable amount. At the same time catalytic process, although efficient in terms of methane production, is not active at temperatures lower than $200^{\circ} \mathrm{C}$. Therefore, it is important to maximize the beneficial effects of both catalyst and plasma. This review is focusing on the catalyst part. As plasma-catalyst interactions are very complex and there is much information that we simply do not know or cannot explain, this review will not answer the question 'what is the best catalyst for plasma-assisted $\mathrm{CO}_{2}$ methanation?'. However, through summarizing studies on catalytic and plasma-catalytic $\mathrm{CO}_{2}$ methanation may be an important source of information for future studies on this topic. 


\section{Catalytic $\mathrm{CO}_{2}$ methanation}

In the current literature, there is a number of recent reviews concerning catalysts for $\mathrm{CO}_{2}$ methanation $[1,2,34-40]$. The appropriate selection of a catalyst for thermal $\mathrm{CO}_{2}$ methanation should be a starting point for the search of an efficient material for the plasma-catalytic process. Therefore, in this part, the main and recent findings concerning catalysts for $\mathrm{CO}_{2}$ methanation will be presented.

\subsection{Role of active metal}

$\mathrm{CO}_{2}$ is a stable gas. Moreover, the reduction of carbon dioxide to $\mathrm{CH}_{4}$ is an 8-electron process. Therefore, $\mathrm{CO}_{2}$ requires a highly active metal catalyst. In general, 8-10 groups' metals ( $\mathrm{Ru}, \mathrm{Rh}, \mathrm{Pd}, \mathrm{Fe}$, $\mathrm{Co}, \mathrm{Ni}$ ) have been reported to be efficient materials for $\mathrm{CO}_{2}$ methanation. Selection of an appropriate metal is very important not only from the point of view of catalytic performance but also from the economic standpoint. Fig. $4 \mathrm{~A}$ presents the activity of various metals in $\mathrm{CO}_{2}$ methanation as a turnover frequency as a function of temperature. The quick comparison based on the presented data (Fig. 4A) shows that noble metals are characterized by much higher activity than other transition metal-based catalysts. However, such direct comparison does not show complete picture as: (i) data presented via various authors, although described the same parameters was established through application of various methodologies e.g. for TOF various approaches of calculating metal dispersion, (ii) catalysts were tested in various reaction conditions, (iii) it does not take into account the role of other catalyst components (support in particular) and (iv) it does not take into account the economic factors (see Fig. 4B) such as cost of catalyst preparation, modification etc. Therefore, the activity of each metal will be first characterized separately.
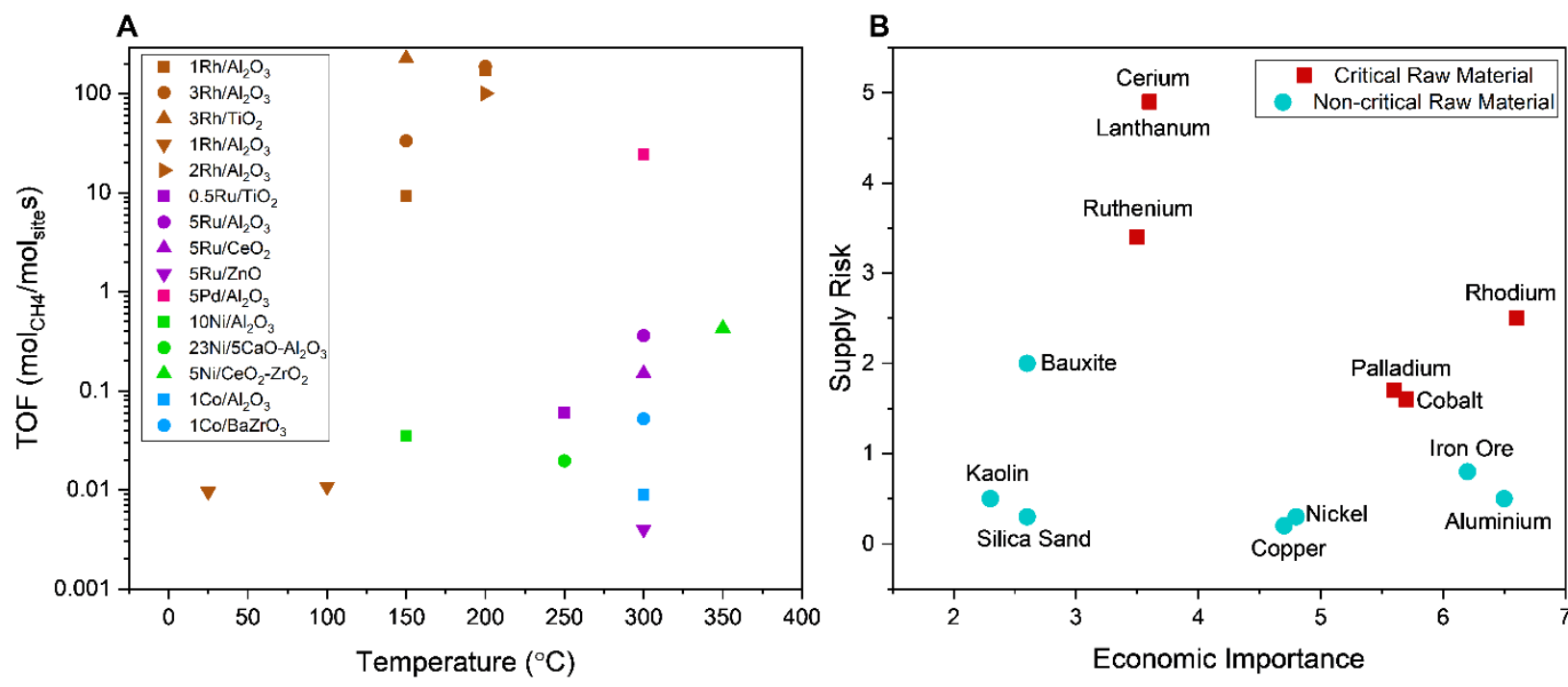

Fig. $4 \mathrm{~A}: \mathrm{CH}_{4}$ production registered for various $\mathrm{CO}_{2}$ methanation catalysts: brown symbols - Rh-based catalysts: - $\mathrm{Rh} / \mathrm{Al}_{2} \mathrm{O}_{3}[4 \mathrm{l}], \bullet 3 \mathrm{Rh} / \mathrm{Al}_{2} \mathrm{O}_{3}[41], \triangle 3 \mathrm{Rh} / \mathrm{TiO}_{2}[42], \nabla 1 \mathrm{Rh} / \mathrm{Al}_{2} \mathrm{O}_{3}[43],-2 \mathrm{Rh} / \mathrm{Al}_{2} \mathrm{O}_{3}[44] ;$ violet symbols - $\mathrm{Ru}$ - 
based catalysts: $\square 0.5 \mathrm{Ru} / \mathrm{TiO}_{2}$ [45], •5Ru/Al${ }_{2} \mathrm{O}_{3}$ [46], $\triangle 5 \mathrm{Ru} / \mathrm{CeO}_{2}$ [46], $\mathbf{\nabla} 5 \mathrm{Ru} / \mathrm{ZnO}$ [46]; green symbols - Ni-based catalysts: $10 \mathrm{Ni} / \mathrm{Al}_{2} \mathrm{O}_{3}$ [47], $-23 \mathrm{Ni} / 5 \mathrm{CaO}-\mathrm{Al}_{2} \mathrm{O}_{3}$ [48], $\triangle 5 \mathrm{Ni} / \mathrm{CeO}_{2}-\mathrm{ZrO}_{2}$ [49]; blue symbols - Co-based catalysts:

$$
1 \mathrm{Co} / \mathrm{Al}_{2} \mathrm{O}_{3}[50],-1 \mathrm{Co} / \mathrm{BaZrO}_{3}[50] ;
$$

B: Criticality assesment prepared by European Commition at EU level on the raw materials relevant for $\mathrm{CO}_{2}$ methanation catalysts: Economic importnace factor - importance of the material for EU economy; Supply risk factor - reflects the risk of a disruption in the EU supply of the material; Data taked from: [51,52]

\section{Rhodium}

$\mathrm{Rh}$ is often mentioned as one of the most active $\mathrm{CO}_{2}$ methanation catalysts. Its high activity at low reaction temperatures $\left(100-200^{\circ} \mathrm{C}\right)$ has been proven in many studies [41-43,53-57]. One of the main advantages of rhodium-based catalysts is low activation/reduction temperature (below $400^{\circ} \mathrm{C}$ ) with respect to nickel (usually above $500^{\circ} \mathrm{C}$ ). Moreover, Rh-based materials were reported to give $100 \%$ $\mathrm{CH}_{4}$ selectivity.

It is generally accepted that $\mathrm{CO}_{2}$ methanation may proceed through two reaction mechanisms. The first one involves hydrogenation of $\mathrm{CO}$ produced from $\mathrm{CO}_{2}$ dissociation. The second mechanism assumes direct hydrogenation of adsorbed $\mathrm{CO}_{2}$ species. Mechanistic studies for Rh-based catalysts confirmed the former and underlined that the type of surface carbonyls originating from $\mathrm{CO}_{2}$ dissociation influence catalyst activity. Gem di-carbonyl species were reported to be more reactive than the linear ones [54]. Formation of the former was enhanced in the presences of surface $\mathrm{Rh}^{+}$ species. Oxidation of metallic $\mathrm{Rh}^{0}$ upon methanation via $\mathrm{O}$ species adsorbed on the surface originating from $\mathrm{CO}_{2}$ dissociation was reported [43,54]. The mechanism via formation of surface formates was reported to be inactive for $\mathrm{CH}_{4}$ production [41]. Research by Karelovic et al. [41,42] showed that large Rh clusters are more active in $\mathrm{CO}_{2}$ methanation. Rh particle of sizes smaller than $7 \mathrm{~nm}$ bind $\mathrm{CO}$ species more strongly than large Rh clusters resulting in lower reaction orders in $\mathrm{CO}_{2}$ and higher activation energies. The performance of Rh catalysts is as well affected by the type of support. Studies by Solymosi et al. [55], who examined Rh supported on $\mathrm{Al}_{2} \mathrm{O}_{3}, \mathrm{MgO}, \mathrm{SiO}_{2}, \mathrm{TiO}_{2}$, revealed that the activity followed the sequence: $\mathrm{TiO}_{2}>\mathrm{Al}_{2} \mathrm{O}_{3}>\mathrm{SiO}_{2}>\mathrm{MgO}$ and was explained by different extends of electronic interaction between Rh and support.

\section{Ruthenium}

Ruthenium is another noble metal considered as one of the most active methanation catalysts. The activity of Ru-based catalysts was reported to be superior to Ni-based materials [58]. It is also affected by many factors including preparation method $[59,60]$, reduction conditions $[58,61]$ or type of support [45,62-65]. Similarly to Rh-based materials, Ru catalysts are reduced at lower temperatures with respect to Ni-based materials $[62,66,67]$. Moreover, a study by Garbarino et al. [58] revealed that higher activity of $\mathrm{Ru} / \mathrm{Al}_{2} \mathrm{O}_{3}$ catalyst was obtained when it was activated upon 
reaction in the stream of $\mathrm{CO}_{2} / \mathrm{H}_{2}$ rather than for the pre-reduced sample. In contrast to Rh-based catalysts, research by Zheng et al. [59] and Xu et al. [68], who both studied $\mathrm{Ru} / \mathrm{Al}_{2} \mathrm{O}_{3}$ catalyst, showed that activity of Ru catalysts was increasing with the decreasing Ru particle size. On the contrary, Xu et al. [61] who examined the effect of reduction temperature on $\mathrm{Ru} / \mathrm{TiO}_{2}$ material, showed that catalyst reduced at $600^{\circ} \mathrm{C}$ gave the best performance, which was attributed to large Ru particle size needed to dissociate $\mathrm{CO}_{2}$. The highest activity of this $\mathrm{Ru} / \mathrm{TiO}_{2}$ catalyst was explained as well by migration of $\mathrm{TiO}_{2}$ onto $\mathrm{Ru}$ particles, which facilitated $\mathrm{CO}_{2}$ dissociation through reaction with surface hydroxyl groups of $\mathrm{TiO}_{2}$. Various effect of Ru particle size tested on different supports clearly points to the large influence of the type of support on catalytic activity. Kowalczyk et al. [62] as well proved that type of support affects the morphology of $\mathrm{Ru}$ and thus $\mathrm{CO}_{2}$ methanation performance. The reaction rates for the tested Ru-supported catalysts followed the sequence: $\mathrm{Al}_{2} \mathrm{O}_{3}>\mathrm{MgAl}_{2} \mathrm{O}_{4}>\mathrm{MgO}>$ activated carbon. Wang et al. [63] who compared the performance of alumina and ceria supported Ru catalyst, showed that type of support affects reaction mechanism. Oxygen vacancies present in ceria support played an important role in activating $\mathrm{CO}_{2}$ molecules, promoting the formation of formate species. On the other hand, the reaction on $\mathrm{Ru} / \mathrm{Al}_{2} \mathrm{O}_{3}$ catalyst proceeded mainly on $\mathrm{Ru}$ particles through $\mathrm{CO}$ formation. The importance of support reducibility and its influence on reaction mechanism was reported as well by Dreyer et al. [46]. $\mathrm{Ru} / \mathrm{TiO}_{2}$ catalysts was examined by many authors $[45,60,61,68-71]$. It was reported that the activity of $\mathrm{Ru} / \mathrm{TiO}_{2}$ catalyst was affected and was superior in the presence of light, pointing to a photocatalytic effect [70]. The crystal structure of $\mathrm{TiO}_{2}$ (anatase or rutile) also affected the performance of Ru catalysts, however, it did not change the reaction mechanism, but the number of active sites [45]. Petala et al. [69] reported that the activity of $\mathrm{Ru} / \mathrm{TiO}_{2}$ catalyst may be enhanced via alkali metal promotion, which was reported to facilitate hydrogenation of adsorbed CO species.

\section{Palladium}

Catalysts containing palladium as an active material are often mentioned as good $\mathrm{CO}_{2}$ methanation catalysts $[35,36,38,72-74]$. Pd was proposed as methanation catalyst due to the fact that it catalyzes both reverse water gas shift (RWGS, eq. 1.2) reaction and methanol synthesis [75-77]. However, from the noble metals used for $\mathrm{CO}_{2}$ methanation, it is the least appropriate metal [2]. Compared to transition metals $\mathrm{Pd}$ is much more expensive material. Moreover, Pd-based catalysts are characterized by low activity (considerable activity was obtained at temperatures above $400^{\circ} \mathrm{C}$ ), low selectivity to $\mathrm{CH}_{4}$ and high selectivity to higher hydrocarbons and methanol $[72,78]$. Nevertheless, the addition of palladium to $\mathrm{Rh} / \mathrm{Al}_{2} \mathrm{O}_{3}$ catalyst was reported to significantly improve catalytic performance (see section 2.3) [44]. 


\section{Cobalt}

Cobalt-based catalytic systems seem to be a natural choice for $\mathrm{CO}_{2}$ methanation as $\mathrm{Co}$, as well as $\mathrm{Fe}$, catalyze Fischer-Tropsch process for hydrocarbons $(\mathrm{HC})$ production from $\mathrm{CO} / \mathrm{H}_{2}$ mixtures [79-81]. The advantage of Co catalyst to produce $\mathrm{HC}$ from $\mathrm{CO} / \mathrm{H}_{2}$ mixtures is the fact that it is not active in water gas shift reaction, which guarantees the production of long chain hydrocarbons. On the other hand, this may be a disadvantage in $\mathrm{CH}_{4}$ production form $\mathrm{CO}_{2} / \mathrm{H}_{2}$ mixtures. Many authors relate $\mathrm{Co}$ activity to the dispersion of Co species and Co particle size, thus decrease of activity for Co-based catalysts upon $\mathrm{CO}_{2}$ methanation is explained via sintering of Co nanoparticles [50,82-85]. Le et al. [85] who investigated various supports, reported that Co activity, as well as product distribution, was dependent on the type of support. Activity followed the sequence: $\mathrm{CeO}_{2}>\mathrm{SiO}_{2}>\mathrm{ZrO}_{2}>\mathrm{Al}_{2} \mathrm{O}_{3}>\mathrm{TiO}_{2}$. $\mathrm{CH}_{4}$ was the main product for all tested catalysts, however, distribution of other products was dependent on Co activity. Carbon monoxide was the main byproduct for low activity catalysts, while the most active catalysts produced ethane as the main byproduct. Similar conclusions were reported by Li et al. [86], who observed following activity sequence for Co-based catalysts: $\mathrm{ZrO}_{2}>\mathrm{SiO}_{2}>\mathrm{Al}_{2} \mathrm{O}_{3}$ $\approx \mathrm{SiC}>$ activated carbon $>\mathrm{TiO}_{2}$. The activity of Co-based catalysts may be significantly improved by $\mathrm{Pt}$ promotion $[87,88]$. As reported by Beaumont et al. [87] addition of Pt to Co supported on mesoporous silica resulted in $\mathrm{H}_{2}$ spillover from $\mathrm{Pt}$ to $\mathrm{Co}$ through silica support which increased 3 times TOF. On the other hand, palladium promotion of $\mathrm{Co} / \mathrm{SiO}_{2}$ resulted in decreased $\mathrm{CO}_{2}$ conversion [84]. Another advantage of Pt addition is the increased reducibility of Co species, as strong interactions between metallic $\mathrm{Co}$ and $\mathrm{Co}_{3} \mathrm{O}_{4}$ hinder Co reduction [81].

\section{Iron}

Iron is the second metal commonly used to catalyze the Fischer-Tropsch process [89,90]. Moreover, Fe species catalyze as well RWGS reaction. Therefore, a reaction mechanism for $\mathrm{CO}_{2}$ methanation was proposed in which Fe-based catalyst firstly reduce $\mathrm{CO}_{2}$ to $\mathrm{CO}$ through RWGS and subsequently CO methanation would proceed [81]. Another advantage which accounts for Fe-based materials is the low price of iron and the low toxicological effect when compared to nickel. However, there are not many reports concerning the activity of Fe-based materials, mainly due to the fact of low selectivity to $\mathrm{CH}_{4}$ of iron catalysts. Owen et al. [91] investigated $\mathrm{Fe} / \mathrm{SiO}_{2}$ catalysts prepared via coprecipitation and impregnation method. The latter showed much better performance which was explained by the change in samples morphology and the formation of small nanoparticles. In the same study, the effect of $\mathrm{Cu}, \mathrm{Ag}$ and $\mathrm{Au}$ was investigated as well. Although in the case of silver addition and increase in activity was observed, all promoters decreased $\mathrm{CH}_{4}$ selectivity. Kirchner et al. [92] studied the activity of commercial iron oxides. Catalysts were activated upon $\mathrm{CO}_{2}$ methanation 
reaction and did not undergo $\mathrm{H}_{2}$ pretreatment. The activity was dependent on the morphology of iron oxides and their phase composition. During the reaction, carbon deposits and iron carbides were formed. High formation of CO due to RWGS was also observed. The best performance was registered for nano-sized $\gamma-\mathrm{Fe}_{2} \mathrm{O}_{3}$ which were attributed to the abundance of surface carbon species vs. low activity carbides observed on $\alpha-\mathrm{Fe}_{2} \mathrm{O}_{3}$. Iron oxides were as well studied by Lee et al. [93] who reported that activity of iron oxides in $\mathrm{CO}_{2}$ methanation may be increased by increasing pressure, $\mathrm{H}_{2} / \mathrm{CO}_{2}$ molar ratio, as well as decreasing space velocity. However, $\mathrm{CH}_{4}$ selectivity remained poor. Nevertheless, iron addition to nickel turned out to improve significantly activity of nickel-based catalyst (see section 2.3).

\section{Nickel}

From all the transition metals nickel is the most studied one. The Ni-based catalyst is so intensively studied because they are characterized by high activity and are much cheaper than materials based on noble metals. What is more, Ni-alumina catalysts are applied in commercial plants $[1,94]$, therefore they are well studied. However, much effort is paid to further enhance the catalytic properties of Ni-based catalysts. Many authors underline that the activity of Ni-based materials is dependent on $\mathrm{Ni}$ dispersion and Ni particle size following the rule: the better the dispersion and the smaller $\mathrm{Ni}$ particle size, the better catalyst activity in $\mathrm{CO}_{2}$ methanation. Such relation has been observed for $\mathrm{Ni}$-catalysts supported on various materials, including $\mathrm{Ni} / \mathrm{Al}_{2} \mathrm{O}_{3}$ [95-99] Ni/MgO [100], $\mathrm{Ni} / \mathrm{Mg}(\mathrm{Al}) \mathrm{O}$ [101,102], Ni/CeO $-\mathrm{ZrO}_{2}$ [103,104], Ni/SiO 2 [105], Ni/USY [106-108], Ni/bentonite [109] or $\mathrm{Ni} / \mathrm{Al}_{2} \mathrm{O}_{3}-\mathrm{TiO}_{2}-\mathrm{ZrO}_{2}[110,111]$. The effect of the support for the Ni-based catalysts will be discussed in more details in the next section. Nevertheless, it is important to underline that the main challenge concerning $\mathrm{Ni}$-based catalysts for $\mathrm{CO}_{2}$ methanation is to increase their low-temperature activity, stability and selectivity to $\mathrm{CH}_{4}$ which may be realized via creating highly dispersed Ni species. A great challenge, especially at low reaction temperatures is to avoid the formation of mobile nickel subcarbonyls resulting in sintering of $\mathrm{Ni}$ particles and thus in a decrease in catalytic activity and formation of carbon deposits. Another important aspect underlined by a number of researchers is the catalysts basicity. Of a special importance are intermediate strength basic sites which are responsible for the formation of monodentate formate species. These species are believed to be an important intermediate in $\mathrm{CO}_{2}$ methanation over $\mathrm{Ni}$-based catalysts, as their formation guarantees high activities and selectivity to methane $[95,102,112-114]$. All of the mentioned properties may be modified via application of appropriate support, promoter and especially catalysts synthesis and post-synthesis treatment $[48,49,113-115]$.

\section{Comparison of various metals}


Although much research has been done regarding the role of various metals in $\mathrm{CO}_{2}$ hydrogenation to $\mathrm{CH}_{4}$, the direct comparison of metals and establishing their activity sequence is not simple for the reasons mentioned at the beginning of this section. The reported catalysts have been studied under various reaction conditions. They differed in composition (support and/or promoter) as well as synthesis method, catalyst conditioning and activation method. Even studies which present activity as turnover frequency or $\mathrm{CH}_{4}$ production do not allow direct comparison, as such activities are usually established under different conditions and with different methodologies. For example, Fig. 4A suggests the much better activity of Pd with respect to nickel, which is not always confirmed in direct comparison (Table 2). Therefore, to correctly establish activity sequence of various metals they need to be tested in the same reaction conditions and undergo the same pretreatment. Table 2 summarizes studies in which such direct comparison was investigated.

Garbarino et al. [58] compared the performance of $\mathrm{Ru}$ and $\mathrm{Ni}$ supported on $\mathrm{Al}_{2} \mathrm{O}_{3}$. The former showed better catalytic performance giving higher $\mathrm{CO}_{2}$ conversions and higher selectivity to $\mathrm{CH}_{4}$ with respect to $\mathrm{Ni}$ catalyst. It is also important to underline that Ru catalyst was loaded with over 6 times less metal loading than $\mathrm{Ni}$, which is important from the economic standpoint. An important difference which was observed between both catalysts showed that $\mathrm{Ru} / \mathrm{Al}_{2} \mathrm{O}_{3}$ to gain full activity needs to be activated on stream, while for $\mathrm{Ni} / \mathrm{Al}_{2} \mathrm{O}_{3} \mathrm{H}_{2}$ pre-activation is required. This points out to various reaction mechanisms for both metals, where $\mathrm{CO}_{2}$ methanation proceeds over oxidized/reduced Ru species or metallic Ni sites, respectively. The former reaction mechanisms for $\mathrm{Ru} / \mathrm{Al}_{2} \mathrm{O}_{3}$ catalyst is well discussed in the other paper of Garbarino et al. [66].

Table 2 Comparison of activity and selectivity of various metals in $\mathrm{CO}_{2}$ methanation.

\begin{tabular}{|c|c|c|c|c|}
\hline $\begin{array}{l}\text { Activity } \\
\text { sequence }\end{array}$ & $\begin{array}{l}\text { Selectivity } \\
\text { sequence }\end{array}$ & $\begin{array}{l}\text { Metal } \\
\text { loading/ } \\
\text { Support }\end{array}$ & Reaction Conditions & Ref. \\
\hline $\mathrm{Ru}>\approx \mathrm{Ni}$ & $\mathrm{Ni}>\approx \mathrm{Ru}$ & $\begin{array}{c}3 \mathrm{wt} . \% \mathrm{Ru}, \\
20 \mathrm{wt} . \% \mathrm{Ni} / \\
\mathrm{Al}_{2} \mathrm{O}_{3}\end{array}$ & $\begin{array}{c}\text { Temp. } 50-200^{\circ} \mathrm{C}, 1 \text { bar, } \\
\mathrm{CO}_{2} / \mathrm{H}_{2} / \mathrm{He}=1 / 4 / 5 \\
\mathrm{GHSV}=15000-5500 \mathrm{~h}^{-1}\end{array}$ & {$[58]$} \\
\hline $\mathrm{Rh} \gg>\mathrm{Ni}$ & $\mathrm{Rh} \gg \mathrm{Ni}$ & $\begin{array}{c}1 \mathrm{wt} . \% / \\
\mathrm{Rh}_{-} \mathrm{Al}_{2} \mathrm{O}_{3} \\
\mathrm{Ni}-\mathrm{AC}\end{array}$ & $\begin{array}{l}\text { Temp. } 125^{\circ} \mathrm{C}, 2 \text { bar, } \\
\text { pulses of } \mathrm{CO}_{2} \text { and } \mathrm{H}_{2} \\
\text { Red. } 350^{\circ} \mathrm{C} \text { for } 1 \mathrm{~h}\end{array}$ & [53] \\
\hline $\mathrm{Rh} \gg \mathrm{Pd}$ & $\mathrm{Rh} \gg>\mathrm{Pd}$ & $\begin{array}{c}\text { 5wt.\%Pd, } \\
\text { 2wt.\%Rh/ } \\
\mathrm{Al}_{2} \mathrm{O}_{3} \\
\end{array}$ & $\begin{array}{c}\text { Temp. } 200^{\circ} \mathrm{C}, 1 \text { bar, } \mathrm{m}_{\text {cat }}=200 \mathrm{mg} \\
\mathrm{CO}_{2} / \mathrm{H}_{2} / \mathrm{Ar}=1 / 4 / 5 \\
\text { Red. } 350^{\circ} \mathrm{C} \text { for } 1 \mathrm{~h} \\
\end{array}$ & {$[44]$} \\
\hline $\mathrm{Ru}>\mathrm{Rh} \gg>\mathrm{Pd}$ & No data & $\begin{array}{l}\mathrm{M} / \mathrm{Mn} / \mathrm{Cu}= \\
5 / 35 / 60 / \mathrm{Al} \\
{ }_{2} \mathrm{O}_{3}\end{array}$ & $\begin{array}{c}\text { Temp. } 100-300^{\circ} \mathrm{C}, \mathrm{p}=1 \text { bar; } \mathrm{m}_{\mathrm{cat}}=5 \mathrm{~g} \\
\mathrm{CO}_{2} / \mathrm{H}_{2}=1 / 4 \\
\text { No data on activation }\end{array}$ & [116] \\
\hline $\begin{array}{c}\mathrm{Ru}>\mathrm{Pt}>\mathrm{Rh}>> \\
\mathrm{Pd}\end{array}$ & $\begin{array}{c}\mathrm{Rh}>\mathrm{Ru}>>\mathrm{Pd} \\
>\mathrm{Pt}\end{array}$ & $\begin{array}{c}0.5 w t . \% / \\
\mathrm{Al}_{2} \mathrm{O}_{3}\end{array}$ & $\begin{array}{c}\text { Temp. } 330^{\circ} \mathrm{C} ; \mathrm{p}=1 \text { bar; } \mathrm{m}_{\text {cat }}=150 \mathrm{mg} \\
\mathrm{CO}_{2} / \mathrm{H}_{2} / \mathrm{He}=1 / 4 / 15 \\
\text { Red. } 300^{\circ} \mathrm{C} \text { for } 1 \mathrm{~h}\end{array}$ & [117] \\
\hline $\mathrm{Rh}>\mathrm{Ru}>\mathrm{Pt}>$ & $\mathrm{Rh}>\mathrm{Ru}>>\mathrm{Pt}>$ & $0.5 w t . \% /$ & Temp. $170-450^{\circ} \mathrm{C} ; \mathrm{p}=1 \mathrm{bar} ; \mathrm{m}_{\text {cat }}=100 \mathrm{mg}$ & [73] \\
\hline
\end{tabular}




\begin{tabular}{|c|c|c|c|c|}
\hline $\mathrm{Pd}$ & $\mathrm{Pd}$ & $\mathrm{TiO}_{2}$ & $\begin{array}{c}\mathrm{CO}_{2} / \mathrm{H}_{2}=15 / 50 ; \\
\text { Red. } 300^{\circ} \mathrm{C} \text { for } 1 \mathrm{~h}\end{array}$ & \\
\hline $\begin{aligned} \mathrm{Pt}> & >\mathrm{Ru}>\mathrm{Pd}>\mathrm{Ir} \\
& >\mathrm{Rh}\end{aligned}$ & $\begin{array}{c}\mathrm{Ru}>\mathrm{Rh} \gg \mathrm{Pd}> \\
\mathrm{Ir} \gg>\mathrm{Pt}\end{array}$ & $\begin{array}{c}1 \mathrm{wt} . \% / \\
\mathrm{CeO}_{2}\end{array}$ & $\begin{array}{c}\text { Temp. } 277^{\circ} \mathrm{C} ; \mathrm{p}=1 \mathrm{bar} ; \\
\mathrm{m}_{\text {cat }}=100-200 \mathrm{mg} \\
\mathrm{CO}_{2} / \mathrm{H}_{2}=1 / 4 ; \mathrm{GHSV}=6000 \mathrm{~h}^{-1} \\
\text { Red. } 227^{\circ} \mathrm{C} \text { for } 2 \mathrm{~h}\end{array}$ & [118] \\
\hline $\begin{array}{c}\mathrm{Ru} \gg \mathrm{Co} \approx \mathrm{Ci} \approx \\
\quad \mathrm{Pd}\end{array}$ & $\begin{array}{c}\mathrm{Ru} \gg>\mathrm{Ni}>>\mathrm{Co}= \\
\mathrm{Pd}\end{array}$ & $\begin{array}{c}\text { Cont. } \\
\text { varied/ } \\
\mathrm{CeO}_{2}\end{array}$ & $\begin{array}{c}\text { Temp. } 500^{\circ} \mathrm{C}, 1 \text { bar, } \mathrm{m}_{\mathrm{cat}}=20 \mathrm{mg} \\
\mathrm{CO}_{2} / \mathrm{H}_{2} / \mathrm{Ar}=2 / 8 / 5\end{array}$ & [119] \\
\hline $\begin{array}{c}\mathrm{Co}>\mathrm{Ru}>\mathrm{Ni}> \\
\mathrm{Fe}\end{array}$ & $\begin{array}{c}\mathrm{Ru}>\mathrm{Ni}>\mathrm{Co}> \\
\mathrm{Fe}\end{array}$ & $\begin{array}{l}\text { Cont. } \\
\text { varied/ } \\
\mathrm{SiO}_{2}\end{array}$ & $\begin{array}{c}\text { Temp.177-377 }{ }^{\circ} \mathrm{C} ; \mathrm{p}=1 \mathrm{bar} ; \\
\mathrm{m}_{\mathrm{cat}}=0.3-1 \mathrm{~g} \\
\mathrm{CO}_{2} / \mathrm{H}_{2}=1 / 4 ; \mathrm{GHSV}=4000-50000 \mathrm{~h}^{-1} \\
\text { Red. } 450^{\circ} \mathrm{C} \text { for } 12 \mathrm{~h}\end{array}$ & [120] \\
\hline $\begin{array}{c}\mathrm{Ni}>\mathrm{Cu} \approx \mathrm{Co}> \\
\mathrm{Zn}\end{array}$ & $\begin{array}{c}\mathrm{Ni}>\mathrm{Co}>>\mathrm{Cu} \approx \\
\mathrm{Zn}\end{array}$ & $\begin{array}{l}\text { Si/Metal } \\
\text { ratio=5/ } \\
\text { MCM-41 }\end{array}$ & $\begin{array}{c}\text { Temp. } 330-550^{\circ} \mathrm{C} ; \mathrm{p}=1 \mathrm{bar} ; \\
\mathrm{CO}_{2} / \mathrm{H}_{2}=1 / 1 ; \\
\text { Red. at } 500^{\circ} \mathrm{C} \text { for } 2 \mathrm{~h}\end{array}$ & [121] \\
\hline $\mathrm{Ni} \gg \mathrm{Cu}>\mathrm{Fe}$ & $\mathrm{Ni} \gg \mathrm{Cu}>\mathrm{Fe}$ & $\begin{array}{c}15 \mathrm{wt} . \% / \mathrm{Al}_{2} \\
\mathrm{O}_{3}\end{array}$ & $\begin{array}{c}\text { Temp. } 250^{\circ} \mathrm{C} ; p=1 \text { bar; } m_{\text {cat }}=100 \mathrm{mg} \\
\mathrm{CO}_{2} / \mathrm{H}_{2}=4 / 96 ; \\
\text { Red. } 550^{\circ} \mathrm{C} \text { for } 4 \mathrm{~h}\end{array}$ & [122] \\
\hline
\end{tabular}

Performance of nickel and rhodium catalyst was compared by Swalus et al. [53]. The authors used alumina and activated carbon (AC) as support for $\mathrm{Rh}$ and $\mathrm{Ni}$ catalysts, respectively. Their studies revealed that $\mathrm{Rh} / \mathrm{Al}_{2} \mathrm{O}_{3}$ catalyst shows a huge affinity to $\mathrm{CO}_{2}$ adsorption, while $\mathrm{Ni} / \mathrm{AC}$ may be treated as hydrogen storage (may sorb high quantities of $\mathrm{H}_{2}$ ). The authors showed that mechanical mixing of both catalysts advantages of both effects and thus results in more efficient performance. However, when $\mathrm{Rh} / \mathrm{Al}_{2} \mathrm{O}_{3}$ and $\mathrm{Ni} / \mathrm{AC}$ are compared directly, the former showed higher $\mathrm{CO}_{2}$ conversions and better selectivity towards $\mathrm{CH}_{4}$.

Karelovic and Ruiz [44] investigated the performance of $\mathrm{Rh} / \mathrm{Al}_{2} \mathrm{O}_{3}$ and $\mathrm{Pd} / \mathrm{Al}_{2} \mathrm{O}_{3}$ catalysts. They observed that both catalysts were able to dissociate $\mathrm{CO}_{2}$ over $\mathrm{Rh}$ and $\mathrm{Pd}$ species resulting in the formation of surface carbonyls. $\mathrm{Pd} / \mathrm{Al}_{2} \mathrm{O}_{3}$ catalyst, however, cannot hydrogenate adsorbed $\mathrm{CO}$ species and thus gave high selectivity to $\mathrm{CO}$. Only in the presence of $\mathrm{Rh} / \mathrm{Al}_{2} \mathrm{O}_{3}$ (a mechanical mixture of both catalysts), $\mathrm{CH}_{4}$ production was observed, due to $\mathrm{H}_{2}$ dissociation over Rh species. Interestingly, mechanical mixture or both catalysts showed a synergetic effect and significantly increased $\mathrm{CH}_{4}$ production and activity, without changing the crystal structure of Rh and Pd particles. Similar results and conclusions were observed by Panagiotopoulou et al. [73,117] and Leitenburg et al. [118] who investigated as well role of Ru and Pt. Their studies showed that only Ru and Rh are able to produce $\mathrm{CH}_{4}$, while $\mathrm{Pt}$ and $\mathrm{Pd}$, although give high $\mathrm{CO}_{2}$ conversions, produce mainly $\mathrm{CO}$ through RWGS. Moreover, the authors showed that the activity and selectivity sequence is dependent on the type of support as different results were obtained for alumina, titania and ceria supports (Table 2). 
Ceria doped with Ru, Pd, Ni or Co prepared via combustion method was investigated by Sharma et al. [119]. They found out that the main effect of dopant is the facile reduction of ceria. Various metals had a different effect. The Pd-based catalyst was active, but selective only to $\mathrm{CO}$, while $\mathrm{Ni}$ and $\mathrm{Co}$ containing samples were active in both RWGS and $\mathrm{CO}_{2}$ methanation, therefore, they were not $100 \%$ selective to $\mathrm{CH}_{4}$. The best performance was showed by $\mathrm{Ru}$ containing the sample. The authors showed that the Ru species were introduced into the lattice of ceria and their substantial amount was present in the bulk. For the Ru-based catalysts, a methanation mechanism proceeding firstly via RWGS to form $\mathrm{CO}$ and further $\mathrm{CO}$ hydrogenation to $\mathrm{CH}_{4}$ was reported $[73,117,118]$. However, Sharma et al. [119] showed that it is not the case when $\mathrm{Ru}$ is incorporated into $\mathrm{CeO}_{2}$ lattice, pointing to the importance of synthesis route and type of metal species.

When the activity of non-noble transition metals is directly compared it can be easily stated that the main difference between them is their selectivity towards $\mathrm{CH}_{4}$ [120-122]. The activity of each metal towards $\mathrm{CO}_{2}$ may be significantly improved via application of appropriate reaction conditions. For instance, in the research by Weatherbee and Bartholomew [120] Co-based sample showed higher activity than Ru-based catalysts, however, its selectivity was mainly to higher hydrocarbons rather than $\mathrm{CH}_{4}$. Ni-based catalysts were reported to give the highest selectivity to methane among other transition metals i.e. $\mathrm{Co}, \mathrm{Cu}, \mathrm{Fe}$ and $\mathrm{Zn}[120-122]$.

\subsection{Ni-based catalysts - Effect of support}

Nickel-based catalysts are the most widely studied materials for $\mathrm{CO}_{2}$ methanation. Their activity depends on the number of factors including the type of support. Similarly, to the role of active metal, it is hard to discuss the effect of support while comparing materials tested in various reaction conditions. For this reasons studies in which supports are directly compared are of great importance. The effect of support for the Ni-based catalyst is summarized in Table 3.

Many authors underline the importance of two factors which greatly influence performance of nickel species in $\mathrm{CO}_{2}$ methanation: (i) basicity of support which directly influences $\mathrm{CO}_{2}$ adsorption capacity [123-128] and (ii) support-nickel interactions which influence reducibility of Ni species, Ni dispersion and Ni particle size [129-135].

Pan et al. [124] compared the performance of $\mathrm{Ni}$ supported on ceria-zirconia and alumina. Both supports differed in acid-basic properties. The former exhibited the presence of intermediate strength basic sites, while alumina is well known for its acidic character. Intermediate strength basic sites facilitated the formation of monodentate formate species and thus accounted for the superior performance of $\mathrm{Ni} / \mathrm{Ce}_{0.5} \mathrm{Zr}_{0.5} \mathrm{O}_{2}$ catalyst. Similar conclusions and the importance of intermediate 
strength basic sites were as well reported by Muroyama et al. [126] and Guo et al. [128]. Basicity thus plays an important role in $\mathrm{CO}_{2}$ methanation, however, research by Fukuhara et al. [127], who compared the performance of $\mathrm{Ni}$ supported on $\mathrm{Al}_{2} \mathrm{O}_{3}, \mathrm{TiO}_{2}, \mathrm{ZrO}_{2}, \mathrm{Y}_{2} \mathrm{O}_{3}, \mathrm{MgO}$ and $\mathrm{CeO}_{2}$ showed that basic support like $\mathrm{MgO}$ adsorbs $\mathrm{CO}_{2}$ too strongly and thus results in the lowest activity.

Bacariza et al. investigated the performance of various $\mathrm{Ni}$ catalysts supported on structured silica [130] or zeolites [135]. Their research showed the great performance of Ni/MCM-41 catalysts which was attributed to the highly developed surface area and thus availability of $\mathrm{Ni}$ active sites. Ni/SBA-15 catalyst, on the other hand, showed lower activity which was explained by the formation of poisoning surface carbonyls. The textural properties of mesostructured silica nanoparticles and MCM-41 played as well an important role in catalysts activity in the investigation carried out by Aziz et al. [125]. In the case of zeolite catalysts, Bacariza et al. [135], underlined the importance of the supports affinity to water, as it turned out to be the function of catalysts activity. Strong interactions of water molecules with the catalyst surface may block the active sites and therefore, water may be treated as an inhibitor of $\mathrm{CO}_{2}$ methanation. The dispersion of nickel species was also an important factor influencing the performance of zeolites with various types of frameworks.

Table 3 Effect of various supports on the performance of Ni-based catalysts

\begin{tabular}{|c|c|c|c|}
\hline Activity sequence & $\begin{array}{c}\mathrm{Ni} \\
\text { loading } \\
\text { (wt.\%) }\end{array}$ & Reaction conditions & Ref. \\
\hline $\mathrm{CeO}_{2}>\alpha-\mathrm{Al}_{2} \mathrm{O}_{3}>\mathrm{TiO}_{2} \approx \mathrm{MgO}$ & 10 & $\begin{array}{c}\text { Temp. } 250-550^{\circ} \mathrm{C} ; \mathrm{p}=1 \text { bar; } \mathrm{m}_{\mathrm{cat}}=300 \mathrm{mg} \\
\mathrm{CO}_{2} / \mathrm{H}_{2}=1 / 4 ; \mathrm{GHSV}=10000 \mathrm{~h}^{-1} \\
\text { Red. } 600^{\circ} \mathrm{C} \text { for } 0.5 \mathrm{~h}\end{array}$ & [123] \\
\hline $\mathrm{Ce}_{0.5} \mathrm{Zr}_{0.5} \mathrm{O}_{2} \gg>{ }^{-} \mathrm{Al}_{2} \mathrm{O}_{3}$ & 7 & $\begin{array}{c}\text { Temp.220-400 }{ }^{\circ} \mathrm{C} ; \mathrm{p}=30 \mathrm{bar} ; \\
\mathrm{CH}_{4} / \mathrm{H}_{2} / \mathrm{H}_{2} \mathrm{O} / \mathrm{CO}_{2}=56 / 33 / 9 / 2 ; \\
\mathrm{GHSV}=20000 \mathrm{~h}^{-1} ; \text { Red. } 500^{\circ} \mathrm{C} \text { for } 4 \mathrm{~h}\end{array}$ & [124] \\
\hline $\begin{array}{c}\mathrm{MSN}>\mathrm{MCM}-41>\mathrm{HY}>\mathrm{SiO}_{2}>\gamma^{-} \\
\mathrm{Al}_{2} \mathrm{O}_{3}\end{array}$ & 5 & $\begin{array}{c}\text { Temp.150-450 } 0^{\circ} \mathrm{C} p=1 \text { bar; } m_{\text {cat }}=200 \mathrm{mg} \\
\mathrm{CO}_{2} / \mathrm{H}_{2} / \mathrm{N}_{2}=1 / 4 / 5 ; \mathrm{GHSV}=2000 \mathrm{~h}^{-1} \\
\text { Red. } 500^{\circ} \mathrm{C} \text { for } 4 \mathrm{~h}\end{array}$ & [125] \\
\hline $\begin{aligned} \mathrm{Y}_{2} \mathrm{O}_{3}>\mathrm{Sm}_{2} \mathrm{O}_{3} & >\mathrm{ZrO}_{2}>\mathrm{CeO}_{2}>\mathrm{Al}_{2} \mathrm{O}_{3} \\
& >\mathrm{La}_{2} \mathrm{O}_{3}\end{aligned}$ & 10 & $\begin{array}{l}\text { Temp.200-450 } \mathrm{C} ; \mathrm{p}=1 \mathrm{bar} \\
\mathrm{CO}_{2} / \mathrm{H}_{2}=1 / 4 ; \mathrm{GHSV}=50000 \mathrm{~h}^{-1} \\
\text { Red. } 600^{\circ} \mathrm{C} \text { for } 3 \mathrm{~h}\end{array}$ & [126] \\
\hline $\begin{array}{c}\mathrm{CeO}_{2} \gg \mathrm{ZrO}_{2}>\mathrm{SiO}_{2}>\mathrm{TiO}_{2} \approx \gamma^{-} \\
\mathrm{Al}_{2} \mathrm{O}_{3}\end{array}$ & 10 & $\begin{array}{c}\text { Temp.150-400 }{ }^{\circ} \mathrm{C} ; \mathrm{p}=1 \mathrm{bar} ; \mathrm{m}_{\mathrm{cat}}=100 \mathrm{mg} \\
\mathrm{CO}_{2} / \mathrm{H}_{2} / \mathrm{He}=1 / 50 / 49 ; \\
\mathrm{F} / \mathrm{W}=1000 \mathrm{mlmin}^{-1} \mathrm{~g}_{\mathrm{cat}^{-1}}\end{array}$ & [129] \\
\hline $\begin{aligned} \mathrm{CeO}_{2}>\mathrm{ZrO}_{2} & \approx \mathrm{Y}_{2} \mathrm{O}_{3}>\mathrm{Al}_{2} \mathrm{O}_{3}>\mathrm{TiO}_{2} \\
& >\mathrm{MgO}\end{aligned}$ & 10 & $\begin{array}{c}\text { Temp.200-500 }{ }^{\circ} \mathrm{C} ; \mathrm{p}=1 \mathrm{bar} ; \mathrm{m}_{\mathrm{cat}}=300 \mathrm{mg} \\
\mathrm{CO}_{2} / \mathrm{H}_{2} / \mathrm{He}=1 / 4 / 5 \\
W H S V \approx 23000 \mathrm{mlg}^{-1} \mathrm{~min}^{-1} \\
\text { Red. } 500^{\circ} \mathrm{C} \text { for } 2 \mathrm{~h}\end{array}$ & [127] \\
\hline $\begin{array}{c}\mathrm{ZSM}-5>\mathrm{SBA}-15>\mathrm{Al}_{2} \mathrm{O}_{3}>\mathrm{SiO}_{2}>> \\
\mathrm{MCM}-41\end{array}$ & 10 & $\begin{array}{c}\text { Temp.200-450 } \mathrm{C} ; \mathrm{p}=1 \mathrm{bar} ; \mathrm{m}_{\mathrm{cat}}=174 \mathrm{mg} \\
\mathrm{CO}_{2} / \mathrm{H}_{2}=1 / 4 ; \mathrm{WHSV}=48 \mathrm{mlg}_{\mathrm{cat}^{-1}} \mathrm{~h}^{-1} \\
\text { Red. } 500^{\circ} \mathrm{C} \text { for } 4 \mathrm{~h}\end{array}$ & [128] \\
\hline MCM-41 > SBA-15 $\approx$ USY & 15 & Temp.200-450 $\mathrm{C} ; \mathrm{p}=1 \mathrm{bar}$ & [130] \\
\hline
\end{tabular}




\begin{tabular}{|c|c|c|c|}
\hline & & $\mathrm{CO}_{2} / \mathrm{H}_{2}=1 / 4 ; \mathrm{GHSV}=2400 \mathrm{~h}^{-1}$ & \\
\hline Red. $470^{\circ} \mathrm{C}$ for $1 \mathrm{~h}$ & \\
\hline & \multirow{2}{*}{15} & $\begin{array}{c}\text { Temp. } 250-450^{\circ} \mathrm{C} ; \mathrm{p}=1 \mathrm{bar} ; \\
\mathrm{CO}_{2} / \mathrm{H}_{2} / \mathrm{N}_{2}=9 / 36 / 10 ; \mathrm{GHSV}=43000 \mathrm{~h}^{-1}\end{array}$ & [135] \\
& & Red. $470^{\circ} \mathrm{C}$ & \\
\hline
\end{tabular}

In the case of all studies presented in Table 3, which included ceria or ceria-zirconia support, the superior performance of $\mathrm{Ni} / \mathrm{CeO}_{2}$ catalyst was proved with respect to other oxide supports $[123,124,126,127,129]$. The beneficial effect of ceria support may be attributed to its redox properties. The presence of surface oxygen vacancies influences the basicity of catalysts which was proven to play an important role in the reaction mechanism creating a redox cycle between ceria support and $\mathrm{Ni}$ species [136]. The beneficial properties of ceria may be lost without carefully considering each catalyst synthesis step. Konishcheva et al. [137] reported a loss of activity of $\mathrm{Ni} / \mathrm{CeO}_{2}$ catalysts prepared via impregnation from chlorine salts due to the blockage of ceria surface by chlorine atoms. Another important factor is the possibility of the introduction of $\mathrm{Ni}$ species into the lattice of ceria, which influences nickel-support interactions, improves dispersion and inhibits sintering of nickel species $[138,139]$. The activity of $\mathrm{Ni} / \mathrm{CeO}_{2}$ catalyst may be further improved via application of mixed ceria-zirconia support. Substitution of $\mathrm{Ce}^{4+}$ with $\mathrm{Zr}^{4+}$ species in the ceria lattice was reported to increase the number of oxygen vacancies and to enhance basicity as well as hydrothermal stability $[138,140]$. The ceria/zirconia molar ratio [140] and method of nickel introduction [49] may also affect the amount of $\mathrm{Ni}$ species introduced into the ceria framework and thus influence materials activity.

\subsection{Ni-based catalysts - Effect of promoters \& bimetallic catalysts}

All catalysts properties which influence the activity, selectivity and stability of $\mathrm{Ni}$-based materials, such as basicity, $\mathrm{CO}_{2}$ adsorption capacity, $\mathrm{Ni}$ dispersion, Ni particle size and its resistance to sintering may be enhanced with the application of appropriate promoter. The effect of various promoters on $\mathrm{Ni}$-based catalysts is presented in Table 4. Addition of promoter affects not only the $\mathrm{Ni}$ species but also may affect support properties and therefore influence catalyst activity in an indirect way. The promoters and their effect may be divided into 4 groups (Table 3): (i) noble metals, which may be as well considered as bi-metallic catalyst, (ii) metals with basic character $-1^{\text {st }}$ and $2^{\text {nd }}$ group metals, (iii) lanthanide promoters and (iv) other transition metals i.e. Mo, Mn, W, Y or V. The fifth group may be distinguished as well (not included in Table 4 but discussed at the end of the section) which are bimetallic catalyst consisting of nickel and second transition group metal which is also active in $\mathrm{CO}_{2}$ methanation. 
In previous sections (2.1 and 2.2) the positive effect of bimetallic catalysts application was briefly mentioned. Bi-metallic noble metal catalysts ( $\mathrm{Pd}-\mathrm{Rh})$ were reported to give synergetic effect without changing the crystal structure of each metal [44]. On the other hand, the addition of noble metal (Rh, $\mathrm{Ru}, \mathrm{Pd}, \mathrm{Pt}$ ) to Ni-based catalyst improved reducibility and dispersion of active nickel species (Table 4) $[47,140]$. In general promotion by noble metals ( $\mathrm{Pt}, \mathrm{Pd}, \mathrm{Rh}, \mathrm{Ru})$ resulted mainly in the enhanced reducibility of $\mathrm{Ni}$ species without affecting $\mathrm{Ni}$ crystal size, which resulted in increased dispersion $[47,140]$.

Metals or metal oxides with basic properties are added to the Ni-based catalyst to enhance catalysts $\mathrm{CO}_{2}$ adsorption capacity. The effect of their addition depends on the strength of their basic properties, as well on their loading [141]. Moreover, their addition may as well influence reducibility of Ni species [142-144].

Promotion with lanthanide species was reported to introduce both basicity and reducibility of $\mathrm{Ni}$ based catalyst [145]. Especially, the addition of lanthanum into Ni-based catalyst turned out to have an interesting effect. Work of Wierzbicki et al. $[112,146,147]$ showed that the method of lanthanum introduction influences the properties of $\mathrm{Ni}(\mathrm{Mg}, \mathrm{Al}) \mathrm{O}_{x}$ hydrotalcite-derived mixed oxides. It especially promoted the formation of intermediate strength basic sites. What is more, operando HERFD-XANES analysis showed that the addition of lanthanum changed the oxidation state of nickel species which was dynamically changing under reaction conditions [146]. This effect was not observed for unpromoted catalysts, pointing to complete change of reaction mechanism. The beneficial properties of ceria support (see section 2.2) may be as well feasible when ceria is introduced as a promoter on the surface of catalyst $[105,106,108,148]$.

Table 4 Effect of various promoters on Ni-based catalysts

\begin{tabular}{|c|c|c|c|}
\hline Promoter & Catalyst & Promotion effect & Ref. \\
\hline $\begin{array}{c}\mathrm{Pt}, \mathrm{Pd}, \mathrm{Rh} \\
(0.5 \mathrm{wt} . \%)\end{array}$ & $15 \% \mathrm{Ni} / \mathrm{Al}_{2} \mathrm{O}_{3}$ & $\begin{array}{c}\text { Small Ni crystallites and improved dispersion; improved } \\
\text { reducibility of } \mathrm{Ni} \text { and } \mathrm{H}_{2} \text { chemisorption capacity; } \mathrm{Pt} \text { and } \\
\mathrm{Pd} \text { improved } \mathrm{CO}_{2} \text { conversion }\end{array}$ & {$[47]$} \\
\hline $\begin{array}{c}\mathrm{Rh}, \mathrm{Ru} \\
(0.5 \mathrm{wt} . \%)\end{array}$ & $\begin{array}{c}5 \% \mathrm{Ni} / \\
\mathrm{Ce}_{0.72} \mathrm{Zr}_{0.28} \mathrm{O}_{2}\end{array}$ & $\begin{array}{c}\text { Promoted support reduction; improved Ni dispersion; } \\
\text { Rh addition resulted in superior activity and stability } \\
\text { than Ru }\end{array}$ & {$[140]$} \\
\hline $\begin{array}{c}\mathrm{K} \\
(0.3 \mathrm{wt} . \%)\end{array}$ & $\mathrm{NiAlO}_{\mathrm{x}}$ & $\begin{array}{c}\mathrm{K} \text { introduced new basic sites, which increased activity } \\
\text { and } \mathrm{CH}_{4} \text { selectivity }\end{array}$ & {$[95]$} \\
\hline $\mathrm{Ca}$ & $\mathrm{Ni} / \mathrm{ZrO}{ }_{2}$ & $\begin{array}{c}\text { Increased } \mathrm{CO}_{2} \text { adsorption capacity via incorporation of } \\
\text { Ca }{ }^{2+} \text { into a } \mathrm{ZrO}_{2} \text { framework which created oxygen } \\
\text { vacancies in the support }\end{array}$ & {$[142]$} \\
\hline $\mathrm{Li}, \mathrm{Na}, \mathrm{K}, \mathrm{Cs}$ & $15 \% \mathrm{Ni} / \mathrm{USY}$ & $\begin{array}{c}\text { Improved } \mathrm{Ni} \text { reducibility and } \mathrm{CO}_{2} \text { adsorption; activity } \\
\text { sequence: } \mathrm{Cs}>\mathrm{Na}>\mathrm{Li}>\mathrm{H}\end{array}$ & {$[143]$} \\
\hline
\end{tabular}




\begin{tabular}{|c|c|c|c|}
\hline $\mathrm{Mg}, \mathrm{Ca}, \mathrm{Ba}$ & & $\begin{array}{c}\mathrm{Mg}^{2+} \text { promoted formation of small } \mathrm{Ni} \text { crystallites; } \\
\text { activity sequence: } \mathrm{Mg}>\mathrm{Ca}>\mathrm{Ba}>\mathrm{H}\end{array}$ & \\
\hline $\begin{array}{c}\mathrm{Mg} \\
(2.5 \mathrm{wt} . \%) \\
\end{array}$ & $5 \% \mathrm{Ni} / \mathrm{USY}$ & Improved $\mathrm{CO}_{2}$ adsorption capacity and $\mathrm{CO}_{2}$ conversion & [144] \\
\hline $\begin{array}{l}\text { La, Ce, Pr, } \\
\text { Eu, Gd } \\
(5 w t . \%)\end{array}$ & $\begin{array}{c}12 \mathrm{wt} . \% \mathrm{Ni} / \\
\mathrm{p}-\mathrm{Al}_{2} \mathrm{O}_{3}\end{array}$ & $\begin{array}{l}\text { Improved dispersion of Ni species; best performance } \\
\text { showed by Pr promotion due to the formation of } \\
\text { praseodymium phase }\end{array}$ & [145] \\
\hline $\begin{array}{c}\text { La } \\
(1,2 \& \\
4 \text { wt.\%) } \\
\end{array}$ & $\mathrm{Ni}(\mathrm{Mg}, \mathrm{Al}) \mathrm{O}$ & $\begin{array}{l}\text { Increased reducibility of } \mathrm{Ni} \text { and basicity which } \\
\text { promoted } \mathrm{CO}_{2} \text { conversion }\end{array}$ & [112] \\
\hline $\begin{array}{l}\text { La } \\
\text { (ca. } 1.5 w t . \%)\end{array}$ & $\mathrm{Ni}(\mathrm{Mg}, \mathrm{Al}) \mathrm{O}$ & $\begin{array}{l}\text { Improved activity; effect dependent on the method of } \\
\text { La introduction and correlated to the amount of } \\
\text { intermediate strength basic sites }\end{array}$ & [147] \\
\hline $\begin{array}{c}\mathrm{CeO}_{2} \\
(2 \mathrm{wt} . \%) \\
\end{array}$ & $15 \% \mathrm{Ni} / \mathrm{Al}_{2} \mathrm{O}_{3}$ & $\begin{array}{c}\text { Improved Ni reducibility and Ni dispersion; effect } \\
\text { dependent on Ce introduction }\end{array}$ & [148] \\
\hline $\begin{array}{c}\mathrm{Ce} \\
(3 w t . \%)\end{array}$ & $\begin{array}{l}7 \% \mathrm{Ni} / \\
\mathrm{SBA}-15 \\
\end{array}$ & $\begin{array}{l}\text { Formation of small } \mathrm{Ni} \text { crystallites resulted in improved } \\
\qquad \mathrm{CO}_{2} \text { conversion and } \mathrm{CH}_{4} \text { selectivity }\end{array}$ & [105] \\
\hline $\begin{array}{c}\mathrm{Ce} \\
(3-15 w t . \%) \\
\end{array}$ & $5 \% \mathrm{Ni} / \mathrm{USY}$ & $\begin{array}{l}\text { Improved activity with the increase of Ce content due } \\
\text { to the increase in oxygen storage capacity }\end{array}$ & [106] \\
\hline $\begin{array}{c}\mathrm{Mn} \\
(1,2 \& 3 \\
\text { wt. } \%)\end{array}$ & $24 \% \mathrm{Ni} / \mathrm{Al}_{2} \mathrm{O}_{3}$ & Increased basicity of catalysts which improved activity & {$[149,150]$} \\
\hline Mo & $\begin{array}{l}\mathrm{Ni} / \mathrm{Al}_{2} \mathrm{O}_{3} \\
\mathrm{Ni} / \mathrm{SiO}_{2}\end{array}$ & $\begin{array}{l}\text { Improved dispersion of } \mathrm{Ni} \text { and catalyst stability at high } \\
\text { reaction temperatures }\end{array}$ & {$[151,152]$} \\
\hline W & $\mathrm{NiMgO}_{x}$ & $\begin{array}{l}\text { W addition promoted the formation of monodentate } \\
\text { formate species as well as } \mathrm{CO}_{2} \text { adsorption }\end{array}$ & {$[100]$} \\
\hline Y & $\mathrm{Ni} / \mathrm{ZrO}_{2}$ & $\begin{array}{l}\text { Increased number of oxygen vacancies in } \mathrm{ZrO}_{2} \text { which } \\
\text { improved the formation of formate species }\end{array}$ & [153] \\
\hline $\begin{array}{c}\mathrm{V}_{2} \mathrm{O}_{5} \\
(3 w t . \%)\end{array}$ & $\begin{array}{l}20 \% \mathrm{Ni} / \\
\text { bentonite }\end{array}$ & $\begin{array}{l}\text { Improved Ni-support interactions and thus } \mathrm{Ni} \\
\text { dispersion }\end{array}$ & {$[109]$} \\
\hline
\end{tabular}

The performance of bimetallic catalysts composed of two transition metals has not yet been discussed and therefore will be shortly summarized. Ni-Fe bimetallic catalysts are the most discussed materials. Pandey et al. [154] investigated the performance of $\mathrm{Ni}-\mathrm{Fe}$ catalysts with various $\mathrm{Ni} / \mathrm{Fe}$ molar ratios and supported on various metal oxides. Acid-basic properties of the tested supports were found to play an important role in the catalyst's activity and $\mathrm{CH}_{4}$ selectivity which both followed the sequence: $\mathrm{Al}_{2} \mathrm{O}_{3}>\mathrm{ZrO}_{2}>\mathrm{TiO}_{2}>\mathrm{SiO}_{2}>\mathrm{Nb}_{2} \mathrm{O}_{3}$. The optimal ratio between iron and nickel was found to be 1:3 for all tested supports (except $\mathrm{Nb}_{2} \mathrm{O}_{5}$ ). The beneficial effects of $\mathrm{Ni} / \mathrm{Fe}$ molar ratio equal to 3:1 were attributed to the formation of $\mathrm{Ni}_{3} \mathrm{Fe}$ alloy and was reported by other scientists as well $[122,155-157]$. The synergetic effect of nickel-iron alloy formation may be explained by the balanced supply of $\mathrm{H}$ atoms from alloy and $\mathrm{CO}_{x}$ species from the support of basic character [155]. Interestingly, the molar ratio of $3 / 1$ was also reported to have a beneficial effect for $\mathrm{NiCu}$ catalyst [122]. 


\section{3. $\mathrm{CO}_{2}$ hydrogenation in plasma}

$\mathrm{CO}_{2}$ splitting into carbon monoxide and oxygen in plasma has been a topic of extensive studies since last few decades $[16,20,31,158-162]$. Application of non-thermal plasma allows activating $\mathrm{CO}_{2}$ via highly energetic electrons at room temperature and hence gained much attention. The extensive study on the plasma-based $\mathrm{CO}_{2}$ technologies, especially $\mathrm{CO}_{2}$ splitting (eq. 3.1) and dry reforming of methane (DRM, eq. 3.2), including the influence of various parameters (plasma sources, packing materials etc.) was recently discussed in an excellent review by Snoeckx and Bogaerts [16]. Therefore, in this section plasma $\mathrm{CO}_{2}$ hydrogenation will be shortly summarized to characterize the background of plasma-catalytic $\mathrm{CO}_{2}$ methanation.

$$
\begin{array}{ll}
\mathrm{CO}_{2} \leftrightharpoons \mathrm{CO}+1 / 2 \mathrm{O}_{2} & \Delta \mathrm{H}^{0}=+283 \mathrm{~kJ} \cdot \mathrm{mol}^{-1} \\
\mathrm{CO}_{2}+\mathrm{CH}_{4} \leftrightharpoons 2 \mathrm{CO}+2 \mathrm{H}_{2} & \Delta \mathrm{H}^{0}=+247 \mathrm{~kJ} \cdot \mathrm{mol}^{-1}
\end{array}
$$

Carbon-oxygen bonds in $\mathrm{CO}_{2}$ are relatively strong (ca. $790 \mathrm{~kJ} / \mathrm{mol}$ ). The Gibbs free energy of $\mathrm{CO}_{2}$ formation is equal to $\Delta_{\mathrm{f}} \mathrm{G}^{0}{ }_{298}=-394 \mathrm{~kJ} / \mathrm{mol}$, making $\mathrm{CO}_{2}$ a very stable molecule. From the thermodynamic point of view, it is easier to convert $\mathrm{CO}_{2}$ when it is combined with a reactant characterized by higher Gibbs free energy of formation, such as hydrogen $\left(\Delta_{\mathrm{f}} \mathrm{G}^{0}=0 \mathrm{~kJ} / \mathrm{mol}\right)$ or $\mathrm{CH}_{4}$ $\Delta_{\mathrm{f}} \mathrm{G}_{298}{ }_{298}=-51 \mathrm{~kJ} / \mathrm{mol}$ ). Although plasma hydrogenation of $\mathrm{CO}_{2}$ is thermodynamically favourable, $\mathrm{H}_{2}$ is an expensive gas and for the economic reasons more studied process of plasma $\mathrm{CO}_{2}$ activation is DRM. The studies of plasma $\mathrm{CO}_{2}$ hydrogenation were focused mainly on the application of DBD discharges [163-169], microwave energy [170-173], surface discharges [174], radio frequency discharges $[175,176]$, glow discharge $[177,178]$ and corona discharge [179]. The discussion of the performance of each system will be discussed in the next sections (3.2)

\subsection{Definitions}

In the beginning, it is important to introduce certain definitions which are commonly used in plasma literature and which will also be presented in this study and which will allow comparing various systems with each other.

Specific energy input (SEI) is defined as the ratio of energy supplied to the gas (plasma power) and flow rate gas. SEI describes the amount of energy supplied to gas molecules and therefore is often expressed in $\mathrm{kJ} / \mathrm{dm}^{3}$ (eq. 3.3) or $\mathrm{eV} /$ molecule (eq. 3.4):

$$
S E I\left[\frac{k J}{d m^{3}}\right]=\frac{P[k W]}{F\left[\frac{d m^{3}}{m i n}\right]}
$$




$$
S E I\left[\frac{\mathrm{eV}}{\text { molecule }}\right]=S E I\left[\frac{\mathrm{kJ}}{\mathrm{dm}^{3}}\right] \cdot \frac{6.241 \cdot 10^{21} \cdot \mathrm{V}_{\mathrm{mol}}}{N_{A}}
$$

where $P$ is the plasma power, $F$ the flow rate of feed gas, $V_{\text {mol }}$ the molar volume at a given pressure and temperature and $N_{A}$ the Avogadro number.

Total process conversion ( $\chi_{\text {total }}$, eq. 3.7) may be defined as the sum of effective conversions of all reactants (eq. 3.6). The latter, in comparison to classical conversion (eq. 3.5), takes into account dilution of the reactant. It is an important factor, as for the plasma-based reactions dilution of the feed gas may completely change plasma composition and hence its properties.

$$
\begin{gathered}
\chi_{\text {reactant }_{i}}=\frac{\dot{n}_{\text {reactant }_{i}, \text { in }}-\dot{n}_{\text {reactant }_{i} \text { out }}}{\dot{n}_{\text {reactant }_{i}, \text { in }}} \\
\chi_{{\text {eff }, \text { reactant }_{i}}}=\chi_{\text {reactant }_{i}} \cdot \frac{\dot{n}_{\text {reactant }_{i}, \text { in }}}{\sum_{i} \dot{n}_{\text {reactant }_{i}, \text { in }}} \\
\chi_{\text {total }_{\text {eal }}}=\sum_{i} \chi_{\text {eff }, \text { reactant }_{i}}
\end{gathered}
$$

Another important parameter characterizing reaction is selectivity to desired product (in the studied case $\mathrm{CH}_{4}$ ) defined as the flow of produced desired compound divided by the amount of converted reactant (in the studied case $\mathrm{CO}_{2}$; eq. 3.8). Yield of desired product may be calculated by multiplying conversion of the investigated reactant by the selectivity to desired product (eq. 3.9).

$$
\begin{aligned}
S_{\text {product }_{i}} & =\frac{\dot{n}_{\text {product }_{i} \text { out }}}{\dot{n}_{\text {reactant }_{j}, \text {, }}-\dot{n}_{\text {reactant }_{j}, \text { out }}} \\
Y_{\text {product }_{i}} & =\frac{\dot{n}_{\text {product }_{i} \text { out }}}{\dot{n}_{\text {reactant }_{j} \text {, }}}=\chi_{\text {reactant }_{j}} \cdot S_{\text {product }_{i}}
\end{aligned}
$$

In general, for various plasma types and various $\mathrm{CO}_{2}$ utilization plasma powered processes, the $\mathrm{CO}_{2}$ conversion increases with the increase of $S E I$, i.e. as more energy is supplied to gas molecules. Therefore, to account for account for costs of energy associated with the conversion of $\mathrm{CO}_{2}$ the energy efficiency parameter $\eta$ was introduced (eq. 3.10):

$$
\eta=\frac{\chi_{t o t a l} \cdot \Delta H^{0}}{S E I}
$$

where: $\chi_{\text {total }}$ is the total conversion of the process and $\Delta H^{0}$ is the standard reaction enthalpy (for $\mathrm{CO}_{2}$ methanation $\left.\Delta H^{0}{ }_{298}=-164 \mathrm{~kJ} / \mathrm{mol}\right)$.

Energy efficiency is often mentioned while discussing and comparing $\mathrm{CO}_{2}$ dissociation/splitting. In case of more complex processes (such as $\mathrm{CO}_{2}$ hydrogenation) during which various reactions may proceed, leading to various products, the application of energy efficiency is not so straightforward as 
it requires to calculate the enthalpy of the overall process. Therefore, for the simplicity of comparison in this review, energy cost (eq. 3.11 or eq. 3.12 below) for various types of plasma and operating conditions will be compared. Energy cost is defined as the amount of energy consumed by the process per converted molecule, expressed often as $\mathrm{kJ}$ or eV per molecule:

$$
\begin{gathered}
E C\left[\frac{\mathrm{kJ}}{\mathrm{mol}_{\text {conv }}}\right]=\frac{S E I\left[\frac{\mathrm{kJ}}{\mathrm{dm}^{3}}\right] \cdot V_{\mathrm{mol}}}{\chi_{\text {total }}} \\
E C\left[\frac{\mathrm{eV}}{\text { molecule }_{\text {conv }}}\right]=E C\left[\frac{\mathrm{kJ}}{\mathrm{mol}_{\text {conv }}}\right] \cdot \frac{6.241 \cdot 10^{21}}{N_{A}}
\end{gathered}
$$

\subsection{Influence of plasma type}

In the following section, the plasma technologies applied to $\mathrm{CO}_{2}$ hydrogenation will be shortly described and the main findings will be presented. Fig. 5 compares different plasma technologies in terms of $\mathrm{CO}_{2}$ conversion, $\mathrm{CH}_{4}$ production and energy costs. The latter was calculated according to the methodology proposed by Snoeckx and Bogaerts [16], eq. 3.4, 3.5. It is important to underline that some of the data presented in Fig. 5 may differ from the original ones, as they were recalculated, among others to include the effect of gas dilution.
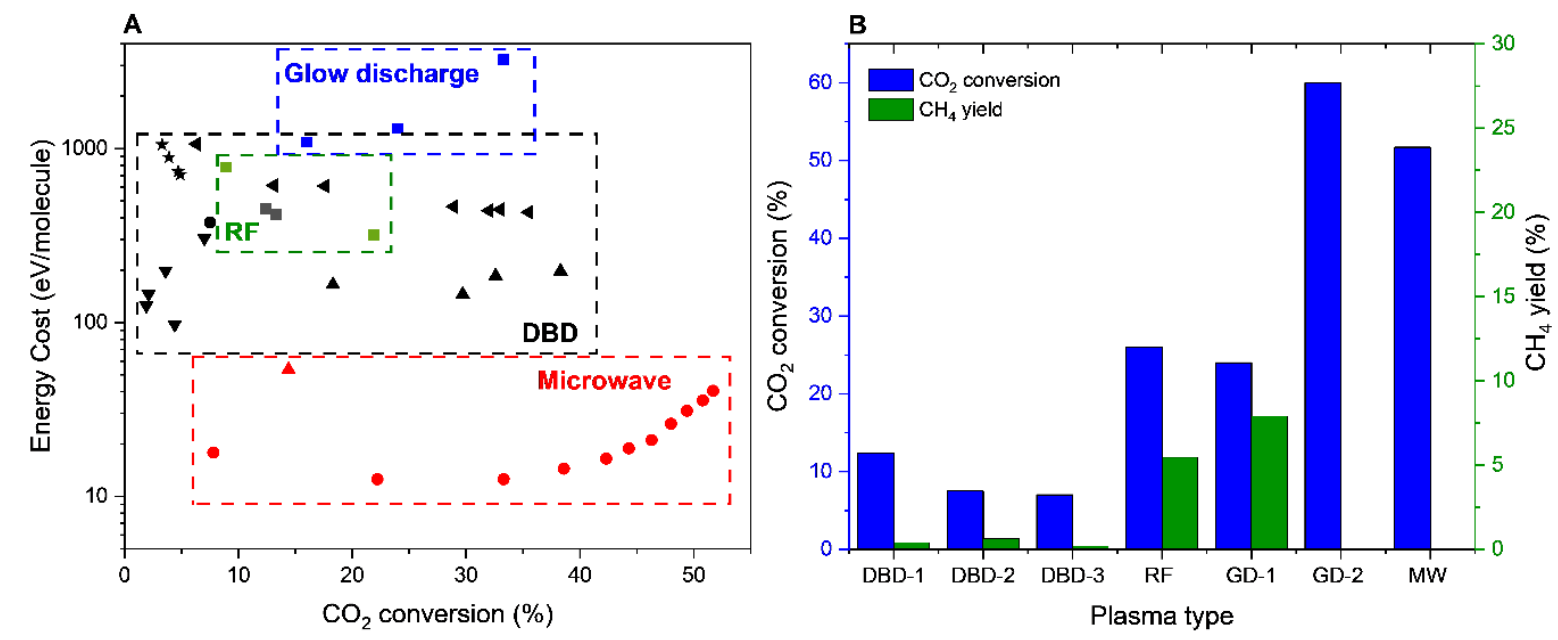

Fig. $5 \mathrm{CO}_{2}$ hydrogenation in plasma without presence of catalyst: (A) Energy cost vs $\mathrm{CO}_{2}$ conversion for various

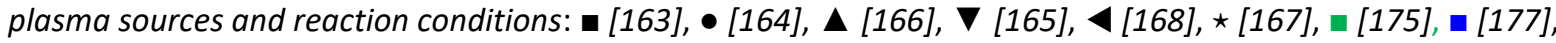
- [170], $\triangle$ [171], (B) $\mathrm{CO}_{2}$ conversion and $\mathrm{CH}_{4}$ yield for various plasma types: DBD-1 [163], DBD-2 [164], DBD-3 [165], RF [175], GD-1 [177], GD-2 [180], MW [170];

Another important point worth mentioning is that the mechanism of $\mathrm{CO}_{2}$ activation differs depending on the type of plasma used. The differences come from the fact that $\mathrm{CO}_{2}$ activation may proceed through various paths including electronic excitation, dissociation, ionization or vibrotational excitation. The distribution of different path of $\mathrm{CO}_{2}$ excitation is dependent on the reduced electric field (eq. 3.11) defined as the ratio of the electric field in plasma (E) over concentration of neutral 
particles (N). The reduced electric field is a property of various plasma types. For example, for microwave discharge (ca. $50 \mathrm{Td}$ ), $\mathrm{CO}_{2}$ activation proceeds mainly through more energy efficient vibrational excitation, while in DBD plasma (above 200Td) it is mainly through electronic excitation [16]. This may explain as well higher $\mathrm{CO}_{2}$ conversions and lower energy costs obtained for microwave plasmas with respect to DBD (Fig. 5).

$$
\text { Reduced Electric Field }=E / N\left[T d, 1 T d=10^{-21} \mathrm{Vm}^{2}\right]
$$

\section{Dielectric Barrier Discharge (DBD)}

DBD plasmas are most commonly used and most commonly studied systems for $\mathrm{CO}_{2}$ hydrogenation. One of the main advantages of such a system is the fact that it is operated at the atmospheric pressure and therefore may be easily upscaled for industrial applications. In a DBD reactor, the dielectric material is placed between electrodes, therefore preventing sparks and arc creation. During discharge energetic electrons are concentrated inside the filament, causing an increase in their kinetic energies. This effect is responsible for the dissipation of energy in the dielectric which is causing an increase in gas temperature (usually temperatures between $100-200^{\circ} \mathrm{C}$ are reported) and is responsible for high energy costs/low energy efficiencies of DBD plasmas (Fig. 5).

The reported $\mathrm{CO}_{2}$ conversions obtained in DBD systems are usually below $20 \%$, with CO being the main product (selectivity's at the level of ca. 90\%) $[163,164,167,169]$. Other products which were observed are $\mathrm{CH}_{3} \mathrm{OH}, \mathrm{CH}_{4}$ [163] with trace amounts of $\mathrm{C}_{2} \mathrm{H}_{6}, \mathrm{C}_{3} \mathrm{H}_{8}$ and $\mathrm{C}_{4} \mathrm{H}_{10}$ [164]. The theoretical modelling studies performed by De Bie et al. [165] stay in line with these findings. The reaction mechanisms proposed via these authors will be discussed in more details in the next section (section 3.3). Zeng et al. [166] reported that $\mathrm{CO}_{2}$ conversion in DBD may be improved when $\mathrm{Ar}$ is introduced into the feed. An increase of $\mathrm{CO}_{2}$ conversion from $18 \%$ to $38 \%$ was observed when $\mathrm{Ar}$ content was increased from 0 to 60 vol\%. Such effect, so-called Penning effect, was explained by the fact that $\mathrm{Ar}$ atoms were excited into a metastable state and via collisions with other molecules created new reaction pathways for dissociation of $\mathrm{CO}_{2}$ and $\mathrm{H}_{2}$ [166]. Mora et al. [168] reported that the type of dielectric present between electrodes may as well influence the overall performance. In their study alumina and quartz were compared. Higher $\mathrm{CO}_{2}$ conversions were always observed when alumina was used as a dielectric. The authors investigated as well as various operating conditions and reported improved $\mathrm{CO}_{2}$ conversion for lower flow rates of gases, which can be explained via longer presence time of gases in the discharge zone. The $\mathrm{CO}_{2}$ conversion was also reported to increase with 
SEI, while the opposite effect was observed for the increase in discharge frequency. $\mathrm{CH}_{4}$ was detected as one of the products of the plasma discharge, however, its production was not discussed.

\section{Microwave (MW) discharge}

Microwave discharge may be classified as a warm plasma (possess characteristics of both nonthermal and thermal plasma) and thus is characterized by higher temperatures than non-thermal plasmas. Indeed, due to the high frequency of microwave discharge $(300 \mathrm{MHz}-10 \mathrm{GHz}$ [16]), the dissipation of energy is higher with respect to non-thermal plasmas e.g. DBD, resulting in absorption of electron energy by gas molecules and thus increase in gas temperature. For these reasons $\mathrm{CO}_{2}$ conversions obtained in microwave plasma reactors are usually higher than in the case of DBD. However, the main disadvantage of microwave plasmas is their low-pressure operation (1-60 mbar) [170-173].

De la Fuente et al. [170] studied $\mathrm{CO}_{2}$ hydrogenation in microwave plasma over a wide range of $\mathrm{CO}_{2} / \mathrm{H}_{2}$ molar ratio and flow rates. In case of all experiments $\mathrm{CO}$ and $\mathrm{H}_{2} \mathrm{O}$ were the main products of the reaction and thus it may be stated that microwave plasma simulated RWGS reaction through $\mathrm{CO}_{2}$ and $\mathrm{H}_{2}$ splitting. $\mathrm{CH}_{4}$ production was not observed. Plasma showed stable performance only at low flow rates of feed gases and became unsustainable at high flow rates (ca. $400 \mathrm{~cm}^{3} / \mathrm{min}$ ) due to an increase in pressure. Applied $\mathrm{CO}_{2} / \mathrm{H}_{2}$ ratio had as well influence on the overall performance. The highest $\mathrm{CO}_{2}$ conversions were obtained for high $\mathrm{H}_{2}$ concentrations. When it comes to the energy efficiency the highest values in terms of $\mathrm{CO}_{2}$ hydrogenation were obtained for the highest flows. Similarly, as for experiments in DBD plasma, the $\mathrm{CO}_{2}$ conversion increased monotonically with the SEI up to ca. $8 \mathrm{eV} /$ molecule. The authors underline, however, that at high SEI the microwave energy is mainly converted into thermal energy rather than a chemical one, which explains the increase in temperature with the increase of SEI. In line with other studies on plasma discharge in $\mathrm{CO}_{2} / \mathrm{H}_{2}$ mixtures, the $\mathrm{H}$ and $\mathrm{O}$ radicals were the dominant intermediate species, as confirmed via optical emission spectroscopy (OES) $[170,173]$.

\section{Radio frequency (RF) discharge}

Radio frequency plasmas are characterized by 1-100 MHz frequency and are typically used for thin film deposition. Their main advantage in $\mathrm{CO}_{2}$ conversion processes is the possibility of obtaining high electron densities at low gas temperatures. On the other hand, similar to microwave discharges, RF operates at low pressures (from several up to hundreds of mbar) which may be considered as the main disadvantage for future commercialization of the process $[175,175]$. 
$\mathrm{CO}_{2}$ hydrogenation in radio frequency plasma was studied by Kano et al. [175]. They investigated the influence of plasma parameters, such as frequency $(10-60 \mathrm{kHz})$ and voltage, as well as flow rate and $\mathrm{CO}_{2} / \mathrm{H}_{2}$ feed ratio. In all experiments, the $\mathrm{CO}_{2}$ conversion was at the level of $20-30 \%$ with $\mathrm{CO}$ being the main product of the reaction. Besides $\mathrm{CO}$ and $\mathrm{H}_{2} \mathrm{O}$, methane and methanol were also detected. $\mathrm{CO}_{2}$ conversion and $\mathrm{CH}_{4}$ production increased with the increasing frequency of radiation and voltage. As the frequency is the number of discharges taking place within 1s, the increasing frequency leads to an increase of the plasma electron density. Moreover, the increase of discharge voltage does not result in the increase of electron temperature but also causes an increase in electron density in plasma. These effects explain the enhanced performance obtained for high values of voltage and frequency. Moreover, $\mathrm{CH}_{4}$ production was strongly enhanced with the increase of voltage, while $\mathrm{CO}$ production increased linearly. In all experiments, the production of $\mathrm{CH}_{4}$ was much higher than $\mathrm{CH}_{3} \mathrm{OH}$. This may be explained by the fact that $\mathrm{CH}_{3} \mathrm{OH}$ formation requires more collisions of various species. At the same time, both organic products may be decomposed in plasma, which also affects their production. $\mathrm{CH}_{4}$ is considered as more stable molecule than $\mathrm{CH}_{3} \mathrm{OH}$, as the $\mathrm{C}-\mathrm{H}$ bond energy $(416 \mathrm{~kJ} / \mathrm{mol})$ is higher than that if a $\mathrm{C}-\mathrm{O}$ bond $\left(326 \mathrm{~kJ} / \mathrm{mol}\right.$ in $\left.\mathrm{CH}_{3} \mathrm{OH}\right)$, which may as well explain higher $\mathrm{CH}_{4}$ production. The authors underlined that it is important to adjust the flow of reactants, as the obtained products may be decomposed to a higher extent in plasma if gases pass slowly through the discharge zone. At the same time, too short contact times with plasma may be not sufficient enough to form required products. The maximum of $\mathrm{CH}_{4}$ production was observed with a high excess of $\mathrm{H}_{2}$ in the feed $\left(\mathrm{CO}_{2} / \mathrm{H}_{2}=1 / 6\right)$. Similar results, regarding $\mathrm{CO}_{2} / \mathrm{H}_{2}$ ratio, were obtained by Yang et al. [176].

\section{Glow discharge (GD)}

Glow discharge is formed via passing through a gas a current from few $\mathrm{V}$ to several $\mathrm{kV}$, which is characterized by the emission of visible light ('glow') in a certain level. Glow discharges plasma may be operated from very low pressures (even mbar) almost up to atmospheric pressure. They are characterized by gas temperatures very close to room temperature. In plasma $\mathrm{CO}_{2}$ hydrogenation application of only low-pressure glow discharge plasmas was reported $[177,180,181]$. As previously mentioned, operating at low pressures is rather a disadvantage form the economic standpoint (problem of upscaling and high costs of vacuum systems). However, the low-pressure operation of glow discharge plasmas guarantees stable plasma operation as well as a prolonged lifetime of excited species.

Azzolina-Jury et al. $[180,181]$ confirmed the high activity of glow discharge plasma in terms of $\mathrm{CO}_{2}$ conversion (ca. 60\%), however, no methane or any other organic product was observed. Thus, 
similarly as in case of MW plasma, glow discharged simulated RWGS reaction. Studies carried out by Arita et al. [177] who, on the other hand, showed that combining plasma discharges with the application of a magnetic field may improve the production of organic compounds. These authors studied system in which electrodes were combined with two types of magnets, which resulted in a glow discharge system with a perpendicular component of the magnetic field. An increased electron density in the plasma core and a decreased electron diffusion across the magnetic field towards downstream regions were mentioned as the main advantages of such system. In order to avoid the catalytic effect of magnets, they were separated from the plasma by mica plates. Similarly, to other studies, the $\mathrm{CO}_{2}$ conversion was the highest with the high excess of $\mathrm{H}_{2}$ in the feed and was increasing with the increase of input power. Besides $\mathrm{CO}$, which was the main product of the reaction, $\mathrm{CH}_{4}$ formation through recombination of decomposed radicals was observed as well. The enhanced production of $\mathrm{CH}_{4}$ was explained by the fact that in a magnetic field, electrons are magnetized and are suppressed to diffuse across the magnetic field toward the downstream region. Neutral species, on the other hand, can diffuse toward the downstream region, where they can recombine to produce $\mathrm{CH}_{4}$. In the downstream region re-decomposition of formed $\mathrm{CH}_{4}$ species is reduced, resulting in increased methane selectivity. 


\subsection{Mechanism of $\mathrm{CO}_{2}$ hydrogenation in plasma}

To the best of our knowledge, the mechanism of plasma $\mathrm{CO}_{2}$ hydrogenation was examined so far only by De Bie et al. [165], who studied $\mathrm{CO}_{2}$ hydrogenation in a DBD plasma with a one-dimensional fluid model. As the reaction pathways in the plasma are an important baseline for the combined plasma-catalytic process, this important work is summarized in this section.

The authors modelled atmospheric pressure DBD reactor operating at near room temperature (ca. $27^{\circ} \mathrm{C}$ ) with a plasma generated by a sinus $5 \mathrm{kV}$ voltage with $10 \mathrm{kHz}$ frequency. The considered feed gas composition varied with $\mathrm{CO}_{2}$ content from 10 to $90 \mathrm{vol} . \%$. The reaction pathways of consumption and production of the main reactants involved in the DBD plasma $\mathrm{CO}_{2}$ hydrogenation are presented in Table 5.

The obtained results stay in line with the experimental data presented in the literature. $\mathrm{CO}$ and $\mathrm{H}_{2} \mathrm{O}$ were the main reaction products. Formation of $\mathrm{CH}_{4}, \mathrm{CH}_{2} \mathrm{O}, \mathrm{C}_{2} \mathrm{H}_{6}, \mathrm{O}_{2}$ and $\mathrm{CH}_{3} \mathrm{OH}$ was also observed. $\mathrm{CO}_{2}$ conversion and $\mathrm{CH}_{4}$ production increased with the decreasing content of $\mathrm{CO}_{2}$ in the feed gas. The yield of $\mathrm{CH}_{4}$ were 1-2 times orders of magnitude higher than that of $\mathrm{C}_{2} \mathrm{H}_{6}, \mathrm{CH}_{2} \mathrm{O}$ and $\mathrm{CH}_{3} \mathrm{OH}$.

The most contributing pathway for $\mathrm{CO}_{2}$ consumption was found to be the electron impact ionization leading to $\mathrm{CO}_{2}{ }^{+}$. However, the produced ion immediately reacts with $\mathrm{H}_{2} \mathrm{O}$ (charge transfer) to give back $\mathrm{CO}_{2}$. Thus, electron impact dissociation of $\mathrm{CO}_{2}$ producing $\mathrm{CO}$ and $\mathrm{O}$ radical was found as the the most important reaction activating carbon dioxide. When it comes to hydrogen, the most important reaction consuming $\mathrm{H}_{2}$ at low $\mathrm{CO}_{2}$ concentrations in the feed was electron impact dissociation giving $\mathrm{H}$ atoms. Part of these $\mathrm{H}$ atoms will recombine back to $\mathrm{H}_{2}$ or together with $\mathrm{CHO}$ radicals and produce $\mathrm{H}_{2}$ and $\mathrm{CO}$. At high $\mathrm{CO}_{2}$ concentrations in the feed (ca. 90\%) the reaction of $\mathrm{H}_{2}$ with $\mathrm{H}_{2} \mathrm{O}^{+}$producing $\mathrm{H}_{3} \mathrm{O}^{+}$species becomes the most important. Regardless of $\mathrm{CO}_{2}$ concentration in the feed, net $\mathrm{H}_{2}$ consumption is much higher than that of $\mathrm{CO}_{2}$. These results may explain lower $\mathrm{CO}_{2}$ conversions observed in the experimental data (section 3.2) for low $\mathrm{H}_{2} / \mathrm{CO}_{2}$ molar ratios. $\mathrm{O}$ and $\mathrm{H}$ atoms originating from $\mathrm{CO}_{2}$ and $\mathrm{H}_{2}$ dissociation recombine to produce $\mathrm{OH}$ radicals and further $\mathrm{H}_{2} \mathrm{O}$.

The main product of the plasma process - carbon monoxide - is the most effectively formed through electron impact $\mathrm{CO}_{2}$ dissociation. An important pathway for $\mathrm{CO}$ production is also a reaction between $\mathrm{CHO}$ and $\mathrm{H}$ atoms. However, it is balanced by the most important $\mathrm{CO}$ consumption reaction i.e. the recombination of $\mathrm{CO}$ and $\mathrm{H}$ atoms forming $\mathrm{CHO}$ radicals. 
Table 5 Main consumption and production paths of main reactants involved in $\mathrm{CO}_{2}$ hydrogenation in DBD plasma (in bold are marked reactions which contribute the most in production/consumption of given molecule) [165].

\begin{tabular}{|c|c|c|}
\hline Molecule & Consumption reactions & Production reactions \\
\hline $\mathrm{CO}_{2}$ & $\begin{array}{c}\mathrm{e}^{-}+\mathrm{CO}_{2} \rightarrow 2 \mathrm{e}^{-}+\mathrm{CO}_{2} \\
\mathrm{e}^{-}+\mathrm{CO}_{2} \rightarrow \mathrm{e}^{-}+\mathrm{CO}+\mathrm{O} \\
\mathrm{e}^{-}+\mathrm{CO}_{2} \rightarrow \mathrm{O}^{-}+\mathrm{CO} \\
\mathrm{CO}^{+}+\mathrm{CO}_{2} \rightarrow \mathrm{CO}_{2}^{+}+\mathrm{CO}\end{array}$ & $\begin{array}{c}\mathrm{O}+\mathrm{CHO} \rightarrow \mathrm{H}+\mathrm{CO}_{2} \\
\mathrm{CO}+\mathrm{OH} \rightarrow \mathrm{CO}_{2}+\mathrm{H} \\
\mathrm{CO}_{2}^{+}+\mathrm{H}_{2} \mathrm{O} \rightarrow \mathrm{H}_{2} \mathrm{O}^{+}+\mathrm{CO}_{2}\end{array}$ \\
\hline $\mathrm{H}_{2}$ & $\begin{array}{c}\mathrm{e}^{-}+\mathrm{H}_{2} \rightarrow \mathrm{e}^{-}+\mathrm{H}+\mathbf{H} \\
\mathrm{e}^{-}+\mathrm{H}_{2} \rightarrow 2 \mathrm{e}^{-}+\mathrm{H}_{2}^{+} \\
\mathrm{H}_{2}^{+}+\mathrm{H}_{2} \rightarrow \mathrm{H}_{3}^{+}+\mathrm{H} \\
\mathrm{H}_{2} \mathrm{O}^{+}+\mathrm{H}_{2} \rightarrow \mathrm{H}_{3} \mathrm{O}^{+}+\mathbf{H} \\
\mathrm{H}_{2}+\mathrm{OH} \rightarrow \mathrm{H}+\mathrm{H}_{2} \mathrm{O}\end{array}$ & $\begin{array}{c}\mathrm{e}^{-}+\mathrm{H}_{3} \mathrm{O}^{+} \rightarrow \mathrm{OH}+\mathrm{H}_{2} \\
\mathrm{H}_{3}^{+}+\mathrm{H}_{2} \mathrm{O} \rightarrow \mathrm{H}_{3} \mathrm{O}^{+}+\mathrm{H}_{2} \\
\mathbf{H}+\mathbf{H}+\mathbf{M} \rightarrow \mathbf{H}_{2}+\mathbf{M} \\
\mathbf{H}+\mathbf{C H O} \rightarrow \mathbf{H}_{2}+\mathbf{C O}\end{array}$ \\
\hline $\mathrm{CO}$ & $\begin{array}{c}\mathrm{H}+\mathrm{CO}+\mathrm{M} \rightarrow \mathrm{CHO}+\mathrm{M} \\
\mathrm{CO}+\mathrm{OH} \rightarrow \mathrm{CO}_{2}+\mathrm{H} \\
\mathrm{e}^{-}+\mathrm{CO} \rightarrow \mathrm{e}^{-}+\mathrm{C}+\mathrm{O}\end{array}$ & $\begin{array}{c}\mathrm{O}+\mathrm{CHO} \rightarrow \mathrm{CO}+\mathrm{OH} \\
\mathrm{CO}^{+}+\mathrm{CO}_{2} \rightarrow \mathrm{CO}_{2}^{+}+\mathrm{CO} \\
\mathrm{e}^{-}+\mathrm{CO}_{2}^{+} \rightarrow \mathrm{CO}+\mathrm{O} \\
\mathrm{e}^{-}+\mathrm{CO}_{2} \rightarrow \mathrm{O}^{-}+\mathrm{CO} \\
\mathrm{e}^{-}+\mathrm{CO}_{2} \rightarrow \mathrm{e}^{-}+\mathrm{CO}+\mathrm{O} \\
\mathrm{H}+\mathrm{CHO} \rightarrow \mathrm{H}_{2}+\mathrm{CO}\end{array}$ \\
\hline $\mathrm{CH}_{4}$ & $\begin{array}{c}\mathrm{H}_{3}^{+}+\mathrm{CH}_{4} \rightarrow \mathrm{CH}_{5}^{+}+\mathrm{H}_{2} \\
\mathrm{CO}_{2}^{+}+\mathrm{CH}_{4} \rightarrow \mathrm{CH}_{4}^{+}+\mathrm{CO}_{2} \\
\mathrm{e}^{-}+\mathrm{CH}_{4} \rightarrow \mathrm{e}^{-}+\mathrm{CH}_{3}+\mathrm{H} \\
\mathrm{e}^{-}+\mathrm{CH}_{4} \rightarrow 2 \mathrm{e}^{-}+\mathrm{CH}_{4}^{+} \\
\mathrm{CH}_{4}+\mathrm{CH} \rightarrow \mathrm{C}_{2} \mathrm{H}_{4}+\mathrm{H} \\
\mathrm{e}^{-}+\mathrm{CH}_{4} \rightarrow 2 \mathrm{e}^{-}+\mathrm{H}+\mathrm{CH}_{3}^{+} \\
\mathrm{CH}_{3}^{+}+\mathrm{CH}_{4} \rightarrow \mathrm{C}_{2} \mathrm{H}_{5}^{+}+\mathrm{H}_{2} \\
\mathrm{e}^{-}+\mathrm{CH}_{4} \rightarrow \mathrm{e}^{-}+\mathrm{CH}_{2}+\mathrm{H}_{2} \\
\mathrm{e}^{-}+\mathrm{CH}_{4} \rightarrow \mathrm{e}^{-}+\mathrm{CH}+\mathrm{H}_{2}+\mathrm{H} \\
\mathrm{H}_{2} \mathrm{O}^{+}+\mathrm{CH}_{4} \rightarrow \mathrm{H}_{3} \mathrm{O}^{+}+\mathrm{CH}_{3}\end{array}$ & $\begin{array}{c}\mathrm{CH}_{5}^{+}+\mathrm{H}_{2} \mathrm{O} \rightarrow \mathrm{H}_{3} \mathrm{O}^{+}+\mathrm{CH}_{4} \\
\mathrm{CH}_{3}+\mathrm{H}+\mathrm{M} \rightarrow \mathrm{CH}_{4}+\mathrm{M}\end{array}$ \\
\hline $\mathrm{CH}_{2} \mathrm{O}$ & $\begin{aligned} \mathrm{H}+\mathrm{CH}_{2} \mathrm{O} & \rightarrow \mathrm{H}_{2}+\mathrm{CHO} \\
\mathrm{OH}+\mathrm{CH}_{2} \mathrm{O} & \rightarrow \mathrm{H}_{2} \mathrm{O}+\mathrm{CHO} \\
\mathrm{O}+\mathrm{CH}_{2} \mathrm{O} & \rightarrow \mathrm{OH}+\mathrm{CHO}\end{aligned}$ & $\begin{array}{c}\mathrm{CHO}+\mathrm{CHO} \rightarrow \mathrm{CH}_{2} \mathrm{O}+\mathrm{CO} \\
\mathrm{CH}_{2}+\mathrm{CO}_{2} \rightarrow \mathrm{CH}_{2} \mathrm{O}+\mathrm{CO}\end{array}$ \\
\hline $\mathrm{CH}_{3} \mathrm{OH}$ & $\begin{array}{c}\mathrm{H}+\mathrm{CH}_{3} \mathrm{OH} \rightarrow \mathrm{CH}_{2} \mathrm{OH}+\mathrm{H}_{2} \\
\mathrm{H}+\mathrm{CH}_{3} \mathrm{OH} \rightarrow \mathrm{CH}_{3} \mathrm{O}+\mathrm{H}_{2} \\
\mathrm{OH}+\mathrm{CH}_{3} \mathrm{OH} \rightarrow \mathrm{H}_{2} \mathrm{O}+\mathrm{CH}_{2} \mathrm{OH} \\
\mathrm{O}+\mathrm{CH}_{3} \mathrm{OH} \rightarrow \mathrm{OH}+\mathrm{CH}_{2} \mathrm{OH} \\
\mathrm{OH}+\mathrm{CH}_{3} \mathrm{OH} \rightarrow \mathrm{H}_{2} \mathrm{O}+\mathrm{CH}_{3} \mathrm{O} \\
\mathrm{O}+\mathrm{CH}_{3} \mathrm{OH} \rightarrow \mathrm{OH}+\mathrm{CH}_{3} \mathrm{O}\end{array}$ & $\begin{array}{c}\mathrm{H}_{2} \mathrm{O}+\mathrm{CH}_{3} \mathrm{O} \rightarrow \mathrm{CH}_{3} \mathrm{OH}+\mathrm{OH} \\
\mathbf{H}+\mathrm{CH}_{2} \mathrm{OH}+\mathrm{M} \rightarrow \mathrm{CH}_{3} \mathrm{OH}+\mathbf{M} \\
\mathrm{CH}_{3}+\mathrm{OH}+\mathrm{M} \rightarrow \mathrm{CH}_{3} \mathrm{OH}+\mathbf{M}\end{array}$ \\
\hline
\end{tabular}


In terms of yield, the second product in DBD plasma discharge of $\mathrm{CO}_{2} / \mathrm{H}_{2}$ mixtures is $\mathrm{CH}_{4}$. Methane production requires hydrogenation of $\mathrm{CH}_{3}$ species, which may be formed from hydrogenation of $\mathrm{C}$ atoms or indirectly via hydrogenation of $\mathrm{CO}$ through $\mathrm{C}_{2} \mathrm{HO}$ radicals. The second reaction producing $\mathrm{CH}_{4}$ (charge transfer between $\mathrm{CH}_{5}{ }^{+}$species and $\mathrm{H}_{2} \mathrm{O}$ ) is balanced via $\mathrm{CH}_{4}$ loss through other charge transfer reaction involving $\mathrm{H}_{3}{ }^{+}$or $\mathrm{CO}_{2}{ }^{+}$(depending on $\mathrm{CO}_{2}$ feed concentration). It is important to underline the abundance of $\mathrm{CH}_{4}$ consuming reactions.

$\mathrm{CH}_{3} \mathrm{OH}$ formation also requires the production of $\mathrm{CH}_{3}$ species. Methanol production reaches much lower yields with respect to $\mathrm{CH}_{4}$, as it requires the formation of more complex intermediates and thus more reactions. For the same reasons the formation of higher hydrocarbons and oxygenates is not observed in plasma $\mathrm{CO}_{2}$ hydrogenation.

The proposed mechanisms and reaction pathways clearly show that in order to improve plasma $\mathrm{CO}_{2}$ methanation it is necessary to increase $\mathrm{CO}_{2}$ concentrations and to increase the concentration of $\mathrm{CH}_{3}$ and $\mathrm{CH}_{2}$ radicals in plasma. This may be achieved via introducing catalyst to the system, which can either influence plasma properties giving a rise to the production of desired radicals or it may produce $\mathrm{CH}_{3}$ and $\mathrm{CH}_{2}$ radicals through surface reactions. Therefore, $\mathrm{CH}_{4}$ production in plasma requires the application of the catalyst.

\subsection{Conclusions}

The presented results (sections 3.2 and 3.3) showed that $\mathrm{CO}_{2}$ hydrogenation in plasma may be considered quite a new approach and much research still needs to be performed in order to fully understand how various type of plasma influence $\mathrm{CO}_{2}$ hydrogenation process. However, some common conclusions may be already drawn. Regardless of the plasma type, the highest conversions of $\mathrm{CO}_{2}$ were obtained with an excess of $\mathrm{H}_{2}$ in the feed (high $\mathrm{H}_{2} / \mathrm{CO}_{2}$ molar ratios). The $\mathrm{CO}_{2}$ conversion was enhanced with the increase of plasma power, which can be explained by the increased electron density. The main product of plasma experiments was carbon monoxide. Microwave plasma, although gave the highest conversions of $\mathrm{CO}_{2}$ and was the most effective in terms of energy cost, was not able to produce any $\mathrm{CH}_{4}$ or any other organic product of $\mathrm{CO}_{2}$ hydrogenation. Glow discharge plasma was able to produce $\mathrm{CH}_{4}$ only after application of a magnetic field, which increased the concentration of activated reactants in the core of plasma. Moreover, glow discharge plasma was characterized by the highest energy costs associated with $\mathrm{CO}_{2}$ conversion. $\mathrm{CH}_{4}$ and other organic compounds production were observed in the case of DBD and RF plasma. However, they were characterized by much lower $\mathrm{CO}_{2}$ conversion with respect to $\mathrm{MW}$ and GD. 
Finally, it was proven that $\mathrm{CH}_{4}$ production is not effective in the plasma process. Therefore, the most important challenge considering plasma $\mathrm{CO}_{2}$ methanation is to find an appropriate catalyst which would tailor plasma properties and selectively react plasma formed $\mathrm{C}$ and $\mathrm{CO}$ species with hydrogen to form $\mathrm{CH}_{4}$. 


\section{Plasma Catalytic $\mathrm{CO}_{2}$ Methanation}

The search for an efficient catalyst of the hybrid plasma-catalytic process of $\mathrm{CO}_{2}$ methanation may be considered as a quite new topic as the first report on that subject come from the late 1990's. Most of the research has been carried out within the last 5 years and still much effort and studies need to be performed to understand the synergetic effects of plasma-catalysis (Fig. 6) and reaction mechanisms. As it was mentioned before, the limited data on the topic comes from the fact that $\mathrm{CO}_{2}$ methanation requires a cheap source of $\mathrm{H}_{2}$, as $\mathrm{CH}_{4}$ is a cheaper gas than hydrogen. With the recent booming development of renewable technologies, the supply of hydrogen via water electrolysis has become economically available option (to some extent) and thus plasma-catalytic $\mathrm{CO}_{2}$ methanation. The beneficial effects of application both plasma and catalysts are illustrated in Fig. 6 . The plasma process is active towards $\mathrm{CO}_{2}$ hydrogenation but shows poor selectivity to $\mathrm{CH}_{4}$. Catalysts, on the other hand, is highly selective to $\mathrm{CH}_{4}$, but show a very low activity at low reaction temperatures (e.g. $150^{\circ} \mathrm{C}$ ). The application of both significantly exceeds activity and selectivity obtained by simple addition, pointing to strong synergetic effect. The origin of that synergetic effect comes from the change of catalyst surface properties eg. surface basicity [182], $\mathrm{CO}$ and $\mathrm{CO}_{2}$ adsorption capacities [183] or the plasma properties which may affect dissociation of $\mathrm{CO}_{2}$ to $\mathrm{CO}$ occurring in the gas phase [184] (see section 4.5). In the present section the summary of research on plasma-catalytic $\mathrm{CO}_{2}$ hydrogenation to $\mathrm{CH}_{4}$ will be presented, as well as the effect of plasma pre-treatment on the catalytic activity in $\mathrm{CO}_{2}$ methanation. The latter is important, as it may help to understand changes/transformations of the catalysts surface under plasma conditions.

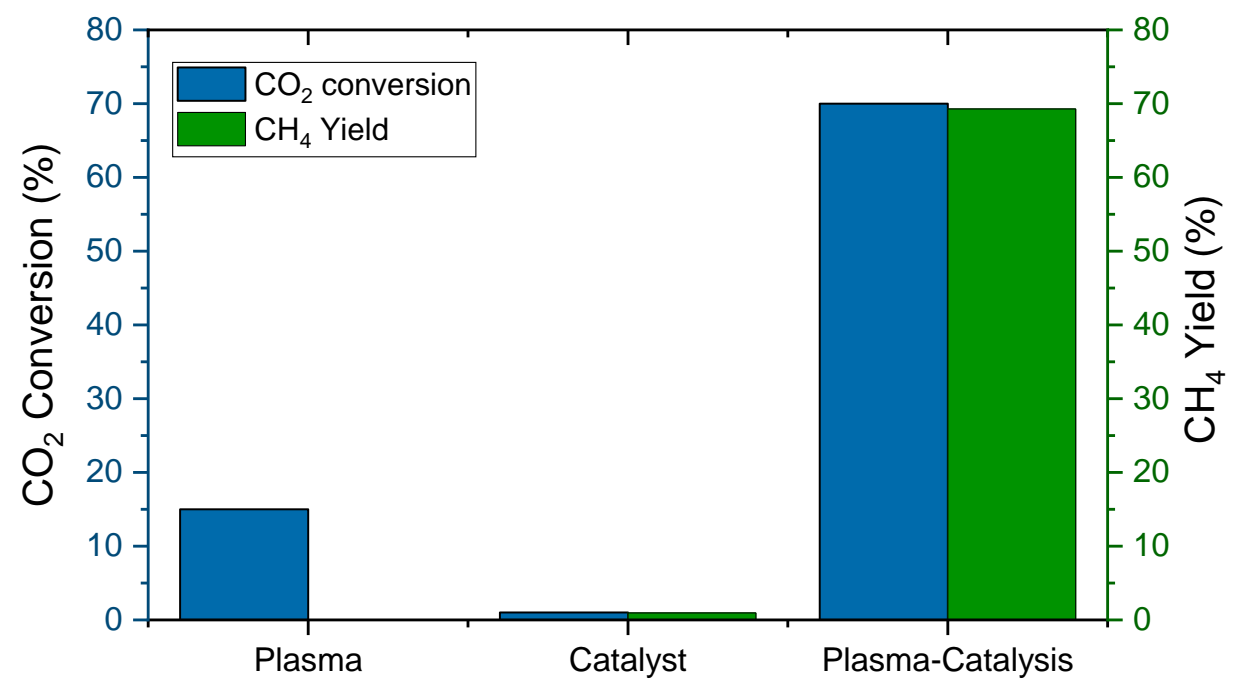

Fig. 6 Synergy for plasma-catalytic $\mathrm{CO}_{2}$ hydrogenation at $150^{\circ} \mathrm{C}$ over $5 \% \mathrm{Co} / \mathrm{CeZrO}_{4}$ catalysts $\mathrm{DBD}$ plasmaassisted process. Data were taken from [184] 


\subsection{Plasma pre-treatment of $\mathrm{CO}_{2}$ methanation catalysts}

Catalyst preparation via plasma technologies has gained much attention in recent years. As plasma is a highly reactive, it may interact with the catalyst or catalyst precursor in various ways. Therefore, plasma treatment of catalyst may result in a material which greatly differs from catalyst prepared via conventional thermal treatment. In general, plasma can be applied at any step of catalyst preparation or regeneration of deactivated catalyst $[24,28,182,185,186]$. For $\mathrm{CO}_{2}$ methanation catalysts, plasma pre-treatment was applied to decompose nickel precursors, usually nickel nitrate. Low-temperature plasma treatment of $\mathrm{Ni}$-based catalyst significantly improved materials performance in $\mathrm{CO}_{2}$ methanation (Fig. 7, Table 6) which was in general attributed to the formation of small nickel crystallites, high dispersion of $\mathrm{Ni}$ species, increased reducibility of nickel, as well as increased $\mathrm{CO}_{2}$ and hydrogen adsorption capacity [101,105,187-191]. As can be observed in Fig. 7 all plasma pre-treated catalysts reported in literature exhibited better performance in $\mathrm{CO}_{2}$ methanation with respect to calcined samples. What is more, reported Ni-based catalysts were pre-treated with various type of plasma, plasma sources, nickel was supported on various materials and finally, they were tested in various reaction conditions (Table 6), pointing to the universal beneficial effect of plasma treatment.

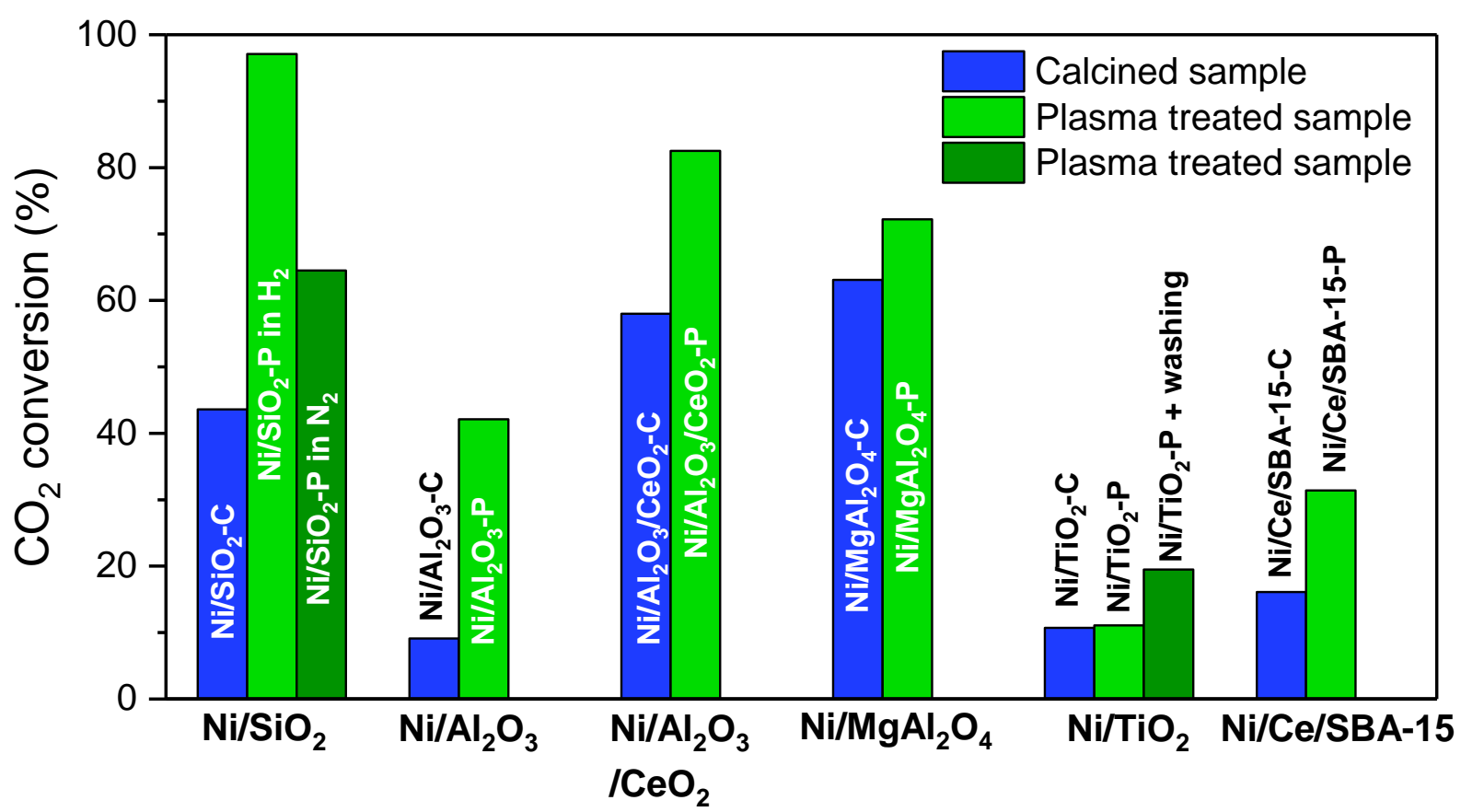

Fig. 7 Beneficial effect of plasma pre-treatment on the performance of various Ni-based catalysts for $\mathrm{CO}_{2}$ methanation tested at $300^{\circ} \mathrm{C}: \mathrm{Ni} / \mathrm{SiO}_{2}$ (data for $\mathrm{Ni} / \mathrm{SiO}_{2}-\mathrm{C}$ sample was recorded at $320^{\circ} \mathrm{C}$ ) [187], $\mathrm{Ni} / \mathrm{Al}_{2} \mathrm{O}_{3}$ \& $\mathrm{Ni} / \mathrm{Al}_{2} \mathrm{O}_{3} / \mathrm{CeO}_{2}$ [188], $\mathrm{Ni} / \mathrm{MgAl}_{2} \mathrm{O}_{4}$ [101], $\mathrm{Ni} / \mathrm{TiO}_{2}$ [189], $\mathrm{Ni} / \mathrm{Ce} / \mathrm{SBA}-15$ [105] 
Table 6 Plasma pre-treatment and reaction conditions of catalysts tested in $\mathrm{CO}_{2}$ methanation and presented in Fig. 3 [101,105,187-189,192].

\begin{tabular}{|c|c|c|c|}
\hline Catalyst & Plasma-pretreatment & Reaction conditions & Ref. \\
\hline $\mathrm{Ni} / \mathrm{SiO}_{2}$ & $\begin{array}{l}\text { Glow discharge in the flow of } \\
\mathrm{H}_{2} \text { or } \mathrm{N}_{2} ; \mathrm{p}=2-200 \mathrm{~Pa} ; \\
13.56 \mathrm{MHz} ; 100 \mathrm{~V} \text { ca. } 100 \mathrm{~mA}\end{array}$ & $\begin{array}{c}\text { Red. at } 600^{\circ} \mathrm{C} ; \mathrm{m}_{\text {cat }}=1 \mathrm{~g} ; \\
\text { Temp. } 180-320^{\circ} \mathrm{C} ; \mathrm{p}=1 \mathrm{bar} ; \mathrm{H}_{2} / \mathrm{CO}_{2}=2 \\
\mathrm{GHSV}=7200 \mathrm{~h}^{-1}\end{array}$ & [187] \\
\hline $\begin{array}{c}(15 w t . \%) \\
\mathrm{Ni} / \mathrm{Al}_{2} \mathrm{O}_{3} \& \\
\mathrm{Ni} / \mathrm{Al}_{2} \mathrm{O}_{3}-\mathrm{CeO}_{2}\end{array}$ & $\begin{array}{l}\text { DBD discharge at atmospheric } \\
\text { pressure } \& \text { room temp. in the } \\
\text { flow of } \mathrm{Ar} ; 40 \mathrm{kV}\end{array}$ & $\begin{array}{c}\text { Red. at } 500^{\circ} \mathrm{C} \text { for } 1 \mathrm{~h} ; \mathrm{m}_{\mathrm{cat}}=200 \mathrm{mg} ; \\
\text { Temp. } 200-500^{\circ} \mathrm{C} ; \mathrm{H}_{2} / \mathrm{CO}_{2}=4 ; \\
\mathrm{GHSV}=30000 \mathrm{~h}^{-1}\end{array}$ & $\begin{array}{c}{[188,1} \\
92]\end{array}$ \\
\hline $\begin{array}{c}\text { (10wt.\%) } \\
\mathrm{Ni} / \mathrm{MgAl}_{2} \mathrm{O}_{4}\end{array}$ & $\begin{array}{c}\text { DBD discharge in air at } \\
\text { atmospheric pressure; } 14 \mathrm{kV} \text {; } \\
200 \mathrm{~W}\end{array}$ & $\begin{array}{l}\text { Red. at } 700^{\circ} \mathrm{C} \text { for } 1 \mathrm{~h} ; \mathrm{m}_{\mathrm{cat}}=200 \mathrm{mg} ; \\
\text { temp. } 250-500^{\circ} \mathrm{C} ; \mathrm{H}_{2} / \mathrm{CO}_{2} / \mathrm{N}_{2}=16 / 4 / 5 ; \\
\mathrm{GHSV}=15000 \mathrm{~h}^{-1}\end{array}$ & [101] \\
\hline $\begin{array}{l}\text { (10wt.\%) } \\
\mathrm{Ni} \mathrm{TiO}_{2} *\end{array}$ & $\begin{array}{c}\text { DBD discharge in air at } \\
\text { atmospheric pressure for } 1 \mathrm{~h} ; \\
14 \mathrm{kV} ; 200 \mathrm{~W}\end{array}$ & $\begin{array}{c}\text { Red. at } 700^{\circ} \mathrm{C} \text { for } 1 \mathrm{~h} ; \mathrm{m}_{\mathrm{cat}}=50 \mathrm{mg} \\
\text { temp. } 250-500^{\circ} \mathrm{C} ; \mathrm{H}_{2} / \mathrm{CO}_{2}=4 \\
\mathrm{GHSV}=60000 \mathrm{~h}^{-1}\end{array}$ & [189] \\
\hline $\begin{array}{c}\text { (7wt.\%) } \\
\mathrm{Ni} / \mathrm{Ce} / \mathrm{SBA}-15\end{array}$ & $\begin{array}{l}\text { DBD discharge at atmospheric } \\
\text { pressure \& room temp. in the } \\
\text { flow of } \mathrm{Ar} ; 40 \mathrm{kV}\end{array}$ & $\begin{array}{l}\text { Red. at } 600^{\circ} \mathrm{C} \text { for } 1 \mathrm{~h} ; \mathrm{m}_{\mathrm{cat}}=200 \mathrm{mg} ; \\
\qquad \begin{array}{c}\mathrm{p}=1 \text { bar; temp. } 250-550^{\circ} \mathrm{C} ; \\
\mathrm{N}_{2} / \mathrm{H}_{2} / \mathrm{CO}_{2}=1 / 7.2 / 1.8\end{array}\end{array}$ & $\begin{array}{c}{[105,1} \\
92]\end{array}$ \\
\hline
\end{tabular}

Zhang et al. [187] investigated $\mathrm{Ni} / \mathrm{SiO}_{2}$ catalysts prepared in glow discharge plasma in the flow of various gases $\left(H_{2}, N_{2}\right.$ or both). Pre-treatment in $H_{2}$ glow discharge gave better results than the decomposition of nickel nitrate in the $\mathrm{N}_{2}$ discharge due to the partial reduction of nickel species and direct formation of metallic nickel phase.

Other papers concerning pre-treatment of $\mathrm{CO}_{2}$ methanation catalyst applied dielectric barrier discharge (DBD) plasma to decompose nickel nitrate (Table 6). In all cases, enhanced catalytic activity was explained by the formation of small $\mathrm{Ni}$ crystallites with high nickel dispersion. Such an effect is obtained, as DBD decomposition is a rapid process, characterized by fast nucleation of nickel crystallites. This prevents diffusion of nickel species into the bulk of support and into support pores, thus influences both textural (pore volume, specific surface area) and structural ( $\mathrm{Ni}$ crystal size and dispersion of $\mathrm{Ni}$ ) properties. For example, low-temperature plasma treatment of $\mathrm{Ni} / \mathrm{MgAl}_{2} \mathrm{O}_{4}$ material prevented the formation of inactive $\mathrm{NiAl}_{2} \mathrm{O}_{4}$ phase which was inevitable in the case of the thermally treated sample [101].

Moreover, it was proven that DBD plasma discharge is selective towards the formation of mainly well-defined $\mathrm{Ni}(111)$ planes $[189,191]$. As $\mathrm{CO}_{2}$ methanation is a structure-sensitive reaction it is affected by the exposition of certain crystal planes. Upon plasma decomposition of nickel precursors highly energetic plasma species favor the formation of low energy $\mathrm{Ni}(111)$ planes [191], while upon calcination nickel species slowly nucleate leading to the formation of irregular crystal structure. High coordinated sites of $\mathrm{Ni}(111)$ were reported to be more active in reactions involving $\mathrm{CO}_{2}$ activation and are also more resistant to catalyze C-forming reactions, are as well more resistant to $\mathrm{H}_{2} \mathrm{~S}$ 
poisoning with respect to low coordinated $\mathrm{Ni}(100)$ and $\mathrm{Ni}(110)$ sites $[11,191,193]$. Such behaviour has a consequence in the reaction mechanism. Zhou et al. [189] investigated the structure and reaction mechanism of $\mathrm{Ni} / \mathrm{TiO}_{2}$ catalysts. $\mathrm{CO}_{2}$ methanation on conventionally calcined sample proceeded through direct hydrogenation of formate species originating from $\mathrm{CO}_{2}$ adsorption on the surface. The authors did not observe any surface carbonyl species, thus they reported that Ni was functional only for hydrogen dissociation. On the other hand, on the plasma treated $\mathrm{Ni} / \mathrm{SiO}_{2}$ sample nickel species were responsible as well for the formation of surface carbonyls via decomposition of formate species. Therefore, plasma pre-treatment led to a change of the reaction route. Moreover, the same authors observed that plasma treatment affected not only nickel species, but support as well [189]. DBD plasma resulted in the transformation of anatase support into rutile and brookite, while the calcined sample showed the presence of only anatase phase. On the other hand, plasma treatment alone turned out to successfully decompose ca. $60 \%$ of nickel nitrate. Therefore, to fully examine plasma-synthesized nickel phase the washing procedure of undecomposed nickel nitrate had to be applied.

The consequence of increased nickel reducibility and improved nickel dispersion may be found in increased adsorption capacities of both hydrogen and carbon dioxide and thus higher activity. $\mathrm{Ni} / \mathrm{Al}_{2} \mathrm{O}_{3}$ and $\mathrm{Ni} / \mathrm{Al}_{2} \mathrm{O}_{3}-\mathrm{CeO}_{2}$ after plasma treatment showed catalytic activity at temperatures ca. 20 $30^{\circ} \mathrm{C}$ lower than corresponding calcined samples [188].

Recently, Kierzkowska-Pawlak et al. [194] reported $\mathrm{CO}_{2}$ methanation activity of thin films containing $\mathrm{CO}_{3} \mathrm{O}_{4}, \mathrm{RuO}_{2}, \mathrm{Ru}_{2} \mathrm{O} / \mathrm{CO}_{3} \mathrm{O}_{4}$ and $\mathrm{Fe}_{2} \mathrm{O}_{3}$ supported on knitted wire gauzes made from kanthel steel (FeCrAl) prepared via plasma enhanced metalorganic chemical vapour deposition. The activity of prepared materials was attributed to the specific nanostructure of metal oxides guaranteed by specific preparation method.

The presented results clearly point to the fact that plasma-prepared catalysts are characterized by an improved performance with respect to calcined samples. At the same time, there is still much room for development and investigation concerning $\mathrm{CO}_{2}$ methanation catalysts involving plasma pretreatment.

\subsection{Effect of active metal in plasma-catalytic $\mathrm{CO}_{2}$ methanation}

As discussed in section 2.1 the active metal has a crucial role in the process of $\mathrm{CH}_{4}$ production from $\mathrm{CO}_{2}$. The activity sequence of noble/transition metals should be studied in order to answer the question, if it follows the same pattern under plasma-catalytic conditions as under thermal catalysis. $\mathrm{Up}$ to this date direct comparison of various metals in plasma-assisted $\mathrm{CO}_{2}$ methanation has not yet 
been performed. In this section activity of various metals will be presented and compared. Table 7 and Fig. 8 present comparison of activity of various metals applied in plasma-assisted $\mathrm{CO}_{2}$ hydrogenation.

Table 7 Comparison of catalytic performance of various metals applied in plasma-assisted catalysis for $\mathrm{CO}_{2}$ hydrogenation in the view of $\mathrm{CH}_{4}$ production

\begin{tabular}{|c|c|c|c|c|c|c|c|c|c|c|c|}
\hline \multirow[b]{2}{*}{ Catalyst } & \multicolumn{4}{|c|}{ Plasma } & \multicolumn{6}{|c|}{ Reaction } & \multirow[b]{2}{*}{ Ref. } \\
\hline & Type & $f(k H z)$ & $\begin{array}{c}V \\
(k V)\end{array}$ & $\begin{array}{c}P \\
\text { (W) }\end{array}$ & $\begin{array}{c}p \\
\text { (bar) }\end{array}$ & $\begin{array}{c}t \\
\left({ }^{\circ} \mathrm{C}\right)\end{array}$ & $\begin{array}{l}\text { Feed } \\
\text { gas }^{\text {a }}\end{array}$ & $\begin{array}{c}\mathrm{CO}_{2} \\
\text { conv. } \\
(\%) \\
\end{array}$ & $\begin{array}{l}\mathrm{CH}_{4} \\
\text { selc. } \\
(\%) \\
\end{array}$ & $\begin{array}{c}\mathrm{CH}_{4} \\
\text { yield } \\
(\%) \\
\end{array}$ & \\
\hline $\begin{array}{c}\mathrm{CuO} / \mathrm{ZnO} / \\
\mathrm{Al}_{2} \mathrm{O}_{3} \\
\end{array}$ & DBD & 30 & 20 & 500 & 8 & 100 & $3 / 1 ; 0.5$ & 14 & 12.5 & 1.75 & [163] \\
\hline $1 \mathrm{Pt} / \mathrm{\gamma}-\mathrm{Al}_{2} \mathrm{O}_{3}$ & \multirow{2}{*}{ DBD } & \multirow{2}{*}{9} & \multirow{2}{*}{30} & \multirow{2}{*}{10} & \multirow{2}{*}{1} & \multirow{2}{*}{25} & \multirow{2}{*}{$\begin{array}{c}3 / 1 \\
40\end{array}$} & 18 & 1.6 & 0.3 & \multirow{2}{*}{ [195] } \\
\hline $15 \mathrm{Cu} / \mathrm{Y}-\mathrm{Al}_{2} \mathrm{O}_{3}$ & & & & & & & & 21 & 2.3 & 0.5 & \\
\hline Pt metal cloth & MW & $\begin{array}{c}2.45 \\
10^{6} \\
\end{array}$ & n.d. & $\begin{array}{l}80- \\
175\end{array}$ & $\begin{array}{l}2.7 \\
10^{-3}\end{array}$ & n.d. & $\begin{array}{c}1 / 1-3 / 1 \\
15\end{array}$ & n.d. & n.d. & n.d. ${ }^{b}$ & [172] \\
\hline $\mathrm{Cu} / \mathrm{Y}-\mathrm{Al}_{2} \mathrm{O}_{3}$ & \multirow{3}{*}{ DBD } & \multirow{3}{*}{8.7} & \multirow{3}{*}{ n.d. } & \multirow{3}{*}{35} & \multirow{3}{*}{1} & \multirow{3}{*}{135} & \multirow{3}{*}{$\begin{array}{l}1 / 1 \\
34.6\end{array}$} & 8 & 8.5 & 0.68 & \multirow{3}{*}{ [164] } \\
\hline $\mathrm{Mn} / \mathrm{\gamma}-\mathrm{Al}_{2} \mathrm{O}_{3}$ & & & & & & & & 10.1 & 7.5 & 0.76 & \\
\hline $\mathrm{Cu}-\mathrm{Mn} / \mathrm{Y}-\mathrm{Al}_{2} \mathrm{O}_{3}$ & & & & & & & & 9.2 & 6.8 & 0.63 & \\
\hline \multirow[b]{2}{*}{$15 \mathrm{Ni} / \mathrm{Y}-\mathrm{Al}_{2} \mathrm{O}_{3}$} & \multirow[b]{2}{*}{ DBD } & \multirow[b]{2}{*}{ n.d. } & \multirow[b]{2}{*}{30} & \multirow[b]{2}{*}{30} & \multirow[b]{2}{*}{1} & \multirow[b]{2}{*}{150} & $4 / 1 ; 69$ & 29 & 3.9 & 1.15 & \multirow[b]{2}{*}{ [166] } \\
\hline & & & & & & & $\begin{array}{c}4 / 1+\mathrm{Ar} \\
69.2\end{array}$ & 56 & 7.4 & 4.15 & \\
\hline $6 \mathrm{Ru} / \mathrm{\gamma}-\mathrm{Al}_{2} \mathrm{O}_{3}$ & DBD & 3 & 9 & n.d. & 1 & 25 & $\begin{array}{c}3 / 1 / 6^{d} \\
50\end{array}$ & 12.8 & 73 & 9.4 & [169] \\
\hline \multirow{2}{*}{$5 \mathrm{Co} / \mathrm{CeZrO}_{4}$} & \multirow{2}{*}{ DBD } & \multirow{2}{*}{1} & \multirow{2}{*}{ n.d. } & \multirow{2}{*}{ n.d. } & & 150 & $4 / 1$ & 70 & 99 & 69.3 & {$[184]$} \\
\hline & & & & & 1 & 200 & 25 & 78 & 98.7 & 77 & [184] \\
\hline La-ZrO & & & & 4.8 & & 386 & & 18.5 & 0 & 0 & \\
\hline $1 \mathrm{Pd} / \mathrm{La}-\mathrm{ZrO}_{2}$ & & & & 5.6 & & 375 & $\mathrm{H}_{2} / \mathrm{CO}_{2} /$ & 40.6 & n.d. & n.d. & \\
\hline $1 \mathrm{Pt} / \mathrm{La}-\mathrm{ZrO}_{2}$ & $D C^{c}$ & & & 3.5 & & 450 & $\mathrm{Ar}=$ & 30.6 & n.d. & n.d. & \\
\hline $1 \mathrm{Ni} / \mathrm{La}-\mathrm{ZrO}_{2}$ & $D^{2}$ & - & $1-2$ & 4.9 & 1 & 343 & $1 / 1 / 2$ & 27.7 & n.d. & n.d. & [196] \\
\hline 1Fe/La-ZrO2 & & & & 4.1 & & 373 & 100 & 27.1 & 0 & 0 & \\
\hline 1Cu/La-ZrO2 & & & & 4.9 & & 393 & & 27.0 & 0 & 0 & \\
\hline $\begin{array}{l}\text { a } \text { Feed gas: } \mathrm{H}_{2} / \mathrm{CO} \\
{ }^{\mathrm{b}} \mathrm{CH}_{4} \text { production } \\
{ }^{\mathrm{c}} \text { direct current hi } \\
{ }^{\mathrm{d}} \mathrm{H}_{2} / \mathrm{CO}_{2} / \mathrm{N}_{2} \\
\end{array}$ & lar rati & $\begin{array}{l}\text { total flon } \\
\text { and alon }\end{array}$ & $\begin{array}{l}\mathrm{Nml/} \\
\text { vith C }\end{array}$ & 1 & 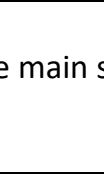 & . & roduct & & & & \\
\hline
\end{tabular}

The $\mathrm{CO}_{2}$ hydrogenation in DBD plasma and in the presence of $\mathrm{CuO} / \mathrm{ZnO} / \mathrm{Al}_{2} \mathrm{O}_{3}$ with the aim of methanol production was studied by Eliasson et al. [163]. It may be considered the first research which reported and discussed $\mathrm{CH}_{4}$ production under plasma-catalytic conditions. Although copper is typically $\mathrm{CH}_{3} \mathrm{OH}$ synthesis catalyst, the studied material showed higher selectivity to $\mathrm{CH}_{4}$ than methanol. This may be caused by the fact that methanol production requires collision of more species if the reaction occurred only in the gas phase. However, $\mathrm{CO}_{2}$ conversion and production of both $\mathrm{CH}_{4}$ and $\mathrm{CH}_{3} \mathrm{OH}$ were higher in the presence of catalysts, clearly pointing to the fact that reaction needs to (at least partially) occur on the catalyst surface. Other important findings of that research include a decrease of catalyst activity with increase of temperature in the presence of 
plasma, which may be explained by the unstable plasma performance at high temperatures. An increase of $\mathrm{CH}_{4}$ selectivity with a decrease of pressure and/or flow of gases and increase of discharge power was observed as well. Therefore, it showed that system optimization (flow, power, pressure, temperature, feed composition) can help to tailor the formation of desired products, which stays in line with other reports $[166,169,171,195-197]$. However, the role of a catalyst and active metal remained unclear. It is worth noticing that the research of Eliasson et al. [163] is so far the only paper which examined plasma-catalytic $\mathrm{CO}_{2}$ methanation at high pressure. Considering thermodynamic analysis (Fig. 1), the elevated pressure should promote formation of methane over RWGS. However, under plasma conditions high pressure requires application of high discharge voltages. This may be to some extent overcome in e.g by decreasing discharge gap for DBD reactors. Unfortunately, such approach creates other problems associated with incorporation of catalyst between the electrodes [29]. Keeping as well in mind that high pressure operation generates costs, the current plasmacatalytic research is aimed at atmospheric pressure operation

Recently, $\mathrm{CH}_{3} \mathrm{OH}$ production via plasma-catalytic $\mathrm{CO}_{2}$ hydrogenation was studied with the application of DBD plasma and $\mathrm{Cu} / \mathrm{Al}_{2} \mathrm{O}_{3}$ and $\mathrm{Pt} / \mathrm{Al}_{2} \mathrm{O}_{3}$ catalysts [195]. The former was characterized by higher $\mathrm{CO}_{2}$ conversion and $\mathrm{CH}_{3} \mathrm{OH}$ yield. In the case of both catalysts, as well as without their presence, $\mathrm{CH}_{4}$ production was observed. In contrast to work of Eliasson et al. [163], the lower yield of $\mathrm{CH}_{4}$ production with respect to $\mathrm{CH}_{3} \mathrm{OH}$ was observed which may be explained by different reaction conditions as well as different reactor design i.e. application of water electrode for $\mathrm{H}_{2}$ production.

Another early research on the topic was carried out by Maya et al. [172], who investigated lowpressure $\mathrm{CO}_{2}$ hydrogenation with the application of microwave energy plasma and Pt metal cloth catalyst, aimed at the production of formic acid. Their research showed that in the tested conditions $\mathrm{CH}_{4}$ and $\mathrm{C}_{2} \mathrm{H}_{6}$ production as main secondary products is possible, however, again the role of the catalyst was not discussed.

$\mathrm{Cu} / \mathrm{Al}_{2} \mathrm{O}_{3}, \mathrm{Mn} / \mathrm{Al}_{2} \mathrm{O}_{3}$ and $\mathrm{Cu}-\mathrm{Mn} / \mathrm{Al}_{2} \mathrm{O}_{3}$ catalysts tested in DBD reactor were studied by Zeng et al. [164]. In this study materials were activated in-situ in plasma in the flow of $\mathrm{H}_{2} / \mathrm{Ar}$. The most active material turned out to be a manganese-based sample. Lower $\mathrm{CO}_{2}$ conversion of copper containing materials was explained by the fact that $\mathrm{Cu}$ is active in water gas shift reaction and therefore contributes to $\mathrm{CO}_{2}$ production. In all experiments, $\mathrm{CH}_{4}$ selectivity did not exceed $2 \%$. The small amounts of $\mathrm{C}_{2} \mathrm{H}_{6}$ and $\mathrm{C}_{4} \mathrm{H}_{10}$ were detected as well. It is important to stress that in this study, $\mathrm{Cu}$ and $\mathrm{Mn}$ catalysts increased the energy efficiency of $\mathrm{CH}_{4}$ production.

At this point it is clear, that the role of active metal is similar to the thermal-catalytic process. In the above discussed studies $\mathrm{Cu}, \mathrm{Pt}$ and Mn-based catalyst were used. All of them are not typical active 
components applied in $\mathrm{CO}_{2}$ methanation. Although, small amounts of $\mathrm{CH}_{4}$ yields were obtained in the presence of these metals, one can expect that in order to boost $\mathrm{CH}_{4}$ production active materials used in thermal $\mathrm{CO}_{2}$ methanation must be applied in plasma-catalytic process (i.e. $\mathrm{Ni}, \mathrm{Co}, \mathrm{Fe}, \mathrm{Rh}, \mathrm{Ru}$ ).

Zeng and Tu [166] examined nickel-alumina catalyst in various reaction conditions. In fact, higher $\mathrm{CO}_{2}$ conversion and $\mathrm{CH}_{4}$ production was observed in the presence of $\mathrm{Ni}$ with respect to their earlier investigations of $\mathrm{Cu}$ and $\mathrm{Mn}$ catalysts (Table 7, Fig. 8). Another important finding of that research was that the activity and selectivity of the plasma-catalytic process may be greatly improved by the introduction of $\mathrm{Ar}$ into the feed. $\mathrm{CO}_{2}$ conversion almost doubled (from ca. 29 to 56\%) when $\mathrm{Ar}$ content was increased from 0 to $60 \mathrm{vol} . \%$. The positive effect of $\mathrm{Ar}$ addition comes from the so-called Penning effect (section 3.2 above). Moreover, the presence of argon in the gas leads to more uniform DBD discharge which might also increase the contact area between plasma and catalyst. CO selectivity was not affected by the presence of $\mathrm{Ar}$, while $\mathrm{CH}_{4}$ selectivity was strongly improved, clearly pointing to the creation of a new reaction pathway for $\mathrm{CH}_{4}$ formation. Similar $\mathrm{Ar}$ addition effect on $\mathrm{CH}_{4}$ selectivity was observed for $\mathrm{Ru} / \mathrm{Al}_{2} \mathrm{O}_{3}$ catalyst tested in DBD discharge [169]. This was most probably caused by the decrease of breakdown voltage, which results in increased amount of excited plasma species and thus enhanced the formation of surface carbon from CO. This surface carbon can be subsequently hydrogenated to $\mathrm{CH}_{4}$. This proved that product distribution may be controlled as well by the presence of Ar in the feed. One needs to keep in mind that on the other hand the dilution of the reactants requires further separation of the reaction products which generates additional costs.

Parastaev et al. [184] recently compared the performance of $\mathrm{Cu}$ and Co catalysts supported on $\mathrm{CeZrO}_{4}$ and tested in DBD reactor. Co-based catalyst turned out to be much more active and selective to $\mathrm{CH}_{4}$ than a copper one. Its activity increased with the increasing cobalt content which could be explained by the increased amount of adsorption sites for $\mathrm{H}_{2}$. Nevertheless, the authors confirmed that $\mathrm{CO}_{2}$ methanation in plasma condition proceeds mainly with hydrogenation of carbon monoxide on cobalt particles and is independent of the support. The higher activity of plasma-catalytic process was observed with respect to thermal catalysis. This synergetic effect could be partially explained by overheating of the catalyst bed, especially at low temperatures $50-250^{\circ} \mathrm{C}$.

Oshima et al. [196] compared the performance of various metals i.e. Pt, Pd, Ni, Fe and $\mathrm{Cu}$, supported on $\mathrm{La}-\mathrm{ZrO}_{2}$ in $\mathrm{CO}_{2}$ hydrogenation in the reactor equipped with direct current high voltage power supply. It is so far, the only research which directly compared performance of various catalysts. Metal loaded catalysts showed better performance than support alone. Noble metal-based catalysts showed higher $\mathrm{CO}_{2}$ conversions than $\mathrm{Ni}$, $\mathrm{Fe}$ and $\mathrm{Cu}$ samples. Iron and copper were $100 \%$ selective to 
$\mathrm{CO}$, while nickel-based catalyst showed the lowest selectivity to $\mathrm{CO}$. The study showed that $\mathrm{CO}_{2}$ conversion dependent more on the effect of electric field rather than the nature of the catalyst. Methane production was unfortunately not discussed.

Fig. 8 summarizes the performance of various metals tested under DBD plasma in $\mathrm{CO}_{2}$ hydrogenation. Clearly, production of $\mathrm{CH}_{4}$ and $\mathrm{CO}_{2}$ conversion is greatly increased in the presence of metals active in thermal $\mathrm{CO}_{2}$ methanation. However, the role of other metals $(\mathrm{Pt}, \mathrm{Cu}, \mathrm{Mn})$ cannot be neglected as they may contribute to $\mathrm{CH}_{4}$ production. It is unclear if this small contribution may be explained by surface catalytic reactions or influencing plasma properties and thus reactions occurring in the gas phase. Another important point is that activity of the metal in plasma-catalytic process is affected by various factors including plasma parameters, support etc. For instance, all catalysts presented in Fig. 8 were tested under atmospheric pressure and with DBD plasma. However, still $\mathrm{CH}_{4}$ production was greatly improved after changing discharge parameters and the support (compare $\mathrm{Ni} /$ Alumina and $\mathrm{Ni} /$ Ceria-Zirconia, Fig. 8). This points to the fact that there is much room for investigation of role of active metal and dependence of its activity on plasma parameters.

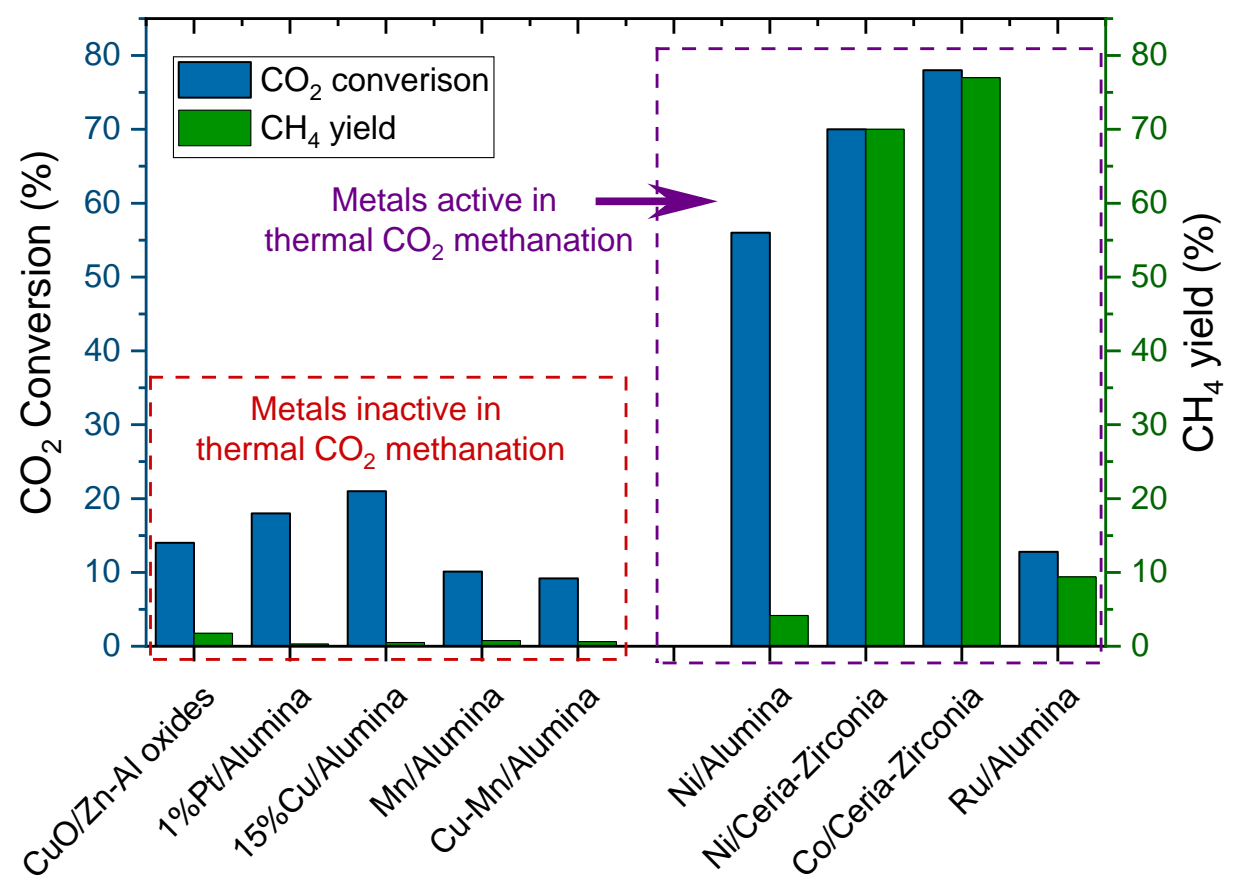

Fig. 8 Comparison of activity of various metals tested in plasma-catalytic $\mathrm{CO}_{2}$ methanation under atmospheric pressure and DBD plasma; CuO/Zn-Al oxides [163], Pt/Alumina \& Cu/Alumina [195], Mn/Alumina \&CuMn/Alumina [197], Ni/Alumina [166] Ni/Ceria-Zirconia [198], Co/Ceria-Zirconia [184], Ru/Alumina [169]

\subsection{Effect of plasma type on the performance $\mathrm{CO}_{2}$ methanation catalyst}

The effectiveness of $\mathrm{CO}_{2}$ hydrogenation in plasma was greatly dependent on the plasma type (see section 3.2). Much higher conversions of $\mathrm{CO}_{2}$ were reported for microwave discharges or glow 
discharge plasmas with respect to DBD. However, high $\mathrm{CO}_{2}$ conversions did not result in high $\mathrm{CH}_{4}$ yields, pointing to the important role of catalyst for boosting $\mathrm{CH}_{4}$ production. The role of plasma type on the catalyst activity is however unclear. The research on various plasma types in the presence of Ni-based catalysts is presented in Table 8.

Table 8 Summary of catalytic performance of plasma-assisted catalysts in $\mathrm{CO}_{2}$ hydrogenation in the view of $\mathrm{CH}_{4}$ production - Effect of plasma type.

\begin{tabular}{|c|c|c|c|c|c|c|c|c|c|c|c|}
\hline \multirow[b]{2}{*}{ Catalyst } & \multicolumn{4}{|c|}{ Plasma } & \multicolumn{6}{|c|}{ Reaction } & \multirow[b]{2}{*}{ Ref. } \\
\hline & Type & $f(k H z)$ & $\begin{array}{c}V \\
(k V)\end{array}$ & $\begin{array}{c}P \\
\text { (W) }\end{array}$ & $\begin{array}{c}p \\
\text { (bar) }\end{array}$ & $\begin{array}{c}t \\
\left({ }^{\circ} \mathrm{C}\right)\end{array}$ & $\begin{array}{l}\text { Feed } \\
\text { gas }^{\text {a }}\end{array}$ & $\begin{array}{c}\mathrm{CO}_{2} \\
\text { conv. } \\
(\%)\end{array}$ & $\begin{array}{c}\mathrm{CH}_{4} \\
\text { selec. } \\
(\%) \\
\end{array}$ & $\begin{array}{c}\mathrm{CH}_{4} \\
\text { yield } \\
(\%)\end{array}$ & \\
\hline $15 \mathrm{Ni} / \mathrm{CeZrO}_{4}$ & DBD & $40-41$ & $\begin{array}{c}14.5- \\
18 \\
\end{array}$ & n.d. & 1 & $\begin{array}{l}170- \\
330 \\
\end{array}$ & $\begin{array}{c}4 / 1 ; \\
200 \\
\end{array}$ & $10-70$ & $20-100$ & $2-70$ & [198] \\
\hline $\mathrm{NiO} / \mathrm{TiO}_{2}$ & MW & 1.67 & n.d. & 388 & 0.04 & n.d. & $\begin{array}{l}1 / 9 ; \\
2000\end{array}$ & 29.3 & n.d. & n.d. & [171] \\
\hline 14Ni/USY(40) & \multirow{4}{*}{ GD } & \multirow{4}{*}{0.05} & \multirow{4}{*}{2} & \multirow{4}{*}{ n.d. } & \multirow{4}{*}{$\begin{array}{l}3.2 \cdot \\
10^{-3}\end{array}$} & \multirow{4}{*}{125} & \multirow{4}{*}{$4 / 1 ; 20$} & 64 & 3.9 & 2.5 & \multirow{4}{*}{$\begin{array}{c}{[180,1} \\
81]\end{array}$} \\
\hline 14Ni/USY(30) & & & & & & & & 63 & 1.9 & 1.2 & \\
\hline $2.5 \mathrm{Ni} / \mathrm{ZSM}-11$ & & & & & & & & 64 & 2.1 & 1.4 & \\
\hline $5 \mathrm{Ni} / \mathrm{ZSM}-11$ & & & & & & & & 64 & 1.4 & 0.9 & \\
\hline $15 \mathrm{Ni} / \gamma-\mathrm{Al}_{2} \mathrm{O}_{3}$ & GD & 0.05 & 2 & n.d. & $\begin{array}{l}3.2 \cdot \\
10^{-3}\end{array}$ & 200 & $4 / 1 ; 20$ & 40 & 8 & 3.2 & [199] \\
\hline $\mathrm{Ni} / \mathrm{Al}_{2} \mathrm{O}_{3}$ & \multirow{3}{*}{ GD } & \multirow{3}{*}{0.066} & \multirow{3}{*}{6} & \multirow{3}{*}{ n.d. } & \multirow{3}{*}{$\begin{array}{l}3.2 \\
10^{-3}\end{array}$} & \multirow{3}{*}{200} & \multirow{3}{*}{$\begin{array}{c}4 / 1 \\
20\end{array}$} & 20 & 50 & 10 & \multirow{3}{*}{ [183] } \\
\hline $\mathrm{Ni} / \mathrm{SiO}_{2}$ & & & & & & & & 32 & 0 & 0 & \\
\hline $\mathrm{Ni} / \mathrm{CeO}_{2} \mathrm{ZrO}_{2}$ & & & & & & & & 19 & 26 & 5 & \\
\hline
\end{tabular}

The most often applied plasma type for plasma-catalytic $\mathrm{CO}_{2}$ methanation is $\mathrm{DBD}$ (see section 4.4). As a representation of DBD catalytic process the recent research performed by Mikhail et al. [198] was selected. The study investigated operation parameters i.e. plasma power, voltage, GHSV and reactor configuration over $15 \mathrm{wt} . \% \mathrm{Ni} / \mathrm{Ce}_{0.52} \mathrm{Zr}_{0.48} \mathrm{O}_{2}$ catalyst. It is worth mentioning that study on nickel-based catalysts and the effect of the support (see section 2.2) pointed out the beneficial aspects of ceriazirconia support. Their findings showed that the $\mathrm{CO}_{2}$ methanation started (significant increase in both $\mathrm{CO}_{2}$ conversion and $\mathrm{CH}_{4}$ yield) when the voltage was raised from 14.5 to $15 \mathrm{kV}$. Such voltage corresponded to the temperature ca. $170-200^{\circ} \mathrm{C}$. Further increase in voltage resulted in increased reactor temperature (up to $300^{\circ} \mathrm{C}$ ) which shifted selectivity to carbon monoxide. As with the increase of voltage specific input energy (SEI) increases as well, the effect of power on the overall performance was the same. Such effect is understandable, as high temperatures shift thermodynamic selectivity to carbon monoxide (Fig. 1). The study on the residence time revealed that lower GHSV resulted in longer residence time and therefore higher $\mathrm{CO}_{2}$ conversions. Depending on the process parameters, the authors observed $\mathrm{CO}_{2}$ conversion and $\mathrm{CH}_{4}$ yield varying respectively from $10-70 \%$ and $2-70 \%$. This clearly points that the plasma parameters have a significant effect on overall performance and may greatly increase synergetic effect between plasma and catalysis. 
$\mathrm{Ni}$ /USY and Ni/ZSM-11 zeolite-based catalysts were tested by Azzolina-Jury et al. [180], who investigated $\mathrm{CO}_{2}$ methanation in a low-pressure glow discharge in the temperature range $200-350^{\circ} \mathrm{C}$. Tested catalysts were pre-reduced at $470^{\circ} \mathrm{C}$, which resulted in an incomplete reduction of $\mathrm{NiO}$, however, such reduction temperature guaranteed preservation of zeolite structure. In glow discharge plasma $\mathrm{CO}_{2}$ dissociation proceeds mainly via electron impact dissociation or vibrational excitation. Moreover, zeolites are characterized by a high dielectric constant which results in a decrease of a breakdown voltage due to localized electric field enhancement. These effects explain high activity in the $\mathrm{CO}_{2}$ conversion of the glow discharge plasma-zeolite system. Similar to catalytic DBD plasma experiments $[166,200,201]$, the negative effect of temperature on $\mathrm{CO}_{2}$ conversion was observed, which was explained by unfavourable adsorption of $\mathrm{CO}_{2}$ on the catalyst surface at high temperatures. The main product observed during plasma-catalytic experiments was carbon monoxide, which may be considered the main disadvantage of low-pressure glow discharge with respect to DBD plasma. Interestingly, improved production of $\mathrm{CH}_{4}$ was observed after plasma extinction. This $\mathrm{CH}_{4}$ release from the surface of catalyst was proportional to the nickel reduction degree and to nickel content and was following the same sequence as $\mathrm{CH}_{4}$ selectivity during plasmacatalytic tests. The methane release was explained by the fact that under plasma conditions nickel species were occupied by $\mathrm{CO}$. Once plasma was stopped $\mathrm{CO}$ production stopped (from $\mathrm{CO}_{2}$ dissociation) and surface coverage decreased allowing $\mathrm{H}_{2}$ adsorption and reaction with remaining $\mathrm{CO}$ molecules to form $\mathrm{CH}_{4}$. It is important to underline that Azzolina-Jury et al. [180] investigated various plasma-catalyst configurations. So far, all reports considered so-called In-Plasmas-Catalysis (IPC) systems in which the catalyst bed is present directly in the plasma discharge zone. The second system described in the literature, so-called Post-Plasma-Catalysis (PPC), corresponds to a configuration where the catalyst bed is placed right after the discharge zone. In this way, gas molecules are firstly activated in plasma and may further react on the catalyst surface. In the presented study [180], PPC system was characterized by much lower $\mathrm{CO}_{2}$ conversions and $\mathrm{CH}_{4}$ selectivity which can be explained by short lifetime of plasma produced excited species, which is not enough to reach catalyst bed.

Another catalytic system investigated by Azzolina-Jury [199] in low-pressure glow discharge plasma was $15 \mathrm{wt} . \% \mathrm{Ni} / \mathrm{\gamma}-\mathrm{Al}_{2} \mathrm{O}_{3}$. The alumina support extrudates were prepared using various preparation conditions. However, the preparation of support extrudates had minimal effect on the final performance in the plasma-catalytic process. The best performance was observed at $200^{\circ} \mathrm{C}$ reaching ca. $40 \% \mathrm{CO}_{2}$ conversion and $8 \% \mathrm{CH}_{4}$ selectivity.

The study of Chen et al. [171] focused on analysing $\mathrm{CO}_{2}$ conversion in $\mathrm{CO}_{2} / \mathrm{H}_{2}$ and $\mathrm{CO}_{2} / \mathrm{H}_{2} \mathrm{O}$ mixtures in the presence of $\mathrm{Ni} / \mathrm{TiO}_{2}$ catalysts and microwave discharge. Their results showed that the presence 
of catalyst increased $\mathrm{CO}_{2}$ conversion and energy efficiency. However, the selectivity of obtained products was not discussed.

Research by Hoeben et al. [179], who examined $\mathrm{CO}_{2}$ methanation in the presence of water in pulsed corona discharge (corona discharge is the ionisation of the gas surrounding charge conductor), showed that electrode material may influence as well the overall process. The authors did not use any catalyst bed in the reactor, but they examined to sets of electrodes: (i) steel electrodes and (ii) $\mathrm{Ni}-\mathrm{Cr}$ electrodes. In the presence of the latter $\mathrm{CH}_{4}$ production was significantly improved with respect to steel electrodes. This clearly suggests that most probably reactor design for the plasma-catalytic process may require a new approach.

The plasma type has a significant influence on the $\mathrm{CH}_{4}$ production. The most studied DBD plasma systems are reported to give the highest $\mathrm{CH}_{4}$ yields and high conversions of $\mathrm{CO}_{2}$. The catalyst performance may be significantly improved by selecting appropriate operation conditions. Glow discharge plasmas operating at low-pressures are less selective to $\mathrm{CH}_{4}$ with respect to DBD (Table 8), which may be explained by their low-pressure operation (few mbar) as well as decomposition of produced $\mathrm{CH}_{4}$ in plasma. On the other hand, the performance of microwave plasma in terms of $\mathrm{CO}_{2}$ conversion may be improved in the presence of catalyst. However, as microwave discharge is considered a warm plasma (temperature above $600^{\circ} \mathrm{C}$ ), the $\mathrm{CH}_{4}$ production may be limited through thermodynamic limitations (Fig. 1).

\subsection{Ni-based catalysts tested under DBD plasma for $\mathrm{CH}_{4}$ production}

The summary on Ni-based catalysts tested for $\mathrm{CH}_{4}$ production in DBD plasma is presented in Table 8 .

Jwa et al. [202] examined nickel catalyst supported on alumina and mixed titania-alumina. Both supports without nickel loading showed $\mathrm{CO}_{2}$ conversion at the level of ca. $10 \%$ and $100 \%$ selectivity to $\mathrm{CO} . \mathrm{CH}_{4}$ formation was not discussed. However, the authors showed that the performance of $\mathrm{Ni} / \mathrm{Al}_{2} \mathrm{O}_{3}$ was better than $\mathrm{Ni} / \mathrm{Al}_{2} \mathrm{O}_{3}-\mathrm{TiO}_{2}$ catalyst, which was explained by higher values of the specific surface area. This clearly points to the importance of catalyst surface in the hybrid plasma-catalytic process. Another research by Jwa et al. [203] examined the performance of Ni-zeolite catalyst in similar DBD plasma system. $\mathrm{CH}_{4}$ production was observed only in the presence of a catalyst. The activity of tested materials increased with increasing Ni content. Interestingly, it was reported that dispersion of $\mathrm{Ni}$ increased after plasma-catalytic tests, pointing to the reorganization of nickel particles upon reaction. The improved activity in the presence of catalyst was explained by the fact that plasma helps to dissociate adsorbed molecules, including breakage of the carbon-oxygen bond. 
The latter is a source of surface carbon which is believed to be necessary intermediate to produce $\mathrm{CH}_{4}$.

Table 9 Summary on Ni-based catalysts tested under DBD plasma

\begin{tabular}{|c|c|c|c|c|c|c|c|c|c|c|}
\hline \multirow[b]{2}{*}{ Catalyst } & \multicolumn{3}{|c|}{ Plasma } & \multicolumn{6}{|c|}{ Reaction } & \multirow[b]{2}{*}{ Ref. } \\
\hline & $\begin{array}{c}f \\
(\mathrm{kH} \\
\mathrm{z}) \\
\end{array}$ & $\begin{array}{c}V \\
(k V)\end{array}$ & $\begin{array}{c}P \\
\text { (W) }\end{array}$ & 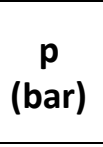 & $\begin{array}{c}t \\
\left({ }^{\circ} \mathrm{C}\right)\end{array}$ & $\begin{array}{l}\text { Feed } \\
\text { gas }^{\text {a }}\end{array}$ & $\begin{array}{c}\mathrm{CO}_{2} \\
\text { conv. } \\
(\%) \\
\end{array}$ & $\begin{array}{c}\mathrm{CH}_{4} \\
\text { selec. } \\
\text { (\%) }\end{array}$ & $\begin{array}{c}\mathrm{CH}_{4} \\
\text { yield } \\
\text { (\%) }\end{array}$ & \\
\hline $\mathrm{Al}_{2} \mathrm{O}_{3}$ & \multirow{4}{*}{1} & \multirow{4}{*}{10.3} & \multirow{4}{*}{ n.d. } & \multirow{4}{*}{1} & \multirow{4}{*}{280} & \multirow{4}{*}{$\begin{array}{c}4 / 1 ; \\
25\end{array}$} & 12 & \multirow{4}{*}{ n.d. } & \multirow{4}{*}{ n.d. } & \multirow{4}{*}{ [202] } \\
\hline $\mathrm{TiO}_{2} / \mathrm{Al}_{2} \mathrm{O}_{3}$ & & & & & & & 10 & & & \\
\hline $10 \mathrm{Ni} / \mathrm{Al}_{2} \mathrm{O}_{3}$ & & & & & & & 90 & & & \\
\hline $10 \mathrm{Ni}-\mathrm{TiO}_{2} / \mathrm{Al}_{2} \mathrm{O}_{3}$ & & & & & & & 82 & & & \\
\hline$\beta$-zeolite & \multirow{5}{*}{1} & \multirow{5}{*}{9.4} & \multirow{5}{*}{ n.d. } & \multirow{5}{*}{1} & \multirow{5}{*}{260} & \multirow{5}{*}{$\begin{array}{c}4 / 1 ; \\
25\end{array}$} & 0 & \multirow{5}{*}{ n.d. } & \multirow{5}{*}{ n.d. } & \multirow{5}{*}{ [203] } \\
\hline 2.5Ni/ $\beta$-zeolite & & & & & & & 4 & & & \\
\hline $5 \mathrm{Ni} / \beta$-zeolite & & & & & & & 48 & & & \\
\hline 7.5Ni/ $\beta$-zeolite & & & & & & & 89 & & & \\
\hline 10Ni/ $\beta$-zeolite & & & & & & & 93 & & & \\
\hline $\mathrm{Ni}(\mathrm{Mg}, \mathrm{Al}) \mathrm{O}$ & \multirow{4}{*}{41} & \multirow{4}{*}{$\begin{array}{l}10- \\
15\end{array}$} & \multirow{4}{*}{16} & \multirow{4}{*}{1} & 160 & \multirow{4}{*}{$4 / 1 ; 200$} & 78 & 98.7 & 77 & \\
\hline $\mathrm{Ni}-\mathrm{Ce}(\mathrm{Mg}, \mathrm{Al}) \mathrm{O}$ & & & & & 220 & & 16 & 18.7 & 3 & \\
\hline $\mathrm{Ni}-\mathrm{Zr}(\mathrm{Mg}, \mathrm{Al}) \mathrm{O}$ & & & & & 240 & & 70 & 78.5 & 55 & [204] \\
\hline $\mathrm{Ni}-\mathrm{Ce}, \mathrm{Zr}(\mathrm{Mg}, \mathrm{Al}) \mathrm{O}$ & & & & & 260 & & 68 & 82.3 & 56 & \\
\hline $15 \mathrm{Ni} / \mathrm{Ce}_{0.1} \mathrm{Zr}_{0.9} \mathrm{O}_{2}$ & & & & & & & 72 & 99.7 & 71.8 & \\
\hline $15 \mathrm{Ni} / \mathrm{Ce}_{0.6} \mathrm{Zr} 0.4 \mathrm{O}_{2}$ & $40-$ & $10-$ & $1-3$ & 1 & 320 & 4/1; & 81 & 99 & 80.4 & [200] \\
\hline $15 \mathrm{Ni} / \mathrm{Ce}_{0.9} \mathrm{Zr}_{0.1} \mathrm{O}_{2}$ & & & & & & & 83 & 99 & 82.8 & \\
\hline $15 \mathrm{Ni} / \mathrm{CZ}-\mathrm{cal}^{\mathrm{b}}$ & & & 14 & & 170 & & 73 & 100 & 73 & \\
\hline $15 \mathrm{Ni} / \mathrm{CZ}-$-red $^{\mathrm{b}}$ & $40-$ & & 16 & & 170 & & 80 & 94 & 75 & \\
\hline 15Ni/CZ-Pred20 & 42. & $\begin{array}{l}13- \\
18\end{array}$ & 4 & 1 & 120 & 4/1; & 36 & 100 & 36 & [205] \\
\hline $15 \mathrm{Ni} / \mathrm{CZ}-\mathrm{Pred} 40^{\mathrm{b}}$ & 8 & & 4 & & 120 & & 73 & 100 & 73 & \\
\hline $15 \mathrm{Ni} / \mathrm{CZ}-\mathrm{Pred} 60^{\mathrm{b}}$ & & & 4 & & 120 & & 60 & 100 & 60 & \\
\hline & & & & & 140 & 4/1; & 80 & 99 & 79 & \\
\hline $15 \mathrm{NI} / \mathrm{CL} / \mathrm{SBA-1S}$ & 40 & 14 & n.d. & 1 & 320 & 200 & 80 & 92 & 74 & [201] \\
\hline Cs-USY(38) & & & & & & & 12 & 12.5 & 1.5 & \\
\hline $10 \mathrm{Ni} / \mathrm{V}-\mathrm{Al}_{2} \mathrm{O}_{3}$ & & & & & & & 61 & 93 & 57 & \\
\hline $15 \mathrm{Ni} / \mathrm{Cs}-U S Y(3)$ & $\begin{array}{l}25- \\
70\end{array}$ & $0-15$ & 35 & 1 & 170 & $\begin{array}{l}36 / 9 / \\
10^{c .}, 250\end{array}$ & 22 & 80 & 17.6 & [167] \\
\hline $15 \mathrm{Ni} / \mathrm{Cs}-\mathrm{USY}(38)$ & & & & & & & 75 & 96 & 72 & \\
\hline Ce-Ni/Cs-USY(38) & & & & & & & 79 & 98 & 77.4 & \\
\hline $15 \mathrm{Ni} / \mathrm{CeO}_{2}-\mathrm{Al}_{2} \mathrm{O}_{3}$ & 54 & $4-15$ & $\begin{array}{c}15- \\
40\end{array}$ & 1 & 150 & $4 / 1 ; 200$ & 70 & 96 & 67 & [206] \\
\hline $\mathrm{Ni}(\mathrm{Mg}, \mathrm{Al}) \mathrm{O}$ & nd & 16 & 18 & 1 & nd & $4 / 1: 200$ & 59 & n.d. & n.d. & [207] \\
\hline $\mathrm{Ni}(\mathrm{Fe}, \mathrm{Mg}, \mathrm{Al}) \mathrm{O}$ & & & & & & & 75 & n.d. & n.d. & \\
\hline $\begin{array}{l}\text { a Feed gas: } \mathrm{H}_{2} / \mathrm{CO}_{2} \mathrm{r} \\
\mathrm{b} \mathrm{CZ}-\mathrm{Ceria-Zirconia} \\
\text { plasma reduction fo } \\
{ }^{\mathrm{C}} \mathrm{H}_{2} / \mathrm{CO}_{2} / \mathrm{N}_{2}\end{array}$ & ar rat & ; total & $\mathrm{w}(\mathrm{Nn}$ & $\min )$ & & & & & & \\
\hline
\end{tabular}

As it was mentioned in section 2.3, $\mathrm{Ni}$ catalysts supported on ceria-zirconia showed good performance in $\mathrm{CO}_{2}$ methanation. Nizio et al. [200] investigated the performance of nickel supported on mixed ceria-zirconia with the various $\mathrm{CeO}_{2} / \mathrm{ZrO}_{2}$ ratio in $\mathrm{DBD}$ reactor. The catalysts without 
plasma were active at temperatures above $280^{\circ} \mathrm{C}$, while in DBD discharge they became active at $90^{\circ} \mathrm{C}$. CO yield increased with the increase of reaction temperature, suggesting working at lower reaction temperatures in the presence of plasma. The best performance was shown by catalyst with the highest ceria content. Long-terms plasma-catalytic tests (100h) showed that the morphology and structure of catalyst were not changed. In the continuation of that work [205], the authors investigated the effect of reduction/activation conditions of $15 \% \mathrm{Ni} / \mathrm{Ce}_{0.52} \mathrm{Zr}_{0.48} \mathrm{O}_{2}$ catalyst. The samples reduced in the stream of $\mathrm{H}_{2}$ at $470^{\circ} \mathrm{C}$ and activated in DBD plasma at room temperature for 20, 40 and 60 minutes were compared. Hydrogen-plasma treatment leads to the formation of $\mathrm{Ni}$ particles similar to the ones obtained for the reduced catalyst, however, incomplete reduction of $\mathrm{NiO}$ to metallic Ni was observed for the former, which may explain slightly lower activities obtained for plasma-reduced samples. The plasma activation resulted as well in the increased $\mathrm{CO}_{2}$ adsorption capacity. Other materials studied in DBD plasma by the same research group were nickel-containing and $\mathrm{Ce}, \mathrm{Zr}$ and or CeZr promoted hydrotalcite-derived materials [204]. In this case promotion with $\mathrm{Ce}, \mathrm{Zr}$ or both metal species turned out to have a negative effect on catalyst activity. On the other hand, Wierzbicki et al. [207] showed that small addition of Fe into matrix of Ni(Mg,Al)O hydrotacitederived oxides may greatly improve $\mathrm{CO}_{2}$ conversion. It is important to mention that the recent study of Mikhail et al. [198] showed that performance of catalyst may be improved by adjusting operation parameters of DBD plasma.

Amouroux and Cavadias [201] and Bacariza et al. [167] identified water adsorption on the active sites as one of the main limiting factors for conventional $\mathrm{CO}_{2}$ methanation. Strong interactions of water with catalyst surface were confirmed as well for $\mathrm{Co} / \mathrm{CeZrO}_{4}$ catalyst in the study by Parastaev et al. [184]. This problem may be easily overcome with the application of plasma. The study by Amouroux and Cavadias included the application of Ni supported on mixed SBA-15 and ceria-zirconia support. Similar to other studies $[166,200]$, an increase in temperature had a negative effect on $\mathrm{CH}_{4}$ production, as at high temperatures RWGS reaction is well developed which contributes to high CO production. The authors stress that the positive effect of plasma application is only observed at temperatures below $220^{\circ} \mathrm{C}$. At higher reaction temperatures the reaction proceeds mainly through catalysis. In the experiments, when no external heating was applied (temp. of ca. $120-140^{\circ} \mathrm{C}$ ), $\mathrm{CO}_{2}$ conversions at the level of ca. $80 \%$ with $100 \% \mathrm{CH}_{4}$ selectivity were reached. Such high performance was explained by increased reactivity within catalyst pores via electrical discharges inside the pores and transfer of electrons between catalyst active sites. The authors underlined that since $\mathrm{CO}_{2}$ methanation in non-thermal plasma at low temperature is possible due to the flow of electrons, the process must be electrochemical and proposed reaction mechanism, which will be discussed in the next section (section 4.5). 
$\mathrm{Ni}$-loaded zeolite materials (USY zeolites with various $\mathrm{Si} / \mathrm{Al}$ ratio) were investigated in atmospheric pressure DBD reactor by Bacariza et al. [167]. Ni supported on commercial alumina was tested as well for comparison. $\mathrm{CO}_{2}$ conversion and $\mathrm{CH}_{4}$ selectivity increased for all tested catalysts with an increase of power input, which stays in line with other studies $[163,169,171]$ and may be explained via higher electron density. The performance of catalyst was dependent on 2 main factors: (i) dielectric constant and (ii) affinity to water. Catalysts with higher dielectric constant showed better performance due to the enhancement of the electric field caused by polarization of catalyst surface and accumulation of the charge on the surface which changes the composition of the plasma. Water, on the other hand, blocks reaction active sites, thus samples with low affinity to water will enhance the effect of plasma on the activity. Contrary to the study by Amouroux and Cavadias [201], who stated that plasma helps to remove water, the authors underlined that plasma is responsible for activation of active sites rather than removal of water molecules from active sites. Therefore, the hydrophobic role of catalyst plays a crucial role in the overall process.

The research performed on $\mathrm{CO}_{2}$ methanation in DBD plasma in the presence of $\mathrm{Ni}$-based catalysts (Table 9) showed that the effectiveness of the overall process is strongly pendent not only on the applied catalysts but also on operating conditions. Thus, although variety of different supports was tested in DBD plasma, their direct comparison is not possible.

\subsection{Mechanisms of plasma-catalytic $\mathrm{CO}_{2}$ methanation}

There are only a few reports proposing and discussing mechanisms of non-thermal plasma $\mathrm{CO}_{2}$ methanation. The main findings considering this topic are summarized below.

Amouroux and Cavadias [201] investigated $\mathrm{Ni} / \mathrm{SBA}-15 / \mathrm{Ce}_{0.9} \mathrm{Zr}_{0.1} \mathrm{O}_{2}$ catalyst in a DBD discharge and considered $\mathrm{CO}_{2}$ methanation as an electrochemical process. The used support $\mathrm{Ce}_{0.9} \mathrm{Zr}_{0.1} \mathrm{O}_{2}$ may be treated as an n-type semiconductor and thus is considered as a source of active sites for $\mathrm{CO}_{2}$ adsorption. Incompletely reduced $\mathrm{NiO}$, on the other hand, may be treated as $\mathrm{p}$-type semiconductor needed for $\mathrm{H}_{2}$ adsorption. These two types of active sites are forming a $\mathrm{p}-\mathrm{n}$ junction, which under a polarization may lead to a transfer of $\mathrm{H}^{+}$from $\mathrm{Ni} / \mathrm{NiO}$ to ceria-zirconia and $\mathrm{O}_{2}$ from ceria-zirconia to $\mathrm{Ni} / \mathrm{NiO}$. This could explain the very high activity observed for the tested catalyst at low temperature. Based on these considerations the authors proposed a mechanism of the $\mathrm{CO}_{2}$ methanation which included: (i) vibrational activation of $\mathrm{CO}_{2}$ and $\mathrm{H}_{2}$ in the gas phase into the catalyst pores by plasma electrons, (ii) redox processes due to the polarization of the catalyst by plasma and (iii) desorption of $\mathrm{H}_{2} \mathrm{O}$ molecules from the active sites. 
Azzolina-Jury and Thibault-Starzyk [181] proposed mechanism of $\mathrm{CO}_{2}$ methanation performed at low pressure using glow discharge plasma and Ni-USY catalyst with the aid of microsecond time-resolved FT-IR spectroscopy. The mechanism involves firstly activation of $\mathrm{CO}_{2}, \mathrm{H}_{2}$ and Ar molecules in the gas phase, leading to partial dissociation of $\mathrm{CO}_{2}$ to $\mathrm{CO}$. The remaining $\mathrm{CO}_{2}$ may be adsorbed on metallic nickel resulting in the formation of monodentate formates, which are further transformed to linear carbonyls under plasma. These linear carbonyls are further hydrogenated to form $\mathrm{CH}, \mathrm{CH}_{2}, \mathrm{CH}_{3}$ species and finally $\mathrm{CH}_{4}$.

$\mathrm{Co} / \mathrm{CeZrO}_{4}$ catalyst in DBD plasma was investigated by Parastaev et al. [184]. Temperature programmed plasma surface reactions with labelled ${ }^{13} \mathrm{CO}_{2}$ allowed to investigate the reaction mechanism. $\mathrm{CO}_{2}$ methanation occurs mainly through the conversion of gaseous $\mathrm{CO}_{2}$. Carbon dioxide is firstly converted to $\mathrm{CO}$ which is further adsorbed on Co particle and hydrogenated to form $\mathrm{CH}_{4}$. This part is consistant with the work of Azzolina-Jury and Thibault-Starzyk [181]. The adsorption of carbon dioxide on the catalyst surface and surface dissociation to $\mathrm{CO}$ is possible as well, however, the contribution of this reaction pathway is rather low. Tests with pre-adsorbed labelled $\mathrm{CO}_{2}$ showed that during plasma experiments, $\mathrm{CO}_{2}$ desorbs from the surface and undergoes dissociation to $\mathrm{CO}$ in the gas phase. The authors underlined that the mechanism of the reaction is not changed in the presence of plasma with respect to thermal catalysis. However, products of the plasma-catalytic process are strongly affected by chemical processes occurring in the plasma.

Recently Mikhail et al. [198] proposed mechanism of $\mathrm{CO}_{2}$ methanation in DBD plasma over $\mathrm{Ni} / \mathrm{CeZrO}_{4}$ catalyst using optical emission spectroscopy. Their study showed that the main role of DBD plasma is to produce $\mathrm{CO}$ and $\mathrm{H}$ species which can be adsorbed respectively on the ceria-zirconia support and metallic nickel crystallite. Further surface reactions result in the formation of $\mathrm{CH}_{\mathrm{x}}$ species and finally $\mathrm{CH}_{4}$. These findings stay in line with the mechanisms proposed by Azzolina-Jury and Thibault-Starzyk [181] and Parastaev et al. [184].

Another recent study performed by Dębek et al. [182,183] who investigated Ni-based catalyst supported on various metal oxides and with the application of low-pressure glow discharge plasma gave insights into mechanistic aspects of hybrid plasma-catalytic process. Their research revealed that plasma promotes creation of strong basic sites, associated with low coordinated oxygen species, on the surface of hydrotalcite-derived catalysts. The origin of that change may come from the electron surface bombardment resulting in the transformation of surface functional groups [182].It is important to underline, that this is only one factor that contributes to the synergetic effect between plasma and catalysis. In another study by the same authors [183], it was proven that in fact plasma changes surface basicity i.e. $\mathrm{CO}_{2}$ adsorption capacity as well as may influence on the oxidation state 
of surface nickel species. However, this effect was dependent on the type of metal oxide support, proving that support may influence reaction mechanism under plasma conditions.

It is important to underline that investigation of plasma-catalytic process mechanisms is not easy due to the co-dependency of catalytic and plasma properties and due to the abundance of reactions occurring in the plasma and on the catalyst surface. For these reasons, a new approach and most probably new techniques need to be developed to understand reaction mechanisms, such as operando microsecond resolved FT-IR spectroscopy [181] or temperature programmed plasma surface reactions with pre-adsorbed labelled carbon dioxide [184].

\section{Comparison of the performance of various $\mathrm{CO}_{2}$ methanation processes}

The presented review on catalyst for $\mathrm{CO}_{2}$ methanation showed that in thermal catalysis it is possible to obtain active and selective material at high reaction temperatures (above $250^{\circ} \mathrm{C}$ ). The main challenge considering $\mathrm{CO}_{2}$ methanation is therefore, to shift process temperature to lower values. For economic reasons, the catalysts most commonly applied to thermal $\mathrm{CO}_{2}$ methanation are based on nickel (section 2). Nickel species at low reaction temperatures may undergo sintering due to the formation of mobile carbonyls, which generates problem in terms of application of low reaction temperatures (below $250^{\circ} \mathrm{C}$ ). These problems may be overcome with the application of non-thermal plasma, which operates at close to room temperature. Moreover, it suppresses sintering of nickel and thus may be directly applied with nickel-based catalyst. On the other hand, it was proven that application of plasma alone (section 3) allows to convert $\mathrm{CO}_{2}$ to $\mathrm{CO}$ while $\mathrm{CH}_{4}$ production is very low. Although, the performance of plasma is greatly dependent on the type of non-thermal plasma used and reaction conditions, the low yield of the desired product make the processes unsuitable for methane production. Therefore, application of plasma-catalytic process is necessary to obtain high conversions of $\mathrm{CO}_{2}$ with high yields of $\mathrm{CH}_{4}$ production at low temperature. 

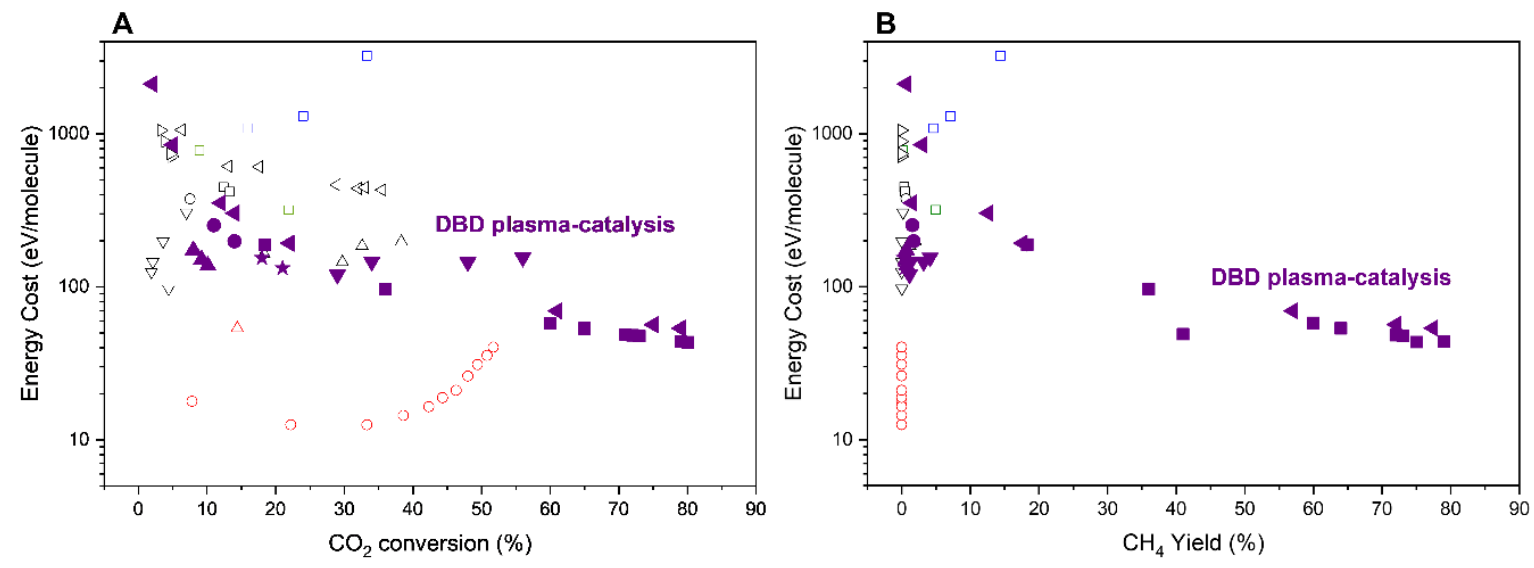

Blank symbols: plasma alone; Full symbols: plasma-catalysis

Fig. 9 Comparison of Energy costs for plasma $\mathrm{CO}_{2}$ hydrogenation vs. (A) $\mathrm{CO}_{2}$ conversion and (B) $\mathrm{CH}_{4} \mathrm{Yield}$ (gray symbols DBD: $\square$ [163], ○ [164], $\triangle$ [166], $\nabla$ [165], $\triangleleft[168], \triangleright$ [167]; blue symbols GD: $\square$ [177]; red symbols MW: $\circ[170], \triangle[171]$; green symbols RF: $\square[175]$ ) and plasma-catalysis $\mathrm{CO}_{2}$ hydrogenation (violet symbols DBD:

$$
\text { [205], • [163], } \Delta[164], \nabla[166],<[167], \star[195])
$$

In terms of energy costs, the application of catalyst is beneficial as well. Fig. 9 presents energy costs of $\mathrm{CO}_{2}$ conversion as a function of $\mathrm{CO}_{2}$ conversion and $\mathrm{CH}_{4}$ yield (calculated based on the methodology proposed by Snoeckx and Bogaerts [16] - see section 3.1) for various plasma types without the presence of a catalyst (grey, blue, red and green blank symbols) and for DBD plasmacatalytic process (full violet symbols). It may be clearly seen that combination of plasma process with catalysts shifts values to the bottom-right part of the graph, making process less energy consuming with higher $\mathrm{CO}_{2}$ conversions (comparison of grey and violet points, Fig. 9A). The importance of catalyst is even more clearly seen when the energy costs associated with $\mathrm{CH}_{4}$ production are compared (Fig. 9B) The industrial application of plasma-catalytic process would require to still improve energy cost, but it seems that it may be achieved in the future with the development of an appropriate catalyst. 


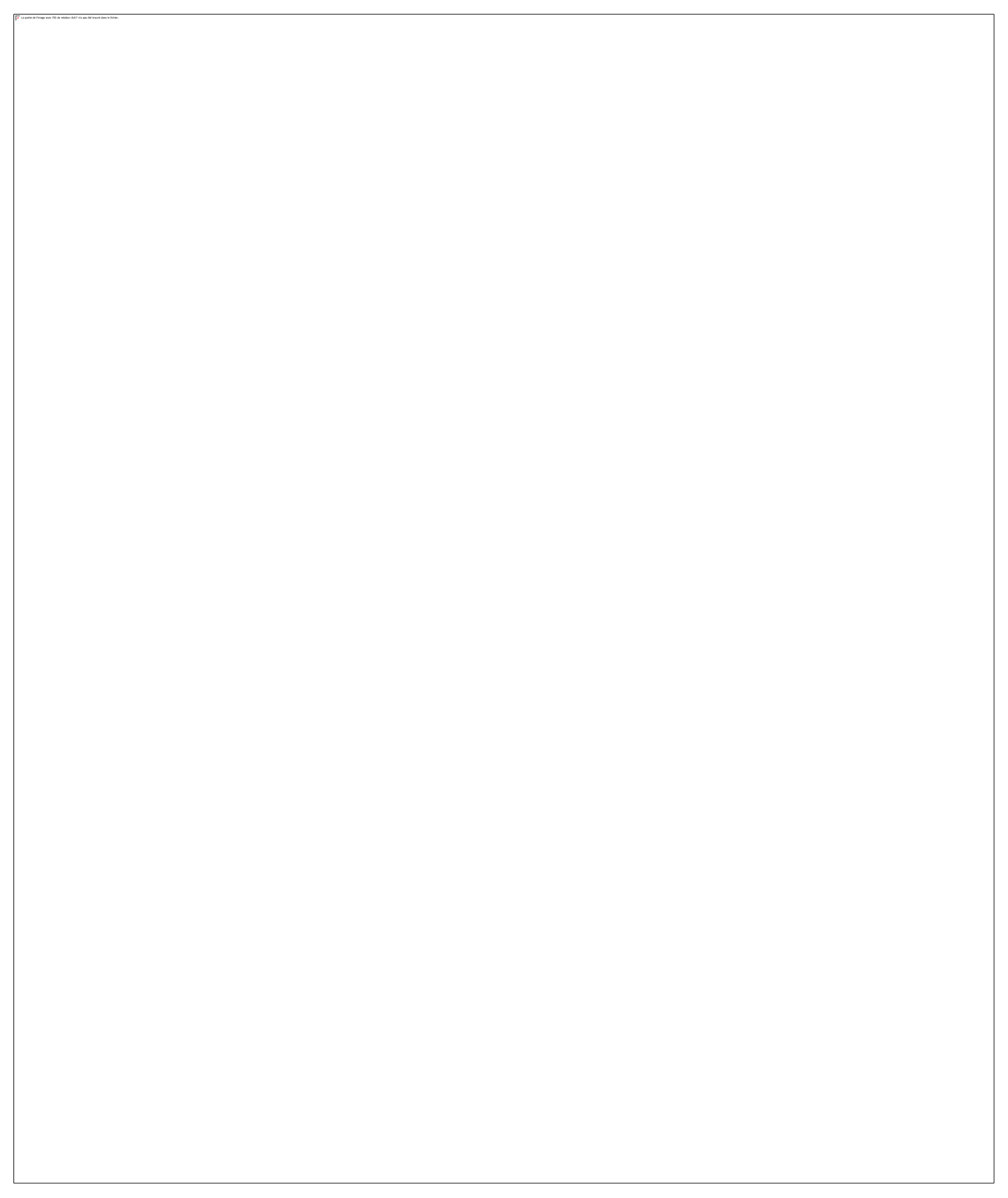

Fig. 10 Map of catalysts activity $(A) \mathrm{CO}_{2}$ conversion and $(B) \mathrm{CH}_{4}$ yield as a function of temperature in thermal and plasma-catalytic $\mathrm{CO}_{2}$ methanation: 1. $\mathrm{CuO} / \mathrm{ZnO} / \mathrm{Al}_{2} \mathrm{O}_{3}[163] ; 2$. $\mathrm{Cu} / \mathrm{Al}_{2} \mathrm{O}_{3}, 3 . \mathrm{Mn} / \mathrm{Al}_{2} \mathrm{O}_{3}[197] ;$ 4. $\mathrm{Ni} / \mathrm{Al}_{2} \mathrm{O}_{3}$ [166]; 5. Ni(Mg,Al)Ox, 6. Ni-Zr(Mg,Al)Ox [204]; 7. Ni/Ceo.1Zro.9O2, 8. Ni/Ceo.9Zro.1O2 [200]; 9. Ni/CeO2-ZrOz-red, $10 \mathrm{Ni} / \mathrm{CeO}_{2}-\mathrm{ZrO} 2-p l a s$ [205]; 11. Ni/CZ/SBA-15 [201]; 12. $\mathrm{Ru} / \mathrm{Al}_{2} \mathrm{O}_{3}$ [169]; 13. Ni/USY, 14. Ni/ZSM-11 [180];

15. $\mathrm{Ni} / \mathrm{Al}_{2} \mathrm{O}_{3}$, 16. $\mathrm{Ni} / \mathrm{USY}$, 17. $\mathrm{Ni}-\mathrm{Ce} / \mathrm{USY}$ [167]; 18. $\mathrm{Co} / \mathrm{CeZrO}_{4}[184]$; 19. $\mathrm{Pt} / \mathrm{Al}_{2} \mathrm{O}_{3}$, 20. $\mathrm{Cu} / \mathrm{Al}_{2} \mathrm{O}_{3}$ [195]; 21. $\mathrm{Pd} / \mathrm{SiO}_{2}$, 22. $\mathrm{Pd}-\mathrm{Ni} / \mathrm{SiO}_{2}[72] ;$ 23. $28 \mathrm{Ni} / \mathrm{Al}_{2} \mathrm{O}_{3}, 24.55 \mathrm{Ni} / \mathrm{Al}_{2} \mathrm{O}_{3}[131,132] ;$ 25. $\mathrm{Ni} / \mathrm{Al}_{2} \mathrm{O}_{3}[115] ;$ 26. $\mathrm{NiAlO} x-1$, 27. $\mathrm{NiAlO}_{x}-2$ [99]; 28. $\mathrm{Ni} / \mathrm{MgAl}_{2} \mathrm{O}_{4}$ [101]; 29. Ni/TiO 2 [189]; 30. Ni/SBA-15, 31. Ni-Ce/SBA-15 [105];

32. $\mathrm{Ni} /$ bentonite, 33. $\mathrm{Ni}-\mathrm{V}_{2} \mathrm{O}_{5} /$ bentonite [109]; 34. $\mathrm{Ni} / \mathrm{Al}_{2} \mathrm{O}_{3}, 35 . \mathrm{Ni} / \mathrm{Al}_{2} \mathrm{O}_{3}-\mathrm{TiO}_{2}-\mathrm{CeO}_{2}-\mathrm{ZrO}_{2}[110]$, 36. $\mathrm{Co} / \mathrm{Al}_{2} \mathrm{O}_{3}$, 37. $\mathrm{Co} / \mathrm{TiO}_{2}$, 38. $\mathrm{Co} / \mathrm{CeO}_{2}$, 39. $\mathrm{Co} / \mathrm{ZrO}_{2}$ [85]; 40. $\mathrm{Co} / \mathrm{SiO}_{2}$, 41. $\mathrm{Co}-\mathrm{Pd} / \mathrm{SiO}_{2}$, 42. $\mathrm{Co}-\mathrm{K} / \mathrm{SiO}_{2}[84] ;$;3. $\mathrm{Fe} / \mathrm{SiO}$, 44. $\mathrm{Fe}-$ $\mathrm{Cu} / \mathrm{SiO}_{2}$, 45. $\mathrm{Fe}-\mathrm{Ag} / \mathrm{SiO}_{2}$ [91]; 46. \& 47. \& 48. Fe-oxides [93]; 49. $\mathrm{Ni} / \mathrm{CeO}_{2}-\mathrm{ZrO}_{2}$ [104]; 50. $\mathrm{Ni}-\mathrm{La}(\mathrm{Mg}, \mathrm{Al}) \mathrm{O}_{x}$ [146] 
Another important factor improving energy costs associated with the operation of $\mathrm{CO}_{2}$ methanation plasma-catalytic unit is the ease of switching on and off plasma reactor with respect to thermal reactors. This is especially important for the energy storage systems using surplus of energy for powering $\mathrm{CO}_{2}$ methanation or $\mathrm{H}_{2}$ production from water electrolysis.

Fig. 10 presents the performance of catalysts (given as $\mathrm{CO}_{2}$ conversion and $\mathrm{CH}_{4}$ yield) for thermal catalysis and plasma-catalytic processes. Map of catalytic activity presented in such a way does not allow to directly compare materials presented on the graph but allows to show general trends observed. It may be clearly seen, that majority of research concerning catalytic and plasma-catalytic process concerns $\mathrm{Ni}$-based materials. It is possible to shift temperature of the process to lower values $\left(100-200^{\circ} \mathrm{C}\right)$ with the application of plasma and still obtain results (i.e. production of methane) at the same level as in case of catalytic processes performed at $250-400^{\circ} \mathrm{C}$. This clearly shows great potential for plasma-catalysis. What is more, it seems that the requirements for catalytic material, to some extent, are the same for both types of process. As it is clearly seen, that only in case of nickel and cobalt-based catalysts in the plasma-catalytic process it is possible to obtain high $\mathrm{CO}_{2}$ conversions and $\mathrm{CH}_{4}$ productions. On the other hand, materials which are not typically considered active in thermal catalysis for $\mathrm{CO}_{2}$ methanation are showing activity in the presence of plasma. However, it is at a level of the plasma performance without catalyst (see section 3.2), thus this effect may be associated only with the gas phase reactions in plasma, while improved selectivity in their presence may be an effect of change of plasma parameters in the presence of various materials.

The most studied type of plasma for plasma-catalytic $\mathrm{CO}_{2}$ methanation is dielectric barrier-discharge, as it can operate at atmospheric pressure and at much lower temperatures than thermal catalysis. For such systems, the most studied materials are nickel-based catalysts, which may be explained by their wide application in thermal catalysis. Although existing literature explains, to some extent, catalytic effects in plasma performance and the role of catalyst, it is still lacking much research. Taking into account that studies on the plasma catalytic process of $\mathrm{CO}_{2}$ methanation may be considered a new area of research (most publications considering the topic were published within last 4-5 years) the lack of wide and complete study on the topic is understandable.

\section{Conclusions}

Basing on the presented research the guidelines and directions were proposed in which development of a catalyst for plasma-catalytic $\mathrm{CO}_{2}$ methanation should develop:

- Role of the active metal. Most research is reported on nickel-based materials. The study in which activity of various metals would be compared is missing. This should be performed 
especially for transition metals, such as iron, cobalt, copper, nickel. According to Oshima et al. [196] activity in $\mathrm{CO}_{2}$ hydrogenation is dependent mostly on the plasma parameters rather than nature of the catalyst, thus maybe it is possible to activate for instance Fe-based materials, which are much cheaper and more environmentally friendly than nickel-based catalysts.

- The question of catalyst activation should be studied in more details. Research by Benrabbah et al. [205] showed that catalyst activation in plasma or thermal reduction in $\mathrm{H}_{2}$ may influence its performance. On the other hand, Amouroux and Cavadias [201] reported that incomplete reduction of $\mathrm{NiO}$ is necessary for the effective production of $\mathrm{CH}_{4}$. In some reports, the activation procedure is not discussed at all. Considering that the presence of reduced metal, its dispersion and particle size are the function of catalyst activity, more attention should be paid to the activation/reduction procedure. The optimization of that process may allow tailoring activity and selectivity of the process.

- Comparison of various supports is missing as well. On the one hand, research on mechanisms of plasma catalytic process showed that reaction proceeds mainly on reduced metal and in the gas phase and is independent of support $[181,184]$. However, one needs to keep in mind, that supports differ in e.g. dielectric constant (which affects plasma parameters) or affinity to water (water may block active sites for reaction) and thus they role in plasma-catalytic performance cannot be excluded. The comparison of various simple oxide supports would be a worthy addition to the topic, as these are well-defined materials, and more importantly, they have much cheaper costs of production with respect to complex systems as zeolites or mesoporous/mesostructured materials.

- Physical properties of catalyst and reactor design need to be considered. It is reported in the literature that plasma performance in various $\mathrm{CO}_{2}$ valorisation processes depends, among others, on the grain size and shape of catalyst, rector design etc $[25,27,158,159]$. Currently, discussion on these parameters is limited. Moreover, maybe the catalyst design should be reconsidered e.g. catalyst present in the form of electrodes or cover material of electrodes.

- One of the biggest advantages of plasma processes is its ability to quickly switching it on and off, which makes it flexible and adaptable to currently existing needs. However, studies on long-term exposure of the catalyst to plasma are missing. The overheating of catalyst bed [184] or reorganization of nickel species [191] were reported, proving that plasma influences properties of the catalyst. Long-term studies are hence necessary, before implementation of plasma-catalytic $\mathrm{CO}_{2}$ methanation on a larger scale. 
- The presented study showed that the plasma-catalytic $\mathrm{CO}_{2}$ methanation has a great potential of industrial application in the future thanks to the high efficiency of the process resulting from the synergetic effects between plasma and catalysis. Plasma-based chemical reactions may become of great industrial importance in the future. The presented study as well as other literature analysis $[16,26]$ underline that plasma-based technologies may already be competitive for conventional technologies. However, still much research is needed, especially fundamental studies concerning plasma-catalyst and their interactions. This will allow to increase yield of desired products (in presented case methane) and thus improve energy efficiency of the process.

Finally, it is important to underline that in terms of any plasma-catalytic process, complex surface and gas-phase chemistry correlated strongly to physical properties of plasma and catalyst are applied. Explanation of mechanisms occurring in such complex systems is therefore challenging and will probably require the development of new approaches and techniques. For these reasons, it seems that studying plasma-catalytic processes with the application of complex catalytic systems simply overcomplicates the process. Thus, simplifying catalyst composition and design may be beneficial for understanding plasma-catalytic $\mathrm{CO}_{2}$ hydrogenation to methane.

\section{Acknowledgements}

The authors acknowledge the Normandy council for the financial support to RIN $\mathrm{CO}_{2}$ VIRIDIS project. A special thanks to Dr F. Thibault-Starzyk for the stimulating discussions 


\section{References}

[1] S. Rönsch, J. Schneider, S. Matthischke, M. Schlüter, M. Götz, J. Lefebvre, P. Prabhakaran, S. Bajohr, Review on methanation - From fundamentals to current projects, Fuel. 166 (2016) 276296. doi:10.1016/j.fuel.2015.10.111.

[2] K. Ghaib, F.-Z. Ben-Fares, Power-to-Methane: A state-of-the-art review, Renew. Sustain. Energy Rev. 81 (2018) 433-446. doi:https://doi.org/10.1016/j.rser.2017.08.004.

[3] M. Huš, D. Kopač, N.S. Štefančič, D.L. Jurković, V.D.B.C. Dasireddy, B. Likozar, Unravelling the mechanisms of $\mathrm{CO} 2$ hydrogenation to methanol on $\mathrm{Cu}$-based catalysts using first-principles multiscale modelling and experiments, Catal. Sci. Technol. 7 (2017) 5900-5913. doi:10.1039/C7CY01659J.

[4] G. Leonzio, State of art and perspectives about the production of methanol, dimethyl ether and syngas by carbon dioxide hydrogenation, J. CO2 Util. 27 (2018) 326-354. doi:10.1016/j.jcou.2018.08.005.

[5] D.L. Jurković, A. Pohar, V.D.B.C. Dasireddy, B. Likozar, Effect of Copper-based Catalyst Support on Reverse Water-Gas Shift Reaction (RWGS) Activity for CO2 Reduction, Chem. Eng. Technol. 40 (2017) 973-980. doi:10.1002/ceat.201600594.

[6] N.A.K. Aramouni, J.G. Touma, B.A. Tarboush, J. Zeaiter, M.N. Ahmad, Catalyst design for dry reforming of methane: Analysis review, Renew. Sustain. Energy Rev. 82 (2018) 2570-2585. doi:10.1016/j.rser.2017.09.076.

[7] R. Dębek, M. Motak, T. Grzybek, M.E. Galvez, P. Da Costa, A Short Review on the Catalytic Activity of Hydrotalcite-Derived Materials for Dry Reforming of Methane, Catalysts. 7 (2017) 32. doi:10.3390/catal7010032.

[8] D. Mukherjee, S.-E. Park, B.M. Reddy, CO2 as a soft oxidant for oxidative dehydrogenation reaction: An eco benign process for industry, J. CO2 Util. 16 (2016) 301-312. doi:10.1016/j.jcou.2016.08.005.

[9] D. Chakrabarti, A. de Klerk, V. Prasad, M.K. Gnanamani, W.D. Shafer, G. Jacobs, D.E. Sparks, B.H. Davis, Conversion of $\mathrm{CO} 2$ over a Co-Based Fischer-Tropsch Catalyst, Ind. Eng. Chem. Res. 54 (2015) 1189-1196. doi:10.1021/ie503496m.

[10] N. Homs, J. Toyir, P.R. de la Piscina, Chapter 1 - Catalytic Processes for Activation of CO2, in: S.L. Suib (Ed.), New Future Dev. Catal., Elsevier, Amsterdam, 2013: pp. 1-26. doi:10.1016/B978-0444-53882-6.00001-2.

[11] A.-H. Liu, J. Gao, L.-N. He, Chapter 4 - Catalytic Activation and Conversion of Carbon Dioxide into Fuels/Value-Added Chemicals Through CC Bond Formation, in: S.L. Suib (Ed.), New Future Dev. Catal., Elsevier, Amsterdam, 2013: pp. 81-147. doi:10.1016/B978-0-444-53882-6.00005-X.

[12] F.D. Meylan, F.-P. Piguet, S. Erkman, Power-to-gas through $\mathrm{CO} 2$ methanation: Assessment of the carbon balance regarding EU directives, J. Energy Storage. 11 (2017) 16-24. doi:10.1016/j.est.2016.12.005.

[13] M. Thema, F. Bauer, M. Sterner, Power-to-Gas: Electrolysis and methanation status review, Renew. Sustain. Energy Rev. 112 (2019) 775-787. doi:10.1016/j.rser.2019.06.030.

[14] C. Wulf, J. Linßen, P. Zapp, Review of Power-to-Gas Projects in Europe, Energy Procedia. 155 (2018) 367-378. doi:10.1016/j.egypro.2018.11.041.

[15] E.C. Neyts, K. (Ken) Ostrikov, M.K. Sunkara, A. Bogaerts, Plasma Catalysis: Synergistic Effects at the Nanoscale, Chem. Rev. 115 (2015) 13408-13446. doi:10.1021/acs.chemrev.5b00362.

[16] R. Snoeckx, A. Bogaerts, Plasma technology - a novel solution for $\mathrm{CO} 2$ conversion?, Chem. Soc. Rev. 46 (2017) 5805-5863. doi:10.1039/C6CS00066E.

[17] W.-C. Chung, M.-B. Chang, Review of catalysis and plasma performance on dry reforming of $\mathrm{CH} 4$ and possible synergistic effects, Renew. Sustain. Energy Rev. 62 (2016) 13-31. doi:10.1016/j.rser.2016.04.007. 
[18] M. Scapinello, E. Delikonstantis, G.D. Stefanidis, The panorama of plasma-assisted non-oxidative methane reforming, Chem. Eng. Process. Process Intensif. 117 (2017) 120-140. doi:10.1016/j.cep.2017.03.024.

[19] T. Nozaki, K. Okazaki, Non-thermal plasma catalysis of methane: Principles, energy efficiency, and applications, Catal. Today. 211 (2013) 29-38. doi:10.1016/j.cattod.2013.04.002.

[20] A. Bogaerts, T. Kozák, K. van Laer, R. Snoeckx, Plasma-based conversion of CO2: current status and future challenges, Faraday Discuss. 183 (2015) 217-232. doi:10.1039/C5FD00053J.

[21] K.-H. Chung, S. Jeong, B.-J. Kim, J.-S. Kim, Y.-K. Park, S.-C. Jung, Development of hydrogen production by liquid phase plasma process of water with $\mathrm{NiTiO2/carbon} \mathrm{nanotube}$ photocatalysts, Int. J. Hydrog. Energy. 43 (2018) 5873-5880. doi:10.1016/j.ijhydene.2017.09.065.

[22] M. Boutonnet Kizling, S.G. Järås, A review of the use of plasma techniques in catalyst preparation and catalytic reactions, Appl. Catal. Gen. 147 (1996) 1-21. doi:10.1016/S0926-860X(96)00215-3.

[23] T. Witvrouwen, S. Paulussen, B. Sels, The Use of Non-Equilibrium Plasmas for the Synthesis of Heterogeneous Catalysts, Plasma Process. Polym. 9 (2012) 750-760. doi:10.1002/ppap.201200004.

[24] Z. Wang, Y. Zhang, E.C. Neyts, X. Cao, X. Zhang, B.W.-L. Jang, C. Liu, Catalyst Preparation with Plasmas: How Does It Work?, ACS Catal. (2018) 2093-2110. doi:10.1021/acscatal.7b03723.

[25] I. Adamovich, S.D. Baalrud, A. Bogaerts, P.J. Bruggeman, M. Cappelli, V. Colombo, U. Czarnetzki, U. Ebert, J.G. Eden, P. Favia, D.B. Graves, S. Hamaguchi, G. Hieftje, M. Hori, I.D. Kaganovich, U. Kortshagen, M.J. Kushner, N.J. Mason, S. Mazouffre, S.M. Thagard, H.-R. Metelmann, A. Mizuno, E. Moreau, A.B. Murphy, B.A. Niemira, G.S. Oehrlein, Z.L. Petrovic, L.C. Pitchford, Y.-K. Pu, S. Rauf, O. Sakai, S. Samukawa, S. Starikovskaia, J. Tennyson, K Terashima, M.M. Turner, M.C.M. van de Sanden, A. Vardelle, The 2017 Plasma Roadmap: Low temperature plasma science and technology, J. Phys. Appl. Phys. 50 (2017) 323001. doi:10.1088/1361-6463/aa76f5.

[26] B. Ashford, X. Tu, Non-thermal plasma technology for the conversion of CO2, Curr. Opin. Green Sustain. Chem. 3 (2017) 45-49. doi:10.1016/j.cogsc.2016.12.001.

[27] A. Bogaerts, E.C. Neyts, Plasma Technology: An Emerging Technology for Energy Storage, ACS Energy Lett. 3 (2018) 1013-1027. doi:10.1021/acsenergylett.8b00184.

[28] J.C. Whitehead, Plasma-catalysis: the known knowns, the known unknowns and the unknown unknowns, J. Phys. Appl. Phys. 49 (2016) 243001. doi:10.1088/0022-3727/49/24/243001.

[29] H. Puliyalil, D.L. Jurković, V.D.B.C. Dasireddy, B. Likozar, A review of plasma-assisted catalytic conversion of gaseous carbon dioxide and methane into value-added platform chemicals and fuels, RSC Adv. 8 (2018) 27481-27508. doi:10.1039/C8RA03146K.

[30] J. Amouroux, S. Cavadias, A. Doubla, Carbon Dioxide reduction by non-equilibrium electrocatalysis plasma reactor, IOP Conf. Ser. Mater. Sci. Eng. 19 (2011) 012005. doi:10.1088/1757-899X/19/1/012005.

[31] A. Lebouvier, S.A. Iwarere, P. d'Argenlieu, D. Ramjugernath, L. Fulcheri, Assessment of Carbon Dioxide Dissociation as a New Route for Syngas Production: A Comparative Review and Potential of Plasma-Based Technologies, Energy Fuels. 27 (2013) 2712-2722. doi:10.1021/ef301991d.

[32] E.C. Neyts, A. Bogaerts, Understanding plasma catalysis through modelling and simulation-a review, J. Phys. Appl. Phys. 47 (2014) 224010. doi:10.1088/0022-3727/47/22/224010.

[33] H.-H. Kim, Y. Teramoto, A. Ogata, H. Takagi, T. Nanba, Plasma Catalysis for Environmental Treatment and Energy Applications, Plasma Chem. Plasma Process. 36 (2016) 45-72. doi:10.1007/s11090-015-9652-7.

[34] E. Baraj, S. Vagaský, T. Hlinčík, K. Ciahotný, V. Tekáč, Reaction mechanisms of carbon dioxide methanation, Chem. Pap. 70 (2016) 395-403. doi:10.1515/chempap-2015-0216.

[35] P. Frontera, A. Macario, M. Ferraro, P. Antonucci, Supported Catalysts for CO2 Methanation: A Review, Catalysts. 7 (2017) 59. doi:10.3390/catal7020059.

[36] K. Ghaib, K. Nitz, F.-Z. Ben-Fares, Chemical Methanation of CO2: A Review, ChemBioEng Rev. 3 (2016) 266-275. doi:10.1002/cben.201600022.

[37] I. Kuznecova, J. Gusca, Property based ranking of $\mathrm{CO}$ and $\mathrm{CO} 2$ methanation catalysts, Energy Procedia. 128 (2017) 255-260. doi:10.1016/j.egypro.2017.09.068. 
[38] M. Younas, L. Loong Kong, M.J.K. Bashir, H. Nadeem, A. Shehzad, S. Sethupathi, Recent Advancements, Fundamental Challenges, and Opportunities in Catalytic Methanation of $\mathrm{CO} 2$, Energy Fuels. 30 (2016) 8815-8831. doi:10.1021/acs.energyfuels.6b01723.

[39] K. Stangeland, D. Kalai, H. Li, Z. Yu, CO2 Methanation: The Effect of Catalysts and Reaction Conditions, Energy Procedia. 105 (2017) 2022-2027. doi:10.1016/j.egypro.2017.03.577.

[40] X. Su, J. Xu, B. Liang, H. Duan, B. Hou, Y. Huang, Catalytic carbon dioxide hydrogenation to methane: A review of recent studies, J. Energy Chem. 25 (2016) 553-565. doi:10.1016/j.jechem.2016.03.009.

[41] A. Karelovic, P. Ruiz, $\mathrm{CO} 2$ hydrogenation at low temperature over Rh/ $\mathrm{Y}$-Al2O3 catalysts: Effect of the metal particle size on catalytic performances and reaction mechanism, Appl. Catal. B Environ. 113-114 (2012) 237-249. doi:10.1016/j.apcatb.2011.11.043.

[42] A. Karelovic, P. Ruiz, Mechanistic study of low temperature $\mathrm{CO} 2$ methanation over Rh/TiO2 catalysts, J. Catal. 301 (2013) 141-153. doi:10.1016/j.jcat.2013.02.009.

[43] M. Jacquemin, A. Beuls, P. Ruiz, Catalytic production of methane from $\mathrm{CO} 2$ and $\mathrm{H} 2$ at low temperature: Insight on the reaction mechanism, Catal. Today. 157 (2010) 462-466. doi:10.1016/j.cattod.2010.06.016.

[44] A. Karelovic, P. Ruiz, Improving the Hydrogenation Function of $\mathrm{Pd} / \mathrm{Y}$-Al2O3 Catalyst by $\mathrm{Rh} / \mathrm{Y}$ Al2O3 Addition in CO2 Methanation at Low Temperature, ACS Catal. 3 (2013) 2799-2812. doi:10.1021/cs400576w.

[45] A. Kim, C. Sanchez, G. Patriarche, O. Ersen, S. Moldovan, A. Wisnet, C. Sassoye, D.P. Debecker, Selective $\mathrm{CO} 2$ methanation on $\mathrm{Ru} / \mathrm{TiO} 2$ catalysts: unravelling the decisive role of the $\mathrm{TiO} 2$ support crystal structure, Catal. Sci. Technol. 6 (2016) 8117-8128. doi:10.1039/C6CY01677D.

[46] J.A.H. Dreyer, P. Li, L. Zhang, G.K. Beh, R. Zhang, P.H.-L. Sit, W.Y. Teoh, Influence of the oxide support reducibility on the $\mathrm{CO} 2$ methanation over Ru-based catalysts, Appl. Catal. B Environ. 219 (2017) 715-726. doi:10.1016/j.apcatb.2017.08.011.

[47] M. Mihet, M.D. Lazar, Methanation of $\mathrm{CO} 2$ on Ni/ $/$-Al2O3: Influence of Pt, Pd or Rh promotion, Catal. Today. (2016). doi:10.1016/j.cattod.2016.12.001.

[48] B. Mutz, H.W.P. Carvalho, S. Mangold, W. Kleist, J.-D. Grunwaldt, Methanation of CO2: Structural response of a Ni-based catalyst under fluctuating reaction conditions unraveled by operando spectroscopy, J. Catal. 327 (2015) 48-53. doi:10.1016/j.jcat.2015.04.006.

[49] P.A.U. Aldana, F. Ocampo, K. Kobl, B. Louis, F. Thibault-Starzyk, M. Daturi, P. Bazin, S. Thomas, A.C. Roger, Catalytic $\mathrm{CO} 2$ valorization into $\mathrm{CH} 4$ on Ni-based ceria-zirconia. Reaction mechanism by operando IR spectroscopy, Catal. Today. 215 (2013) 201-207. doi:10.1016/j.cattod.2013.02.019.

[50] H.H. Shin, L. Lu, Z. Yang, C.J. Kiely, S. McIntosh, Cobalt Catalysts Decorated with Platinum Atoms Supported on Barium Zirconate Provide Enhanced Activity and Selectivity for $\mathrm{CO} 2$ Methanation, ACS Catal. 6 (2016) 2811-2818. doi:10.1021/acscatal.6b00005.

[51] European Commission, Study on the review of the list of Critical Raw Materials. Critical Raw Materials Factsheets, (2017).

[52] European Commission, Study on the review of the list of Critical Raw Materials. Non-critical Raw Materials Factsheets, (2017).

[53] C. Swalus, M. Jacquemin, C. Poleunis, P. Bertrand, P. Ruiz, CO2 methanation on Rh/ $\mathrm{Y}-\mathrm{Al} 2 \mathrm{O} 3$ catalyst at low temperature: "In situ" supply of hydrogen by Ni/activated carbon catalyst, Appl. Catal. B Environ. 125 (2012) 41-50. doi:10.1016/j.apcatb.2012.05.019.

[54] A. Beuls, C. Swalus, M. Jacquemin, G. Heyen, A. Karelovic, P. Ruiz, Methanation of CO2: Further insight into the mechanism over Rh/ $\mathrm{Y}$-Al2O3 catalyst, Appl. Catal. B Environ. 113-114 (2012) 210. doi:10.1016/j.apcatb.2011.02.033.

[55] F. Solymosi, A. Erdöhelyi, T. Bánsági, Methanation of $\mathrm{CO} 2$ on supported rhodium catalyst, J. Catal. 68 (1981) 371-382. doi:10.1016/0021-9517(81)90106-8.

[56] A. Trovarelli, C. Deleitenburg, G. Dolcetti, J.L. Lorca, CO2 Methanation Under Transient and Steady-State Conditions over Rh/CeO2 and CeO2-Promoted Rh/SiO2: The Role of Surface and Bulk Ceria, J. Catal. 151 (1995) 111-124. doi:10.1006/jcat.1995.1014. 
[57] C. Deleitenburg, A. Trovarelli, Metal-Support Interactions in Rh/CeO2, Rh/TiO2, and Rh/Nb2O5 Catalysts as Inferred from CO2 Methanation Activity, J. Catal. 156 (1995) 171-174. doi:10.1006/jcat.1995.1244.

[58] G. Garbarino, D. Bellotti, P. Riani, L. Magistri, G. Busca, Methanation of carbon dioxide on $\mathrm{Ru} / \mathrm{Al} 2 \mathrm{O} 3$ and Ni/Al2O3 catalysts at atmospheric pressure: Catalysts activation, behaviour and stability, Int. J. Hydrog. Energy. 40 (2015) 9171-9182. doi:10.1016/j.ijhydene.2015.05.059.

[59] J. Zheng, C. Wang, W. Chu, Y. Zhou, K. Köhler, CO2 Methanation over Supported Ru/Al2O3 Catalysts: Mechanistic Studies by In situ Infrared Spectroscopy, ChemistrySelect. 1 (2016) 31973203. doi:10.1002/slct.201600651.

[60] T. Abe, M. Tanizawa, K. Watanabe, A. Taguchi, $\mathrm{CO} 2$ methanation property of Ru nanoparticleloaded TiO2 prepared by a polygonal barrel-sputtering method, Energy Environ. Sci. 2 (2009) 315-321. doi:10.1039/B817740F.

[61] J. Xu, X. Su, H. Duan, B. Hou, Q. Lin, X. Liu, X. Pan, G. Pei, H. Geng, Y. Huang, T. Zhang, Influence of pretreatment temperature on catalytic performance of rutile TiO2-supported ruthenium catalyst in CO2 methanation, J. Catal. 333 (2016) 227-237. doi:10.1016/j.jcat.2015.10.025.

[62]Z. Kowalczyk, K. Stołecki, W. Raróg-Pilecka, E. Miśkiewicz, E. Wilczkowska, Z. Karpiński, Supported ruthenium catalysts for selective methanation of carbon oxides at very low $\mathrm{COx} / \mathrm{H} 2$ ratios, Appl. Catal. Gen. 342 (2008) 35-39. doi:10.1016/j.apcata.2007.12.040.

[63] F. Wang, S. He, H. Chen, B. Wang, L. Zheng, M. Wei, D.G. Evans, X. Duan, Active Site Dependent Reaction Mechanism over Ru/CeO2 Catalyst toward CO2 Methanation, J. Am. Chem. Soc. 138 (2016) 6298-6305. doi:10.1021/jacs.6b02762.

[64] S. Tada, O.J. Ochieng, R. Kikuchi, T. Haneda, H. Kameyama, Promotion of $\mathrm{CO} 2$ methanation activity and $\mathrm{CH} 4$ selectivity at low temperatures over $\mathrm{Ru} / \mathrm{CeO} 2 / \mathrm{Al} 2 \mathrm{O} 3$ catalysts, Int. J. Hydrog. Energy. 39 (2014) 10090-10100. doi:10.1016/j.ijhydene.2014.04.133.

[65] S. Scirè, C. Crisafulli, R. Maggiore, S. Minicò, S. Galvagno, Influence of the support on CO<Subscript $>2</$ Subscript $>$ methanation over Ru catalysts: an FT-IR study, Catal. Lett. 51 (1998) 41-45. doi:10.1023/A:1019028816154.

[66] G. Garbarino, D. Bellotti, E. Finocchio, L. Magistri, G. Busca, Methanation of carbon dioxide on Ru/Al2O3: Catalytic activity and infrared study, Catal. Today. 277 (2016) 21-28. doi:10.1016/j.cattod.2015.12.010.

[67] L. Falbo, M. Martinelli, C.G. Visconti, L. Lietti, C. Bassano, P. Deiana, Kinetics of CO2 methanation on a Ru-based catalyst at process conditions relevant for Power-to-Gas applications, Appl. Catal. B Environ. 225 (2018) 354-363. doi:10.1016/j.apcatb.2017.11.066.

[68] J. Xu, Q. Lin, X. Su, H. Duan, H. Geng, Y. Huang, CO2 methanation over TiO2-Al2O3 binary oxides supported Ru catalysts, Chin. J. Chem. Eng. 24 (2016) 140-145. doi:10.1016/j.cjche.2015.07.002.

[69] A. Petala, P. Panagiotopoulou, Methanation of $\mathrm{CO} 2$ over alkali-promoted Ru/TiO2 catalysts: I. Effect of alkali additives on catalytic activity and selectivity, Appl. Catal. B Environ. 224 (2018) 919-927. doi:10.1016/j.apcatb.2017.11.048.

[70] K.R. Thampi, J. Kiwi, M. Grätzel, Methanation and photo-methanation of carbon dioxide at room temperature and atmospheric pressure, Nature. 327 (1987) 506-508. doi:10.1038/327506a0.

[71] A. Kim, D.P. Debecker, F. Devred, V. Dubois, C. Sanchez, C. Sassoye, CO2 methanation on Ru/TiO2 catalysts: On the effect of mixing anatase and rutile TiO2 supports, Appl. Catal. B Environ. 220 (2018) 615-625. doi:10.1016/j.apcatb.2017.08.058.

[72] J.-N. Park, E.W. McFarland, A highly dispersed Pd-Mg/SiO2 catalyst active for methanation of CO2, J. Catal. 266 (2009) 92-97. doi:10.1016/j.jcat.2009.05.018.

[73] P. Panagiotopoulou, Hydrogenation of $\mathrm{CO} 2$ over supported noble metal catalysts, Appl. Catal. Gen. 542 (2017) 63-70. doi:10.1016/j.apcata.2017.05.026.

[74] H.Y. Kim, H.M. Lee, J.-N. Park, Bifunctional Mechanism of CO2 Methanation on Pd-MgO/SiO2 Catalyst: Independent Roles of MgO and Pd on CO2 Methanation, J. Phys. Chem. C. 114 (2010) 7128-7131. doi:10.1021/jp100938v. 
[75] N. Rui, Z. Wang, K. Sun, J. Ye, Q. Ge, C. Liu, CO2 hydrogenation to methanol over Pd/In2O3: effects of Pd and oxygen vacancy, Appl. Catal. B Environ. 218 (2017) 488-497. doi:https://doi.org/10.1016/j.apcatb.2017.06.069.

[76] V. Lebarbier, R. Dagle, A. Datye, Y. Wang, The effect of PdZn particle size on reverse-water-gasshift reaction, Appl. Catal. Gen. 379 (2010) 3-6. doi:https://doi.org/10.1016/j.apcata.2010.02.008.

[77] H. Bahruji, M. Bowker, G. Hutchings, N. Dimitratos, P. Wells, E. Gibson, W. Jones, C. Brookes, D. Morgan, G. Lalev, Pd/ZnO catalysts for direct $\mathrm{CO} 2$ hydrogenation to methanol, J. Catal. 343 (2016) 133-146. doi:https://doi.org/10.1016/j.jcat.2016.03.017.

[78] A. Erdöhelyi, M. Pásztor, F. Solymosi, Catalytic hydrogenation of $\mathrm{CO} 2$ over supported palladium, J. Catal. 98 (1986) 166-177. doi:10.1016/0021-9517(86)90306-4.

[79] E. Rytter, $\varnothing$. Borg, N.E. Tsakoumis, A. Holmen, Water as key to activity and selectivity in Co Fischer-Tropsch synthesis: $\gamma$-alumina based structure-performance relationships, J. Catal. 365 (2018) 334-343. doi:https://doi.org/10.1016/j.jcat.2018.07.003.

[80] W. Chen, T. Lin, Y. Dai, Y. An, F. Yu, L. Zhong, S. Li, Y. Sun, Recent advances in the investigation of nanoeffects of Fischer-Tropsch catalysts, Catal. Today. 311 (2018) 8-22. doi:https://doi.org/10.1016/j.cattod.2017.09.019.

[81] R.W. Dorner, D.R. Hardy, F.W. Williams, H.D. Willauer, Heterogeneous catalytic CO2 conversion to value-added hydrocarbons, Energy Environ. Sci. 3 (2010) 884-890. doi:10.1039/C001514H.

[82] W. Li, A. Zhang, X. Jiang, C. Chen, Z. Liu, C. Song, X. Guo, Low Temperature CO2 Methanation: ZIF67-Derived Co-Based Porous Carbon Catalysts with Controlled Crystal Morphology and Size, ACS Sustain. Chem. Eng. 5 (2017) 7824-7831. doi:10.1021/acssuschemeng.7b01306.

[83] H. Liu, S. Xu, G. Zhou, K. Xiong, Z. Jiao, S. Wang, CO2 hydrogenation to methane over Co/KIT-6 catalysts: Effect of Co content, Fuel. 217 (2018) 570-576. doi:10.1016/j.fuel.2017.12.112.

[84] R.E. Owen, J.P. O'Byrne, D. Mattia, P. Plucinski, S.I. Pascu, M.D. Jones, Cobalt catalysts for the conversion of $\mathrm{CO} 2$ to light hydrocarbons at atmospheric pressure, Chem. Commun. 49 (2013) 11683-11685. doi:10.1039/C3CC46791K.

[85] T.A. Le, M.S. Kim, S.H. Lee, E.D. Park, CO and CO2 Methanation Over Supported Cobalt Catalysts, Top. Catal. 60 (2017) 714-720. doi:10.1007/s11244-017-0788-y.

[86] W. Li, X. Nie, X. Jiang, A. Zhang, F. Ding, M. Liu, Z. Liu, X. Guo, C. Song, ZrO2 support imparts superior activity and stability of Co catalysts for $\mathrm{CO} 2$ methanation, Appl. Catal. B Environ. 220 (2018) 397-408. doi:10.1016/j.apcatb.2017.08.048.

[87] S.K. Beaumont, S. Alayoglu, C. Specht, N. Kruse, G.A. Somorjai, A Nanoscale Demonstration of Hydrogen Atom Spillover and Surface Diffusion Across Silica Using the Kinetics of $\mathrm{CO} 2$ Methanation Catalyzed on Spatially Separate Pt and Co Nanoparticles., Nano Lett. 14 (2014) 4792-4796. doi:10.1021/nl501969k.

[88] M. Schubert, S. Pokhrel, A. Thomé, V. Zielasek, T.M. Gesing, F. Roessner, L. Mädler, M. Bäumer, Highly active $\mathrm{Co}-\mathrm{Al} 2 \mathrm{O} 3$-based catalysts for $\mathrm{CO} 2$ methanation with very low platinum promotion prepared by double flame spray pyrolysis, Catal. Sci. Technol. 6 (2016) 7449-7460. doi:10.1039/C6CY01252C.

[89] S. Abelló, D. Montané, Exploring iron-based multifunctional catalysts for Fischer-Tropsch synthesis: a review, ChemSusChem. 4 (2011) 1538-1556. doi:10.1002/cssc.201100189.

[90] H. Mahmoudi, M. Mahmoudi, O. Doustdar, H. Jahangiri, A. Tsolakis, S. Gu, M. LechWyszynski, A review of Fischer Tropsch synthesis process, mechanism, surface chemistry and catalyst formulation, Biofuels Eng. 2 (2017) 11-31. doi:10.1515/bfuel-2017-0002.

[91] R.E. Owen, J.P. O'Byrne, D. Mattia, P. Plucinski, S.I. Pascu, M.D. Jones, Promoter Effects on IronSilica Fischer-Tropsch Nanocatalysts: Conversion of Carbon Dioxide to Lower Olefins and Hydrocarbons at Atmospheric Pressure, ChemPlusChem. 78 (2013) 1536-1544. doi:10.1002/cplu.201300263.

[92] J. Kirchner, J.K. Anolleck, H. Lösch, S. Kureti, Methanation of $\mathrm{CO} 2$ on iron based catalysts, Appl. Catal. B Environ. 223 (2018) 47-59. doi:10.1016/j.apcatb.2017.06.025. 
[93] M.-D. Lee, J.-F. Lee, C.-S. Chang, Catalytic Behavior and Phase Composition Change of Iron Catalyst in Hydrogenation of Carbon Dioxide, J. Chem. Eng. Jpn. 23 (1990) 130-136. doi:10.1252/jcej.23.130.

[94] C.H. Bartholomew, R.J. Farrauto, Chemistry of nickel-alumina catalysts, J. Catal. 45 (1976) 41-53. doi:https://doi.org/10.1016/0021-9517(76)90054-3.

[95] L. He, Q. Lin, Y. Liu, Y. Huang, Unique catalysis of Ni-Al hydrotalcite derived catalyst in CO2 methanation: cooperative effect between Ni nanoparticles and a basic support, J. Energy Chem. 23 (2014) 587-592. doi:10.1016/S2095-4956(14)60144-3.

[96] S. Rahmani, M. Rezaei, F. Meshkani, Preparation of highly active nickel catalysts supported on mesoporous nanocrystalline Y-Al2O3 for CO2 methanation, J. Ind. Eng. Chem. 20 (2014) 13461352. doi:10.1016/j.jiec.2013.07.017.

[97] F. Song, Q. Zhong, Y. Yu, M. Shi, Y. Wu, J. Hu, Y. Song, Obtaining well-dispersed Ni/Al2O3 catalyst for CO2 methanation with a microwave-assisted method, Int. J. Hydrog. Energy. 42 (2017) 41744183. doi:10.1016/j.ijhydene.2016.10.141.

[98] S. Abelló, C. Berrueco, D. Montané, High-loaded nickel-alumina catalyst for direct CO2 hydrogenation into synthetic natural gas (SNG), Fuel. 113 (2013) 598-609. doi:10.1016/j.fuel.2013.06.012.

[99] S. Abate, K. Barbera, E. Giglio, F. Deorsola, S. Bensaid, S. Perathoner, R. Pirone, G. Centi, Synthesis, Characterization, and Activity Pattern of Ni-Al Hydrotalcite Catalysts in $\mathrm{CO} 2$ Methanation, Ind. Eng. Chem. Res. 55 (2016) 8299-8308. doi:10.1021/acs.iecr.6b01581.

[100] Y. Yan, Y. Dai, H. He, Y. Yu, Y. Yang, A novel W-doped Ni-Mg mixed oxide catalyst for CO2 methanation, Appl. Catal. B Environ. 196 (2016) 108-116. doi:10.1016/j.apcatb.2016.05.016.

[101] Z. Fan, K. Sun, N. Rui, B. Zhao, C. Liu, Improved activity of Ni/MgAl2O4 for $\mathrm{CO} 2$ methanation by the plasma decomposition, J. Energy Chem. 24 (2015) 655-659. doi:10.1016/j.jechem.2015.09.004.

[102] D. Wierzbicki, R. Baran, R. Dębek, M. Motak, T. Grzybek, M.E. Gálvez, P. Da Costa, The influence of nickel content on the performance of hydrotalcite-derived catalysts in $\mathrm{CO} 2$ methanation reaction, Int. J. Hydrog. Energy. 42 (2017) 23548-23555. doi:10.1016/j.ijhydene.2017.02.148.

[103] Q. Pan, J. Peng, T. Sun, D. Gao, S. Wang, S. Wang, CO2 methanation on Ni/Ce0.5Zr0.5O2 catalysts for the production of synthetic natural gas, Fuel Process. Technol. 123 (2014) 166-171. doi:10.1016/j.fuproc.2014.01.004.

[104] F. Ocampo, B. Louis, A.-C. Roger, Methanation of carbon dioxide over nickel-based Ce0.72Zr0.2802 mixed oxide catalysts prepared by sol-gel method, Appl. Catal. Gen. 369 (2009) 90-96. doi:10.1016/j.apcata.2009.09.005.

[105] L. Bian, L. Zhang, Z. Zhu, Z. Li, Methanation of carbon oxides on Ni/Ce/SBA-15 pretreated with dielectric barrier discharge plasma, Mol. Catal. 446 (2018) 131-139. doi:10.1016/j.mcat.2017.12.027.

[106] I. Graça, L.V. González, M.C. Bacariza, A. Fernandes, C. Henriques, J.M. Lopes, M.F. Ribeiro, CO2 hydrogenation into CH4 on NiHNaUSY zeolites, Appl. Catal. B Environ. 147 (2014) 101-110. doi:10.1016/j.apcatb.2013.08.010.

[107] A. Westermann, B. Azambre, M.C. Bacariza, I. Graça, M.F. Ribeiro, J.M. Lopes, C. Henriques, Insight into CO2 methanation mechanism over NiUSY zeolites: An operando IR study, Appl. Catal. B Environ. 174-175 (2015) 120-125. doi:10.1016/j.apcatb.2015.02.026.

[108] A. Westermann, B. Azambre, M.C. Bacariza, I. Graça, M.F. Ribeiro, J.M. Lopes, C. Henriques, The promoting effect of $\mathrm{Ce}$ in the $\mathrm{CO} 2$ methanation performances on NiUSY zeolite: A FTIR In Situ/Operando study, Catal. Today. 283 (2017) 74-81. doi:10.1016/j.cattod.2016.02.031.

[109] X. Lu, F. Gu, Q. Liu, J. Gao, Y. Liu, H. Li, L. Jia, G. Xu, Z. Zhong, F. Su, VOx promoted Ni catalysts supported on the modified bentonite for $\mathrm{CO}$ and $\mathrm{CO} 2$ methanation, Fuel Process. Technol. 135 (2015) 34-46. doi:10.1016/j.fuproc.2014.10.009.

[110] S. Abate, C. Mebrahtu, E. Giglio, F. Deorsola, S. Bensaid, S. Perathoner, R. Pirone, G. Centi, Catalytic Performance of $\mathrm{y}$-Al2O3-ZrO2-TiO2-CeO2 Composite Oxide Supported Ni-Based 
Catalysts for CO2 Methanation, Ind. Eng. Chem. Res. 55 (2016) 4451-4460.

doi:10.1021/acs.iecr.6b00134.

[111] C. Mebrahtu, S. Abate, S. Perathoner, S. Chen, G. Centi, CO2 methanation over Ni catalysts based on ternary and quaternary mixed oxide: A comparison and analysis of the structureactivity relationships, Catal. Today. 304 (2018) 181-189. doi:10.1016/j.cattod.2017.08.060.

[112] D. Wierzbicki, R. Debek, M. Motak, T. Grzybek, M.E. Gálvez, P. Da Costa, Novel Ni-Lahydrotalcite derived catalysts for $\mathrm{CO} 2$ methanation, Catal. Commun. 83 (2016) 5-8. doi:10.1016/j.catcom.2016.04.021.

[113] R. Daroughegi, F. Meshkani, M. Rezaei, Enhanced activity of CO2 methanation over mesoporous nanocrystalline $\mathrm{Ni}-\mathrm{Al} 2 \mathrm{O} 3$ catalysts prepared by ultrasound-assisted co-precipitation method, Int. J. Hydrog. Energy. 42 (2017) 15115-15125. doi:10.1016/j.ijhydene.2017.04.244.

[114] N. Bette, J. Thielemann, M. Schreiner, F. Mertens, Methanation of CO2 over a (Mg,Al)Ox Supported Nickel Catalyst Derived from a (Ni,Mg,Al)-Hydrotalcite-like Precursor, ChemCatChem. 8 (2016) 2903-2906. doi:10.1002/cctc.201600469.

[115] S. Danaci, L. Protasova, J. Lefevere, L. Bedel, R. Guilet, P. Marty, Efficient CO2 methanation over Ni/Al2O3 coated structured catalysts, Catal. Today. 273 (2016) 234-243. doi:10.1016/j.cattod.2016.04.019.

[116] A.H. Zamani, R. Ali, W.A.W. Abu Bakar, Optimization of $\mathrm{CO} 2$ methanation reaction over M*/Mn/Cu-Al2O3 (M*: Pd, Rh and Ru) catalysts, J. Ind. Eng. Chem. 29 (2015) 238-248. doi:10.1016/j.jiec.2015.02.028.

[117] P. Panagiotopoulou, D.I. Kondarides, X.E. Verykios, Selective methanation of CO over supported noble metal catalysts: Effects of the nature of the metallic phase on catalytic performance, Appl. Catal. Gen. 344 (2008) 45-54. doi:10.1016/j.apcata.2008.03.039.

[118] C. de Leitenburg, A. Trovarelli, J. Kašpar, A Temperature-Programmed and Transient Kinetic Study of CO2Activation and Methanation over CeO2Supported Noble Metals, J. Catal. 166 (1997) 98-107. doi:10.1006/jcat.1997.1498.

[119] S. Sharma, Z. Hu, P. Zhang, E.W. McFarland, H. Metiu, CO2 methanation on Ru-doped ceria, J. Catal. 278 (2011) 297-309. doi:10.1016/j.jcat.2010.12.015.

[120] G.D. Weatherbee, C.H. Bartholomew, Hydrogenation of $\mathrm{CO} 2$ on group VIII metals: IV. Specific activities and selectivities of silica-supported Co, Fe, and Ru, J. Catal. 87 (1984) 352-362. doi:10.1016/0021-9517(84)90196-9.

[121] B. Lu, K. Kawamoto, Transition metal-rich mesoporous silicas and their enhanced catalytic properties, Catal. Sci. Technol. 4 (2014) 4313-4321. doi:10.1039/C4CY00688G.

[122] K. Ray, G. Deo, A potential descriptor for the $\mathrm{CO} 2$ hydrogenation to $\mathrm{CH} 4$ over $\mathrm{Al} 2 \mathrm{O} 3$ supported Ni and Ni-based alloy catalysts, Appl. Catal. B Environ. 218 (2017) 525-537. doi:10.1016/j.apcatb.2017.07.009.

[123] S. Tada, T. Shimizu, H. Kameyama, T. Haneda, R. Kikuchi, Ni/CeO2 catalysts with high $\mathrm{CO} 2$ methanation activity and high $\mathrm{CH} 4$ selectivity at low temperatures, Int. J. Hydrog. Energy. 37 (2012) 5527-5531. doi:10.1016/j.ijhydene.2011.12.122.

[124] Q. Pan, J. Peng, T. Sun, S. Wang, S. Wang, Insight into the reaction route of $\mathrm{CO} 2$ methanation: Promotion effect of medium basic sites, Catal. Commun. 45 (2014) 74-78. doi:10.1016/j.catcom.2013.10.034.

[125] M.A.A. Aziz, A.A. Jalil, S. Triwahyono, R.R. Mukti, Y.H. Taufiq-Yap, M.R. Sazegar, Highly active Ni-promoted mesostructured silica nanoparticles for $\mathrm{CO} 2$ methanation, Appl. Catal. B Environ. 147 (2014) 359-368. doi:10.1016/j.apcatb.2013.09.015.

[126] H. Muroyama, Y. Tsuda, T. Asakoshi, H. Masitah, T. Okanishi, T. Matsui, K. Eguchi, Carbon dioxide methanation over $\mathrm{Ni}$ catalysts supported on various metal oxides, J. Catal. 343 (2016) 178-184. doi:10.1016/j.jcat.2016.07.018.

[127] C. Fukuhara, K. Hayakawa, Y. Suzuki, W. Kawasaki, R. Watanabe, A novel nickel-based structured catalyst for $\mathrm{CO} 2$ methanation: A honeycomb-type $\mathrm{Ni} / \mathrm{CeO} 2$ catalyst to transform greenhouse gas into useful resources, Appl. Catal. Gen. 532 (2017) 12-18. doi:10.1016/j.apcata.2016.11.036. 
[128] X. Guo, A. Traitangwong, M. Hu, C. Zuo, V. Meeyoo, Z. Peng, C. Li, Carbon dioxide methanation over Nickel-based catalysts supported on various mesoporous material, Energy Fuels. (2018). doi:10.1021/acs.energyfuels.7b03826.

[129] T.A. Le, M.S. Kim, S.H. Lee, T.W. Kim, E.D. Park, CO and CO2 methanation over supported Ni catalysts, Catal. Today. 293-294 (2017) 89-96. doi:10.1016/j.cattod.2016.12.036.

[130] M.C. Bacariza, I. Graça, S.S. Bebiano, J.M. Lopes, C. Henriques, Micro- and mesoporous supports for $\mathrm{CO} 2$ methanation catalysts: A comparison between SBA-15, MCM-41 and USY zeolite, Chem. Eng. Sci. 175 (2018) 72-83. doi:10.1016/j.ces.2017.09.027.

[131] G. Garbarino, S. Campodonico, A.R. Perez, M.M. Carnasciali, P. Riani, E. Finocchio, G. Busca, Spectroscopic characterization of $\mathrm{Ni} / \mathrm{Al} 2 \mathrm{O} 3$ catalytic materials for the steam reforming of renewables, Appl. Catal. Gen. 452 (2013) 163-173. doi:10.1016/j.apcata.2012.10.039.

[132] G. Garbarino, P. Riani, L. Magistri, G. Busca, A study of the methanation of carbon dioxide on $\mathrm{Ni} / \mathrm{Al} 2 \mathrm{O} 3$ catalysts at atmospheric pressure, Int. J. Hydrog. Energy. 39 (2014) 11557-11565. doi:10.1016/j.ijhydene.2014.05.111.

[133] F. Koschany, D. Schlereth, O. Hinrichsen, On the kinetics of the methanation of carbon dioxide on coprecipitated NiAl(O)x, Appl. Catal. B Environ. 181 (2016) 504-516. doi:10.1016/j.apcatb.2015.07.026.

[134] M. Gabrovska, R. Edreva-Kardjieva, D. Crişan, P. Tzvetkov, M. Shopska, I. Shtereva, Ni-Al layered double hydroxides as catalyst precursors for $\mathrm{CO}<$ Subscript $>2</$ Subscript $>$ removal by methanation, React. Kinet. Mech. Catal. 105 (2012) 79-99. doi:10.1007/s11144-011-0378-0.

[135] M.C. Bacariza, M. Maleval, I. Graça, J.M. Lopes, C. Henriques, Power-to-methane over $\mathrm{Ni} / z e o l i t e s:$ Influence of the framework type, Microporous Mesoporous Mater. 274 (2019) 102112. doi:10.1016/j.micromeso.2018.07.037.

[136] G. Zhou, H. Liu, K. Cui, A. Jia, G. Hu, Z. Jiao, Y. Liu, X. Zhang, Role of surface Ni and Ce species of Ni/CeO2 catalyst in $\mathrm{CO} 2$ methanation, Appl. Surf. Sci. 383 (2016) 248-252. doi:10.1016/j.apsusc.2016.04.180.

[137] M.V. Konishcheva, D.I. Potemkin, S.D. Badmaev, P.V. Snytnikov, E.A. Paukshtis, V.A. Sobyanin, V.N. Parmon, On the Mechanism of $\mathrm{CO}$ and $\mathrm{CO}<$ Subscript $>2</$ Subscript $>$ Methanation Over $\mathrm{Ni} / \mathrm{CeO}<$ Subscript $>2</$ Subscript $>$ Catalysts, Top. Catal. 59 (2016) 1424-1430. doi:10.1007/s11244-016-0650-7.

[138] M. Radlik, M. Adamowska-Teyssier, A. Krztoń, K. Kozieł, W. Krajewski, W. Turek, P. Da Costa, Dry reforming of methane over $\mathrm{Ni} / \mathrm{Ce} 0.62 \mathrm{Zr0.3802}$ catalysts: Effect of $\mathrm{Ni}$ loading on the catalytic activity and on H2/CO production, Comptes Rendus Chim. 18 (2015) 1242-1249. doi:10.1016/j.crci.2015.03.008.

[139] J. Ashok, M.L. Ang, S. Kawi, Enhanced activity of $\mathrm{CO} 2$ methanation over Ni/CeO2-ZrO2 catalysts: Influence of preparation methods, Catal. Today. 281 (2017) 304-311. doi:10.1016/j.cattod.2016.07.020.

[140] F. Ocampo, B. Louis, L. Kiwi-Minsker, A.-C. Roger, Effect of Ce/Zr composition and noble metal promotion on nickel based CexZr1-xO2 catalysts for carbon dioxide methanation, Appl. Catal. Gen. 392 (2011) 36-44. doi:10.1016/j.apcata.2010.10.025.

[141] T.A. Le, T.W. Kim, S.H. Lee, E.D. Park, Effects of $\mathrm{Na}$ content in $\mathrm{Na} / \mathrm{Ni} / \mathrm{SiO} 2$ and $\mathrm{Na} / \mathrm{Ni} / \mathrm{CeO} 2$ catalysts for CO and CO2 methanation, Catal. Today. 303 (2018) 159-167. doi:10.1016/j.cattod.2017.09.031.

[142] H. Takano, H. Shinomiya, K. Izumiya, N. Kumagai, H. Habazaki, K. Hashimoto, CO2 methanation of $\mathrm{Ni}$ catalysts supported on tetragonal $\mathrm{ZrO} 2$ doped with $\mathrm{Ca} 2+$ and $\mathrm{Ni2}+$ ions, Int. J. Hydrog. Energy. 40 (2015) 8347-8355. doi:10.1016/j.ijhydene.2015.04.128.

[143] M.C. Bacariza, R. Bértolo, I. Graça, J.M. Lopes, C. Henriques, The effect of the compensating cation on the catalytic performances of Ni/USY zeolites towards $\mathrm{CO} 2$ methanation, J. $\mathrm{CO} 2$ Util. 21 (2017) 280-291. doi:10.1016/j.jcou.2017.07.020.

[144] M.C. Bacariza, I. Graça, S.S. Bebiano, J.M. Lopes, C. Henriques, Magnesium as Promoter of CO2 Methanation on Ni-Based USY Zeolites, Energy Fuels. 31 (2017) 9776-9789. doi:10.1021/acs.energyfuels.7b01553. 
[145] W. Ahmad, M.N. Younis, R. Shawabkeh, S. Ahmed, Synthesis of lanthanide series (La, Ce, Pr, Eu \& Gd) promoted $\mathrm{Ni} / \mathrm{\gamma}$-Al2O3 catalysts for methanation of $\mathrm{CO} 2$ at low temperature under atmospheric pressure, Catal. Commun. 100 (2017) 121-126. doi:10.1016/j.catcom.2017.06.044.

[146] D. Wierzbicki, R. Baran, R. Dębek, M. Motak, M.E. Gálvez, T. Grzybek, P. Da Costa, P. Glatzel, Examination of the influence of La promotion on Ni state in hydrotalcite-derived catalysts under CO2 methanation reaction conditions: Operando X-ray absorption and emission spectroscopy investigation, Appl. Catal. B Environ. 232 (2018) 409-419. doi:10.1016/j.apcatb.2018.03.089.

[147] D. Wierzbicki, M. Motak, T. Grzybek, M.E. Gálvez, P. Da Costa, The influence of lanthanum incorporation method on the performance of nickel-containing hydrotalcite-derived catalysts in CO2 methanation reaction, Catal. Today. (2017). doi:10.1016/j.cattod.2017.04.020.

[148] Z. Li, B. Li, Z. Li, X. Rong, The promoter action of CeO<Subscript $>2</$ Subscript $>$ for the $\mathrm{Ni} /$ Al $<$ Subscript $>2<$ /Subscript $>0<$ Subscript $>3<$ /Subscript $>$-catalyzed methanation of CO<Subscript $>2</$ Subscript $>$, Kinet. Catal. 56 (2015) 329-334. doi:10.1134/S0023158415030143.

[149] A. Zhao, W. Ying, H. Zhang, M. Hongfang, D. Fang, Ni/Al2O3 catalysts for syngas methanation: Effect of Mn promoter, J. Nat. Gas Chem. 21 (2012) 170-177. doi:10.1016/S10039953(11)60350-2.

[150] K. Zhao, Z. Li, L. Bian, CO2 methanation and co-methanation of CO and CO $<$ Subscript $>2<$ /Subscript $>$ over Mn-promoted $\mathrm{Ni} /$ Al $<$ Subscript $>2</$ Subscript $>0<$ Subscript $>3</$ Subscript $>$ catalysts, Front. Chem. Sci. Eng. 10 (2016) 273-280. doi:10.1007/s11705-016-1563-5.

[151] A.E. Aksoylu, Z. Mısırlı, Z.i. Önsan, Interaction between nickel and molybdenum in NiMo/Al2O3 catalysts: I: CO2 methanation and SEM-TEM studies, Appl. Catal. Gen. 168 (1998) 385-397. doi:10.1016/S0926-860X(97)00369-4.

[152] J. Zhang, Z. Xin, X. Meng, Y. Lv, M. Tao, Effect of MoO3 on Structures and Properties of Ni$\mathrm{SiO} 2$ Methanation Catalysts Prepared by the Hydrothermal Synthesis Method, Ind. Eng. Chem. Res. 52 (2013) 14533-14544. doi:10.1021/ie401708h.

[153] H. Takano, Y. Kirihata, K. Izumiya, N. Kumagai, H. Habazaki, K. Hashimoto, Highly active Ni/Ydoped ZrO2 catalysts for CO2 methanation, Appl. Surf. Sci. 388 (2016) 653-663. doi:10.1016/j.apsusc.2015.11.187.

[154] D. Pandey, G. Deo, Effect of support on the catalytic activity of supported Ni-Fe catalysts for the CO2 methanation reaction, J. Ind. Eng. Chem. 33 (2016) 99-107. doi:10.1016/j.jiec.2015.09.019.

[155] C. Mebrahtu, F. Krebs, S. Perathoner, S. Abate, G. Centi, R. Palkovits, Hydrotalcite based Ni$\mathrm{Fe} /(\mathrm{Mg}, \mathrm{Al}) \mathrm{Ox}$ catalysts for $\mathrm{CO} 2$ methanation - tailoring Fe content for improved CO dissociation, basicity, and particle size, Catal. Sci. Technol. 8 (2018) 1016-1027. doi:10.1039/C7CY02099F.

[156] B. Mutz, M. Belimov, W. Wang, P. Sprenger, M.-A. Serrer, D. Wang, P. Pfeifer, W. Kleist, J.-D. Grunwaldt, Potential of an Alumina-Supported Ni3Fe Catalyst in the Methanation of CO2: Impact of Alloy Formation on Activity and Stability, ACS Catal. 7 (2017) 6802-6814. doi:10.1021/acscatal.7b01896.

[157] T. Burger, F. Koschany, O. Thomys, K. Köhler, O. Hinrichsen, $\mathrm{CO} 2$ methanation over Fe- and Mn-promoted co-precipitated Ni-Al catalysts: Synthesis, characterization and catalysis study, Appl. Catal. Gen. 558 (2018) 44-54. doi:10.1016/j.apcata.2018.03.021.

[158] I. Michielsen, Y. Uytdenhouwen, J. Pype, B. Michielsen, J. Mertens, F. Reniers, V. Meynen, A. Bogaerts, $\mathrm{CO} 2$ dissociation in a packed bed DBD reactor: First steps towards a better understanding of plasma catalysis, Chem. Eng. J. 326 (2017) 477-488. doi:10.1016/j.cej.2017.05.177.

[159] Y. Uytdenhouwen, S. Van Alphen, I. Michielsen, V. Meynen, P. Cool, A. Bogaerts, A packedbed DBD micro plasma reactor for CO2 dissociation: Does size matter?, Chem. Eng. J. 348 (2018) 557-568. doi:10.1016/j.cej.2018.04.210.

[160] J.-Y. Wang, G.-G. Xia, A. Huang, S.L. Suib, Y. Hayashi, H. Matsumoto, CO2 Decomposition Using Glow Discharge Plasmas, J. Catal. 185 (1999) 152-159. doi:10.1006/jcat.1999.2499. 
[161] R. Castell, E.J. Iglesias, J. Ruiz-Camacho, Glow discharge plasma properties of gases of environmental interest, Braz. J. Phys. 34 (2004) 1734-1737. doi:10.1590/S010397332004000800040.

[162] G. Chen, V. Georgieva, T. Godfroid, R. Snyders, M.-P. Delplancke-Ogletree, Plasma assisted catalytic decomposition of CO2, Appl. Catal. B Environ. 190 (2016) 115-124. doi:10.1016/j.apcatb.2016.03.009.

[163] B. Eliasson, U. Kogelschatz, B. Xue, L.-M. Zhou, Hydrogenation of Carbon Dioxide to Methanol with a Discharge-Activated Catalyst, Ind. Eng. Chem. Res. 37 (1998) 3350-3357. doi:10.1021/ie9709401.

[164] Y. Zeng, X. Tu, Plasma-Catalytic CO2 Hydrogenation at Low Temperatures, IEEE Trans. Plasma Sci. 44 (2016) 405-411. doi:10.1109/TPS.2015.2504549.

[165] C. De Bie, J. van Dijk, A. Bogaerts, CO2 Hydrogenation in a Dielectric Barrier Discharge Plasma Revealed, J. Phys. Chem. C. 120 (2016) 25210-25224. doi:10.1021/acs.jpcc.6b07639.

[166] Y. Zeng, X. Tu, Plasma-catalytic hydrogenation of $\mathrm{CO} 2$ for the cogeneration of $\mathrm{CO}$ and $\mathrm{CH} 4$ in a dielectric barrier discharge reactor: effect of argon addition, J. Phys. Appl. Phys. 50 (2017) 184004. doi:10.1088/1361-6463/aa64bb.

[167] M.C. Bacariza, M. Biset-Peiró, I. Graça, J. Guilera, J. Morante, J.M. Lopes, T. Andreu, C. Henriques, DBD plasma-assisted CO2 methanation using zeolite-based catalysts: Structure composition-reactivity approach and effect of Ce as promoter, J. CO2 Util. 26 (2018) 202-211. doi:10.1016/j.jcou.2018.05.013.

[168] E.Y. Mora, A. Sarmiento, E. Vera, Alumina and quartz as dielectrics in a dielectric barrier discharges DBD system for CO 2 hydrogenation, J. Phys. Conf. Ser. 687 (2016) 012020. doi:10.1088/1742-6596/687/1/012020.

[169] C.J. Lee, D.H. Lee, T. Kim, Enhancement of methanation of carbon dioxide using dielectric barrier discharge on a ruthenium catalyst at atmospheric conditions, Catal. Today. 293-294 (2017) 97-104. doi:10.1016/j.cattod.2017.01.022.

[170] J.F. de la Fuente, S.H. Moreno, A.I. Stankiewicz, G.D. Stefanidis, Reduction of CO2 with hydrogen in a non-equilibrium microwave plasma reactor, Int. J. Hydrog. Energy. 41 (2016) 21067-21077. doi:10.1016/j.ijhydene.2016.08.032.

[171] G. Chen, N. Britun, T. Godfroid, V. Georgieva, R. Snyders, Marie-Paule Delplancke-Ogletree, An overview of $\mathrm{CO} 2$ conversion in a microwave discharge: the role of plasma-catalysis, J. Phys. Appl. Phys. 50 (2017) 084001. doi:10.1088/1361-6463/aa5616.

[172] L. Maya, Plasma-assisted reduction of carbon dioxide in the gas phase, J. Vac. Sci. Technol. A. 18 (2000) 285-287. doi:10.1116/1.582148.

[173] S. Dobrea, I. Mihaila, V. Tiron, G. Popa, A.I. Cuza, OPTICAL AND MASS SPECTROMETRY DIAGNOSIS OF A CO2 MICROWAVE PLASMA DISCHARGE, Romanian Rep. Phys. 66 (n.d.) 11471154.

[174] N. Hayashi, T. Yamakawa, S. Baba, Effect of additive gases on synthesis of organic compounds from carbon dioxide using non-thermal plasma produced by atmospheric surface discharges, Vacuum. 80 (2006) 1299-1304. doi:10.1016/j.vacuum.2006.01.062.

[175] M. Kano, G. Satoh, S. lizuka, Reforming of Carbon Dioxide to Methane and Methanol by Electric Impulse Low-Pressure Discharge with Hydrogen, Plasma Chem. Plasma Process. 32 (2012) 177-185. doi:10.1007/s11090-011-9333-0.

[176] R. Yang, D. Zhang, K. Zhu, H. Zhou, X. Ye, A.W. Kleyn, Y. Hu, Q. Huang, In Situ Study of the Conversion reaction of $\mathrm{CO} 2$ and $\mathrm{CO} 2-\mathrm{H} 2$ Mixtures in Radio Frequency Discharge Plasma, Acta Phys.-Chim. Sin. 35 (2019) 292-298.

[177] K. Arita, S. lizuka, Production of $\mathrm{CH} 4$ in a Low-Pressure CO2/H2 Discharge with Magnetic Field, J. Mater. Sci. Chem. Eng. 03 (2015) 69. doi:10.4236/msce.2015.312011.

[178] S. Kato, S.J. Lee, EXPERIMENTAL STUDY ON PLASMA-ASSISTED MASS CONVERSIONS OF CO2 PURE AND (CO2 + H2) MIXTURE MOLECULES, (1997). doi:info:doi/10.1080/108939597200269. 
[179] W.F.L.M. Hoeben, E.J.M. van Heesch, F.J.C.M. Beckers, W. Boekhoven, A.J.M. Pemen, PlasmaDriven Water Assisted CO2 Methanation, IEEE Trans. Plasma Sci. 43 (2015) 1954-1958. doi:10.1109/TPS.2015.2429316.

[180] F. Azzolina-Jury, D. Bento, C. Henriques, F. Thibault-Starzyk, Chemical engineering aspects of plasma-assisted $\mathrm{CO} 2$ hydrogenation over nickel zeolites under partial vacuum, J. CO2 Util. 22 (2017) 97-109. doi:10.1016/j.jcou.2017.09.017.

[181] F. Azzolina-Jury, F. Thibault-Starzyk, Mechanism of Low Pressure Plasma-Assisted CO<Subscript $>2</$ Subscript $>$ Hydrogenation Over Ni-USY by Microsecond Time-resolved FTIR Spectroscopy, Top. Catal. 60 (2017) 1709-1721. doi:10.1007/s11244-017-0849-2.

[182] R. Debek, D. Wierzbicki, M. Motak, M.E. Galvez, P.D. Costa, F.A. JURY, Operando FT-IR study on basicity improvement of $\mathrm{Ni}(\mathrm{Mg}, \mathrm{Al}) \mathrm{O}$ hydrotalcite-derived catalysts promoted by glow plasma discharge, Plasma Sci. Technol. (2018). doi:10.1088/2058-6272/aaf759.

[183] R. Dębek, F. Azzolina-Jury, A. Travert, F. Maugé, F. Thibault-Starzyk, Low-pressure glow discharge plasma-assisted catalytic $\mathrm{CO} 2$ hydrogenation-The effect of metal oxide support on the performance of the Ni-based catalyst, Catal. Today. 337 (2019) 182-194. doi:10.1016/j.cattod.2019.03.039.

[184] A. Parastaev, W.F.L.M. Hoeben, B.E.J.M. van Heesch, N. Kosinov, E.J.M. Hensen, Temperature-programmed plasma surface reaction: An approach to determine plasma-catalytic performance, Appl. Catal. B Environ. 239 (2018) 168-177. doi:10.1016/j.apcatb.2018.08.011.

[185] C. Liu, G.P. Vissokov, B.W.-L. Jang, Catalyst preparation using plasma technologies, Catal. Today. 72 (2002) 173-184. doi:10.1016/S0920-5861(01)00491-6.

[186] C. Liu, M. Li, J. Wang, X. Zhou, Q. Guo, J. Yan, Y. Li, Plasma methods for preparing green catalysts: Current status and perspective, Chin. J. Catal. 37 (2016) 340-348. doi:10.1016/S18722067(15)61020-8.

[187] X. Zhang, W. Sun, W. Chu, Effect of glow discharge plasma treatment on the performance of $\mathrm{Ni} / \mathrm{SiO} 2$ catalyst in $\mathrm{CO} 2$ methanation, J. Fuel Chem. Technol. 41 (2013) 96-101. doi:10.1016/S1872-5813(13)60012-2.

[188] L. Bian, L. Zhang, R. Xia, Z. Li, Enhanced low-temperature CO2 methanation activity on plasma-prepared Ni-based catalyst, J. Nat. Gas Sci. Eng. 27 (2015) 1189-1194. doi:10.1016/j.jngse.2015.09.066.

[189] R. Zhou, N. Rui, Z. Fan, C. Liu, Effect of the structure of Ni/TiO2 catalyst on CO2 methanation, Int. J. Hydrog. Energy. 41 (2016) 22017-22025. doi:10.1016/j.ijhydene.2016.08.093.

[190] P. Shi, C.-J. Liu, Characterization of Silica Supported Nickel Catalyst for Methanation with Improved Activity by Room Temperature Plasma Treatment, Catal. Lett. 133 (2009) 112. doi:10.1007/s10562-009-0163-0.

[191] X. Yan, B. Zhao, Y. Liu, Y. Li, Dielectric barrier discharge plasma for preparation of Ni-based catalysts with enhanced coke resistance: Current status and perspective, Catal. Today. 256 (2015) 29-40. doi:10.1016/j.cattod.2015.04.045.

[192] Z.-H. Li, S.-X. Tian, H.-T. Wang, H.-B. Tian, Plasma treatment of Ni catalyst via a corona discharge, J. Mol. Catal. Chem. 211 (2004) 149-153. doi:10.1016/j.molcata.2003.10.003.

[193] Y.H. Hu, E. Ruckenstein, Catalytic Conversion of Methane to Synthesis Gas by Partial Oxidation and CO2 Reforming, in: Adv. Catal., Academic Press, 2004: pp. 297-345. doi:10.1016/S0360-0564(04)48004-3.

[194] H. Kierzkowska-Pawlak, P. Tracz, W. Redzynia, J. Tyczkowski, Plasma deposited novel nanocatalysts for CO2 hydrogenation to methane, J. CO2 Util. 17 (2017) 312-319. doi:10.1016/j.jcou.2016.12.013.

[195] L. Wang, Y. Yi, H. Guo, X. Tu, Atmospheric Pressure and Room Temperature Synthesis of Methanol through Plasma-Catalytic Hydrogenation of CO2, ACS Catal. 8 (2018) 90-100. doi:10.1021/acscatal.7b02733.

[196] K. Oshima, T. Shinagawa, Y. Nogami, R. Manabe, S. Ogo, Y. Sekine, Low temperature catalytic reverse water gas shift reaction assisted by an electric field, Catal. Today. 232 (2014) 27-32. doi:10.1016/j.cattod.2013.11.035. 
[197] Y. Zeng, X. Tu, Plasma-Catalytic CO2Hydrogenation at Low Temperatures, IEEE Trans. Plasma Sci. 44 (2016) 405-411. doi:10.1109/TPS.2015.2504549.

[198] M. Mikhail, B. Wang, R. Jalain, S. Cavadias, M. Tatoulian, S. Ognier, M.E. Gálvez, P. Da Costa, Plasma-catalytic hybrid process for $\mathrm{CO} 2$ methanation: optimization of operation parameters, React. Kinet. Mech. Catal. (2018). doi:10.1007/s11144-018-1508-8.

[199] F. Azzolina-Jury, Novel boehmite transformation into $\gamma$-alumina and preparation of efficient nickel base alumina porous extrudates for plasma-assisted CO2 methanation, J. Ind. Eng. Chem. (2018). doi:10.1016/j.jiec.2018.11.053.

[200] M. Nizio, A. Albarazi, S. Cavadias, J. Amouroux, M.E. Galvez, P. Da Costa, Hybrid plasmacatalytic methanation of $\mathrm{CO} 2$ at low temperature over ceria zirconia supported $\mathrm{Ni}$ catalysts, Int. J. Hydrog. Energy. 41 (2016) 11584-11592. doi:10.1016/j.ijhydene.2016.02.020.

[201] J. Amouroux, S. Cavadias, Electrocatalytic reduction of carbon dioxide under plasma DBD process, J. Phys. Appl. Phys. 50 (2017) 465501. doi:10.1088/1361-6463/aa8b56.

[202] E. Jwa, Y.S. Mok, S.B. Lee, Nonthermal plasma-assisted catalytic methanation of CO and CO2 over nickel-loaded alumina, in: 2011: pp. 361-368. doi:10.2495/ESUS110311.

[203] E. Jwa, S.B. Lee, H.W. Lee, Y.S. Mok, Plasma-assisted catalytic methanation of $\mathrm{CO}$ and $\mathrm{CO} 2$ over Ni-zeolite catalysts, Fuel Process. Technol. 108 (2013) 89-93. doi:10.1016/j.fuproc.2012.03.008.

[204] M. Nizio, R. Benrabbah, M. Krzak, R. Debek, M. Motak, S. Cavadias, M.E. Gálvez, P. Da Costa, Low temperature hybrid plasma-catalytic methanation over Ni-Ce-Zr hydrotalcite-derived catalysts, Catal. Commun. 83 (2016) 14-17. doi:10.1016/j.catcom.2016.04.023.

[205] R. Benrabbah, C. Cavaniol, H. Liu, S. Ognier, S. Cavadias, M.E. Gálvez, P. Da Costa, Plasma DBD activated ceria-zirconia-promoted Ni-catalysts for plasma catalytic $\mathrm{CO} 2$ hydrogenation at low temperature, Catal. Commun. 89 (2017) 73-76. doi:10.1016/j.catcom.2016.10.028.

[206] M. Biset-Peiró, J. Guilera, T. Zhang, J. Arbiol, T. Andreu, On the role of ceria in Ni-Al2O3 catalyst for CO2 plasma methanation, Appl. Catal. Gen. 575 (2019) 223-229. doi:10.1016/j.apcata.2019.02.028.

[207] D. Wierzbicki, M.V. Moreno, S. Ognier, M. Motak, T. Grzybek, P. Da Costa, M.E. Gálvez, Ni-Fe layered double hydroxide derived catalysts for non-plasma and DBD plasma-assisted $\mathrm{CO} 2$ methanation, Int. J. Hydrog. Energy. (2019). doi:10.1016/j.ijhydene.2019.06.095. 